Supporting Information

\title{
Cascade Reaction of Tryptamine-Derived Isocyanides with Nitrile Oxides: Construction of Oxazine Fused-Spiroindoline Derivatives
}

\author{
Xiao-Feng Wang ${ }^{a}$, Wen-Bin $\mathrm{Cao}^{a}$, Hai-Yan $\mathrm{Li}^{b}$, Xiao-Ping Xu ${ }^{a *}$, and Shun-Jun $\mathrm{Ji}^{a *}$ \\ ${ }^{a}$ Key Laboratory of Organic Synthesis of Jiangsu Province, College of Chemistry, Chemical Engineering and \\ Materials Science \& Collaborative Innovation Center of Suzhou Nano Science and Technology, Soochow University, \\ Suzhou 215123, People's Republic of China \\ ${ }^{b}$ Analysis and Testing Center, Soochow University, Suzhou 215123, People's Republic of China \\ E-mail: xuxp@suda.edu.cn, shunjun@suda.edu.cn;
}

\section{Table of Contents}

1. ${ }^{1} \mathrm{H},{ }^{13} \mathrm{C}$ and ${ }^{19} \mathrm{~F}$ NMR spectra of products ...

2. Crystal data and structure refinement for 3aa 


\section{1. ${ }^{1} \mathrm{H},{ }^{13} \mathrm{C}$ and ${ }^{19} \mathrm{~F}$ NMR spectra of products}

${ }^{1} \mathbf{H}$ NMR (400 MHz, $\mathrm{CDCl}_{3}$ ) spectrum of $\mathbf{3 a a}$
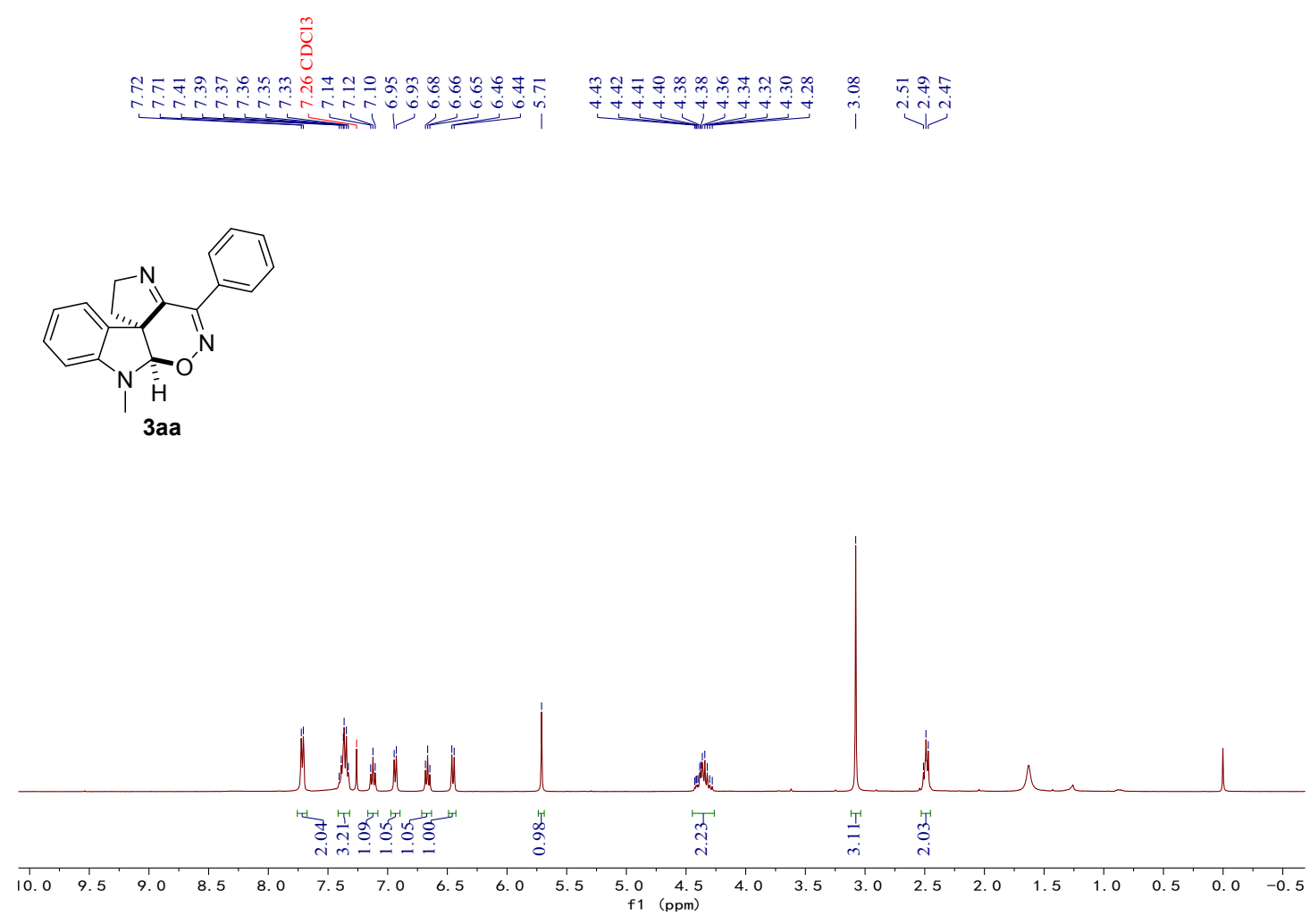

${ }^{13} \mathbf{C}\left\{{ }^{1} \mathbf{H}\right\}$ NMR $\left(100 \mathrm{MHz}, \mathrm{CDCl}_{3}\right)$ spectrum of $\mathbf{3 a a}$
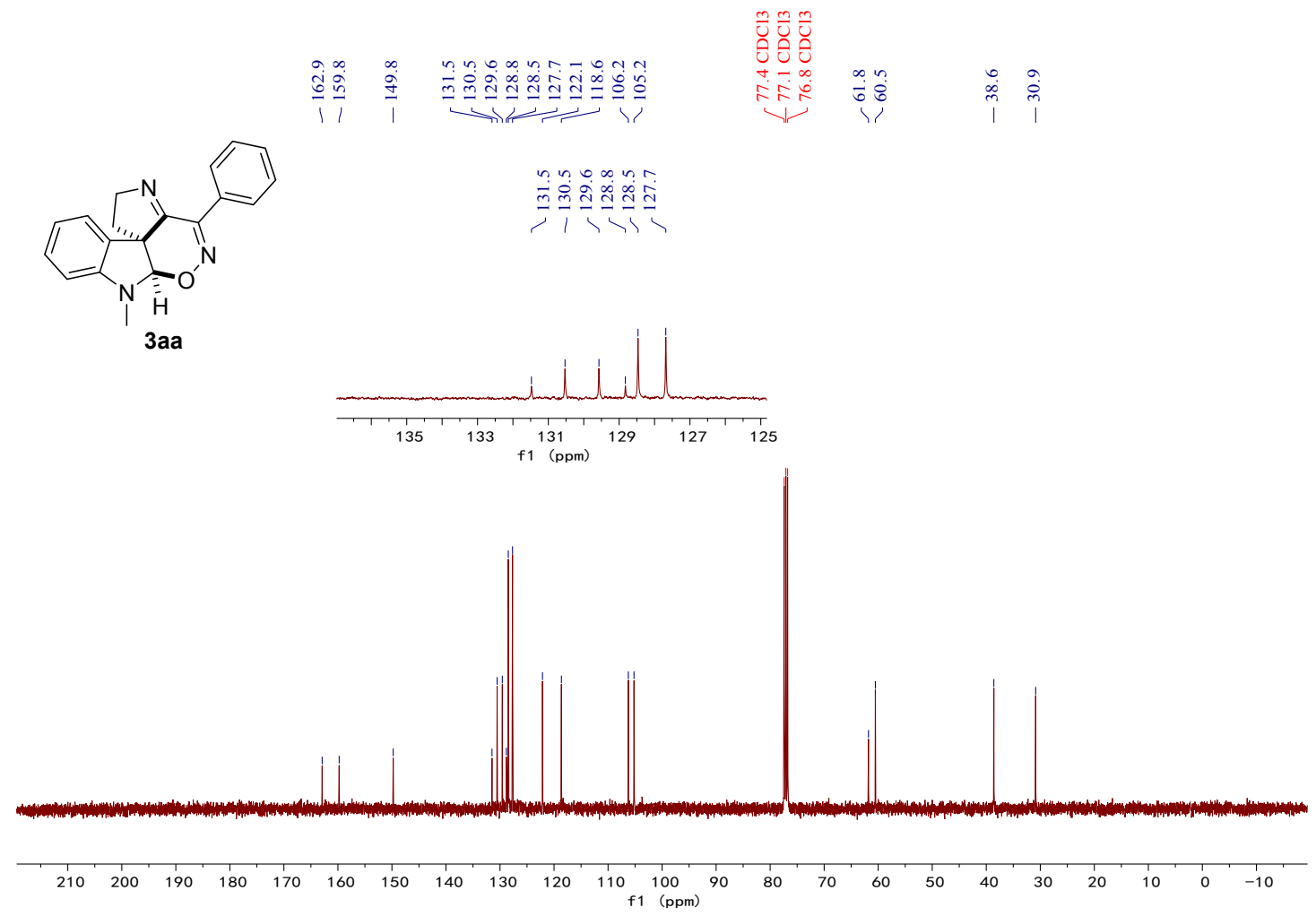
${ }^{\mathbf{1}} \mathbf{H}$ NMR (400 MHz, $\mathrm{CDCl}_{3}$ ) spectrum of $\mathbf{3 b a}$
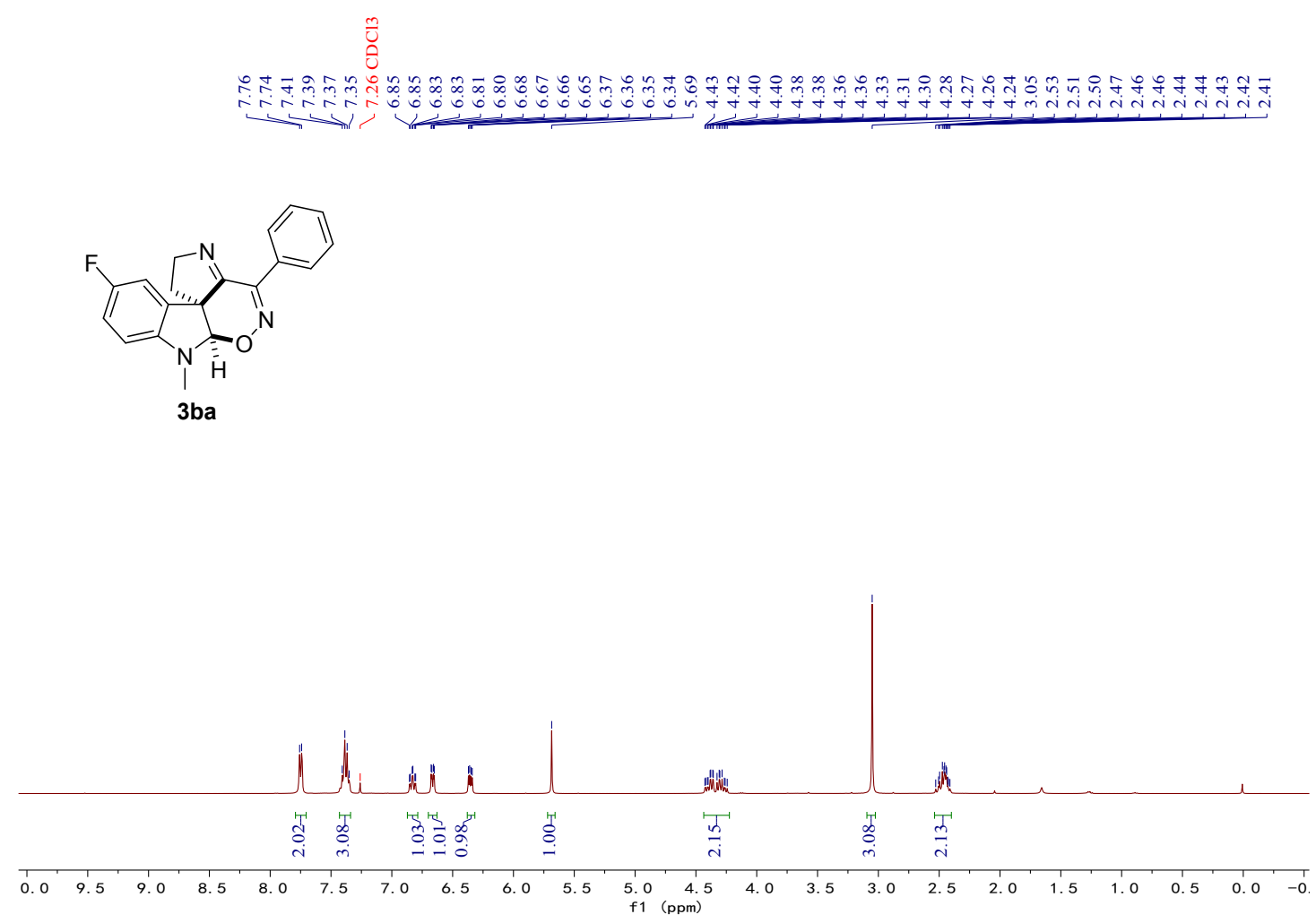

${ }^{13} \mathbf{C}\left\{{ }^{1} \mathbf{H}\right\}$ NMR $\left(100 \mathrm{MHz}, \mathrm{CDCl}_{3}\right)$ spectrum of $\mathbf{3} \mathbf{b a}$

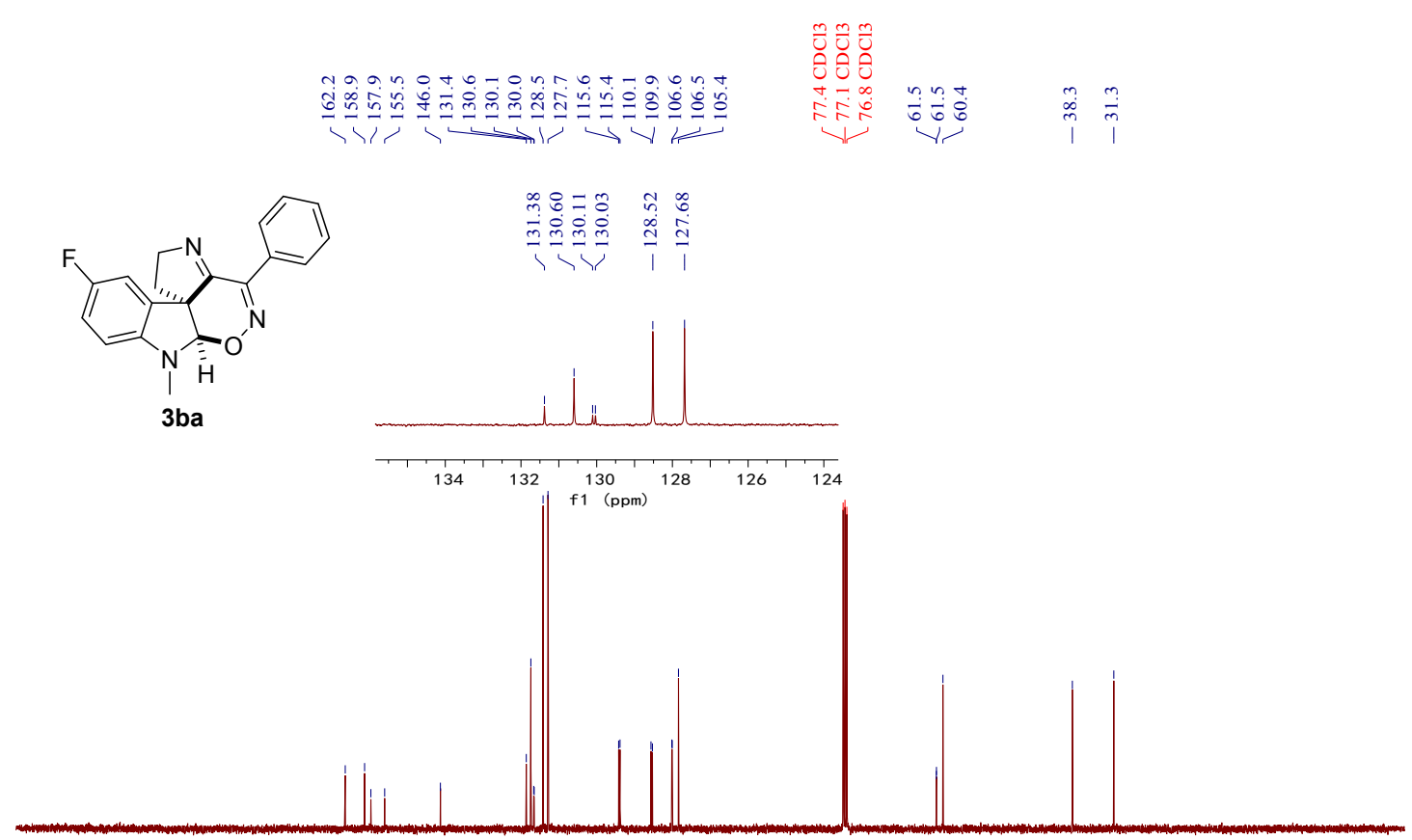

$\begin{array}{lllllllllllllllllllllllllllll} & 210 & 200 & 190 & 180 & 170 & 160 & 150 & 140 & 130 & 120 & 110 & 100 & 90 & 80 & 70 & 60 & 50 & 40 & 30 & 20 & 10 & 0 & -10\end{array}$ 
${ }^{19} \mathbf{F}$ NMR (376 MHz, $\mathrm{CDCl}_{3}$ ) spectrum of $\mathbf{3 b a}$
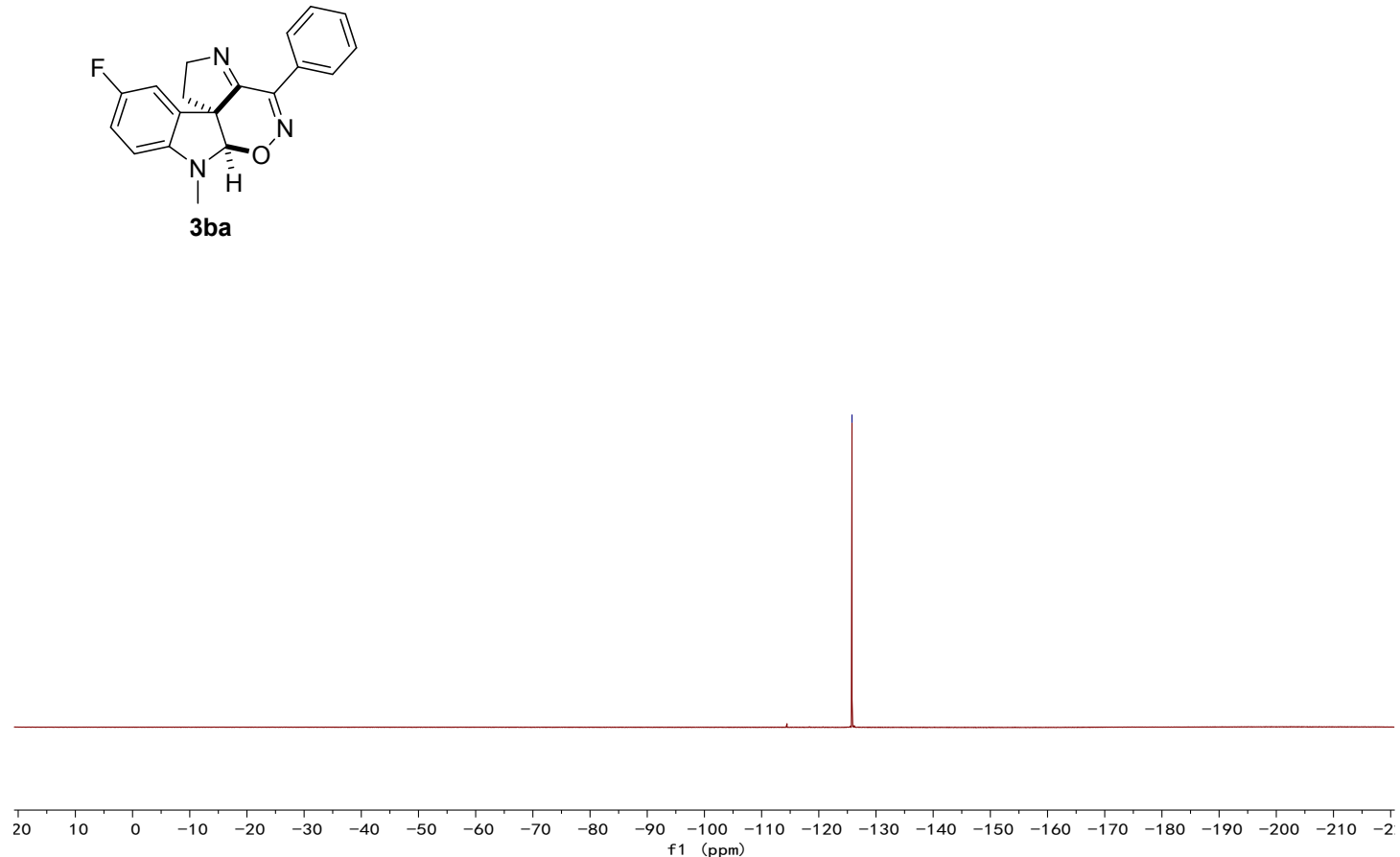
${ }^{1} \mathbf{H}$ NMR (400 MHz, $\mathrm{CDCl}_{3}$ ) spectrum of $\mathbf{3 c a}$
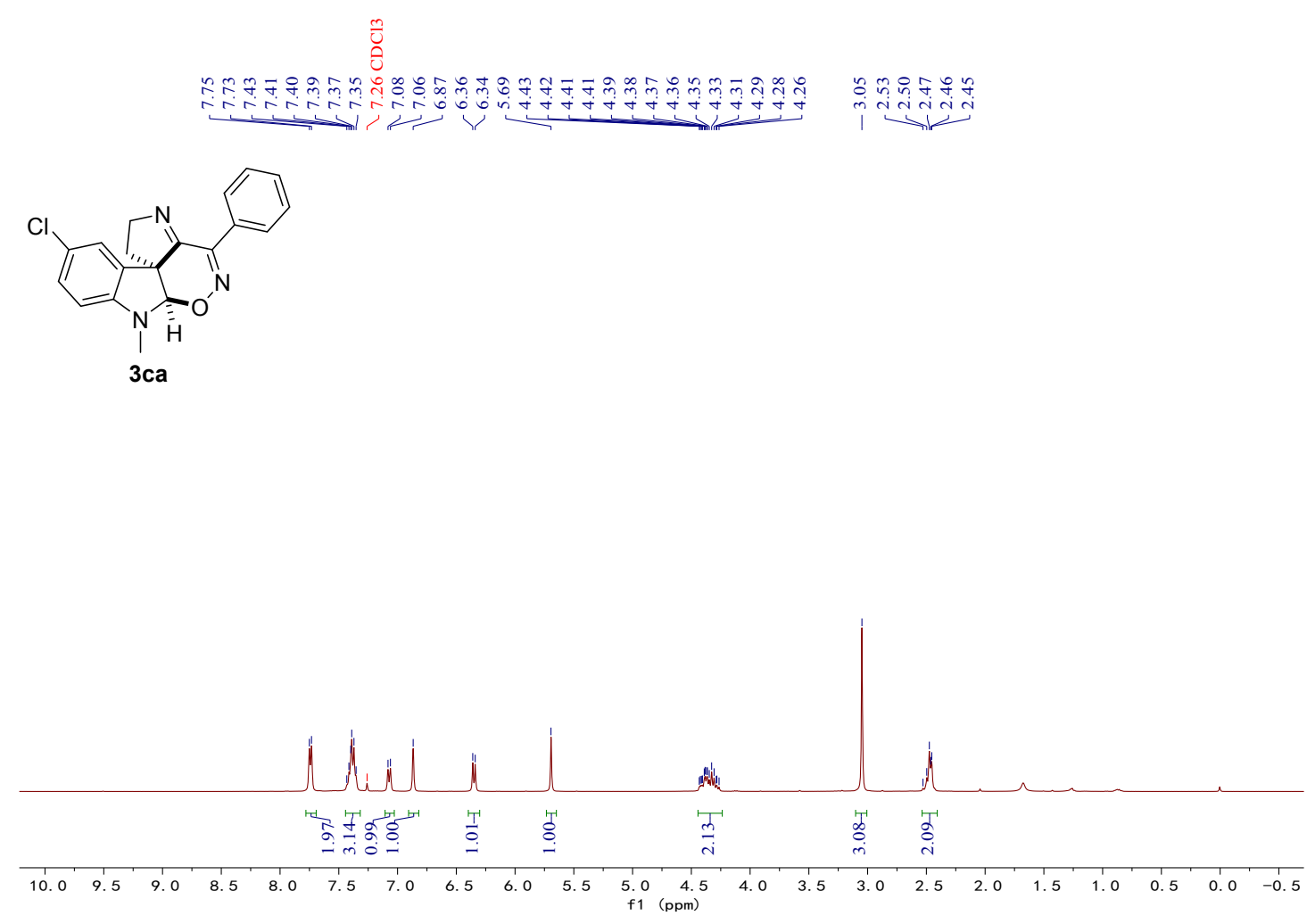

${ }^{13} \mathbf{C}\left\{{ }^{1} \mathbf{H}\right\}$ NMR $\left(100 \mathrm{MHz}, \mathrm{CDCl}_{3}\right)$ spectrum of $\mathbf{3} \mathbf{c a}$

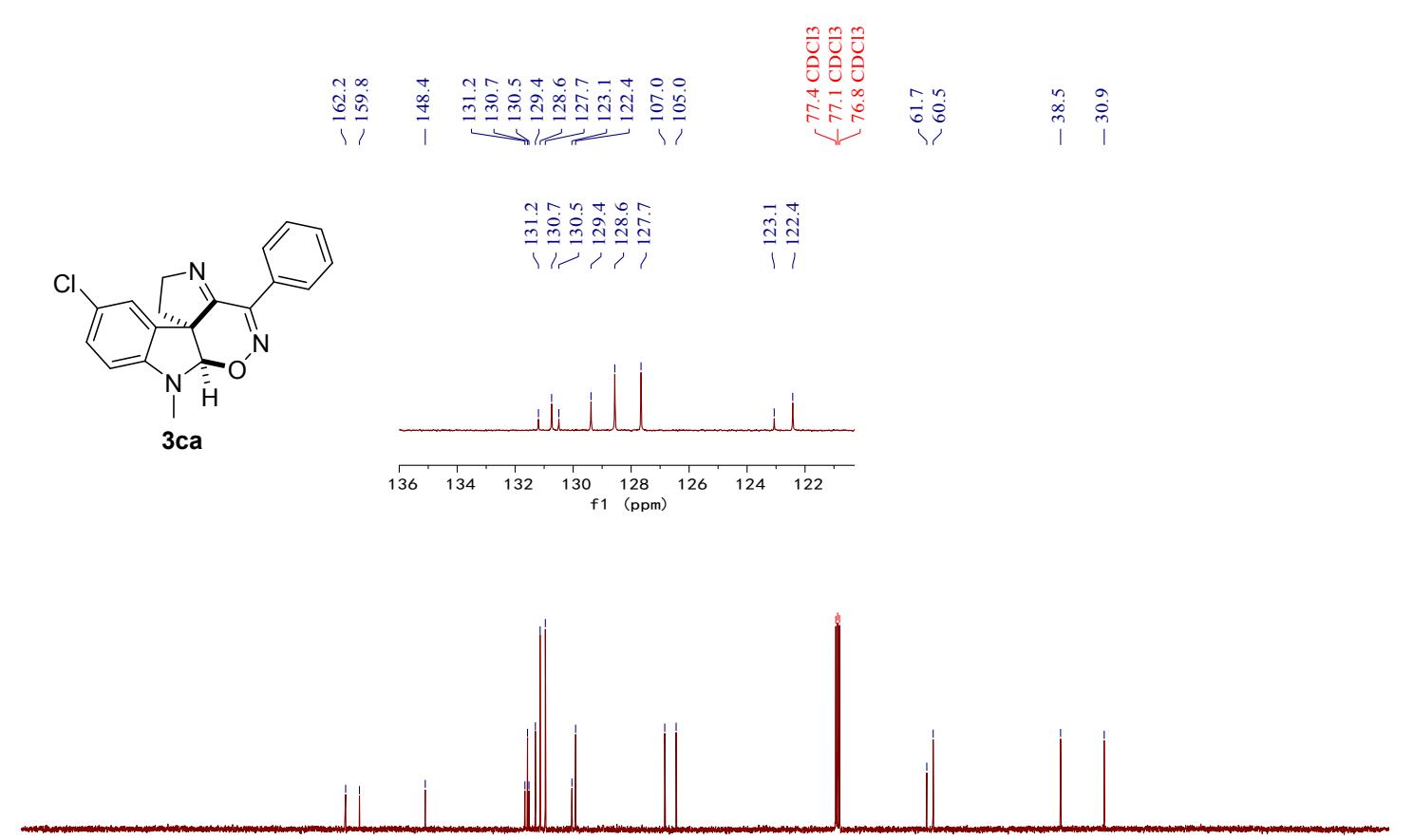

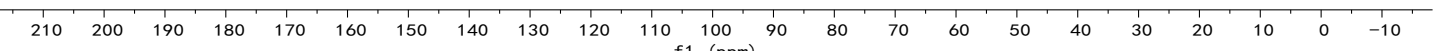


${ }^{1} \mathbf{H}$ NMR (400 MHz, $\mathrm{CDCl}_{3}$ ) spectrum of 3da
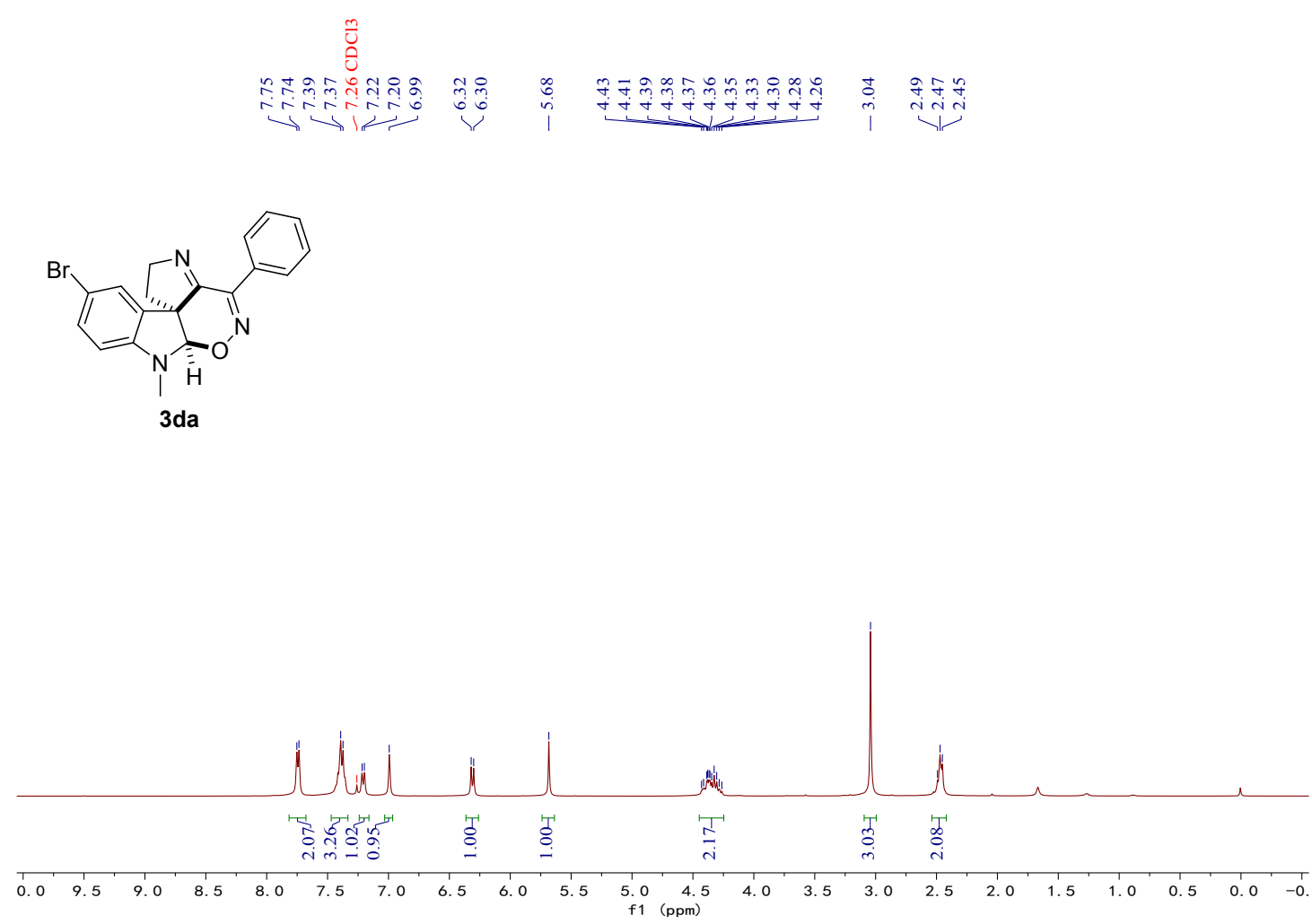

${ }^{13} \mathbf{C}\left\{{ }^{1} \mathbf{H}\right\}$ NMR $\left(100 \mathrm{MHz}, \mathrm{CDCl}_{3}\right)$ spectrum of $\mathbf{3 d a}$

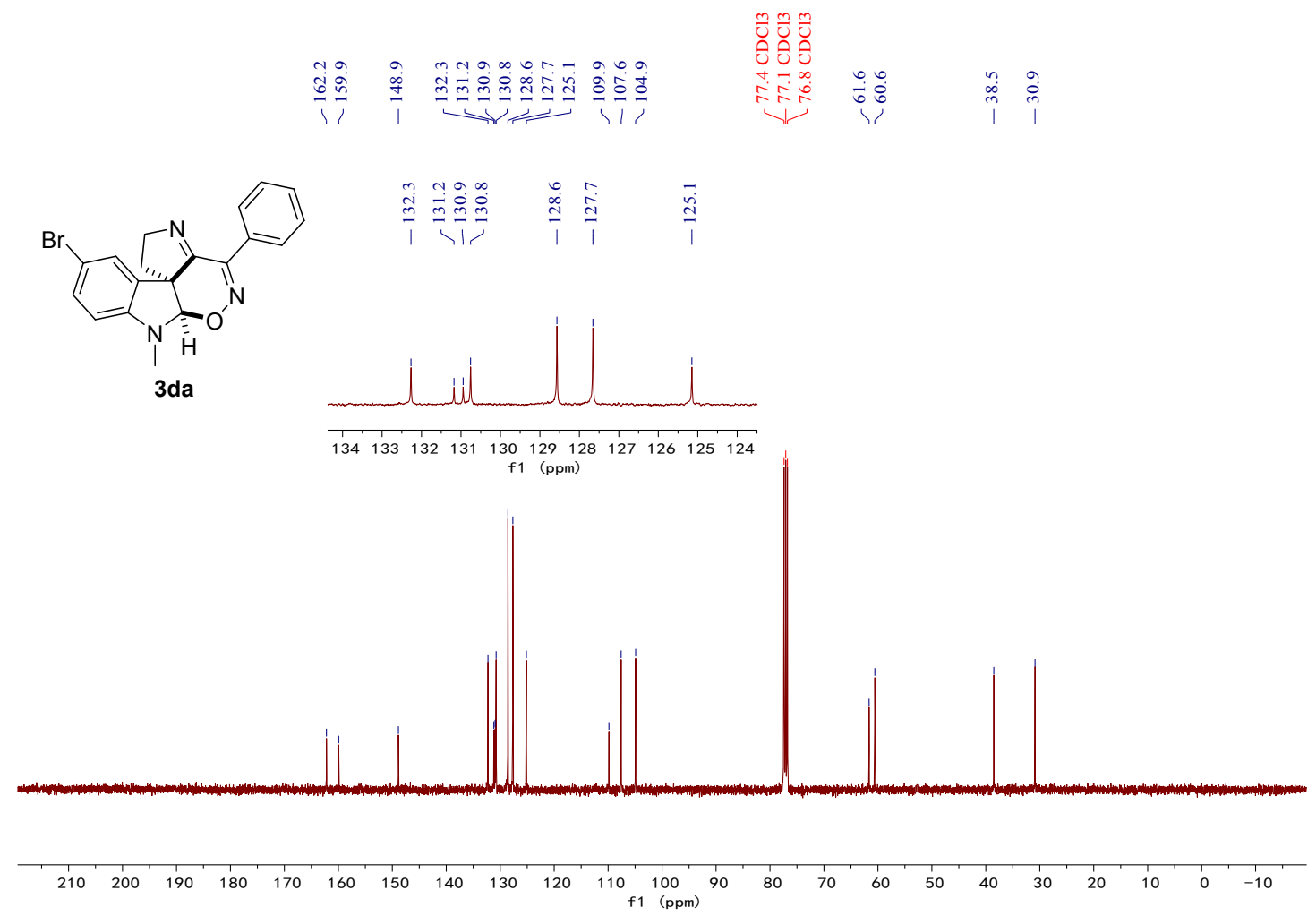


${ }^{\mathbf{1}} \mathbf{H}$ NMR (400 MHz, $\mathrm{CDCl}_{3}$ ) spectrum of 3ea
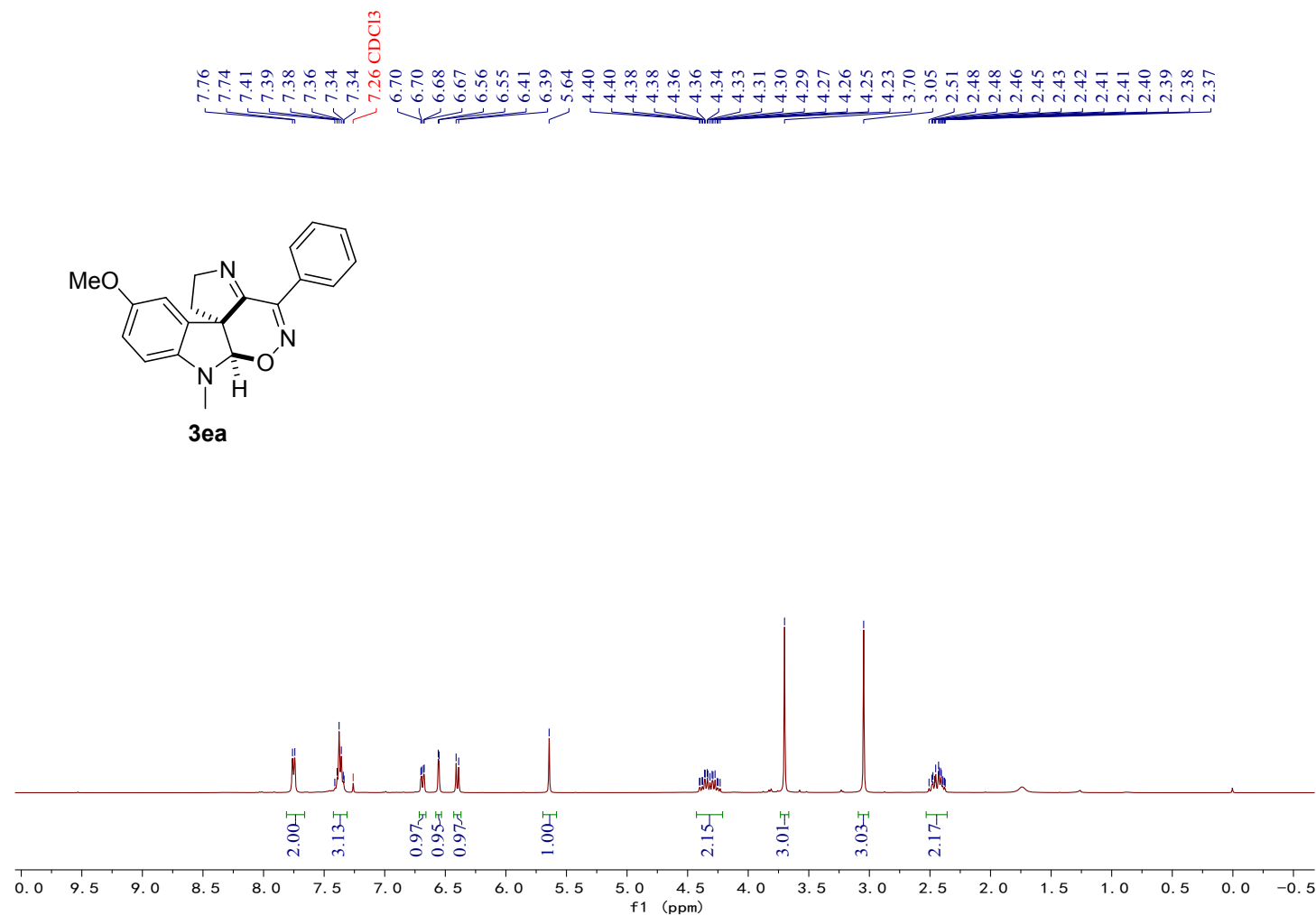

${ }^{13} \mathbf{C}\left\{{ }^{1} \mathbf{H}\right\}$ NMR $\left(100 \mathrm{MHz}, \mathrm{CDCl}_{3}\right)$ spectrum of $\mathbf{3 e a}$
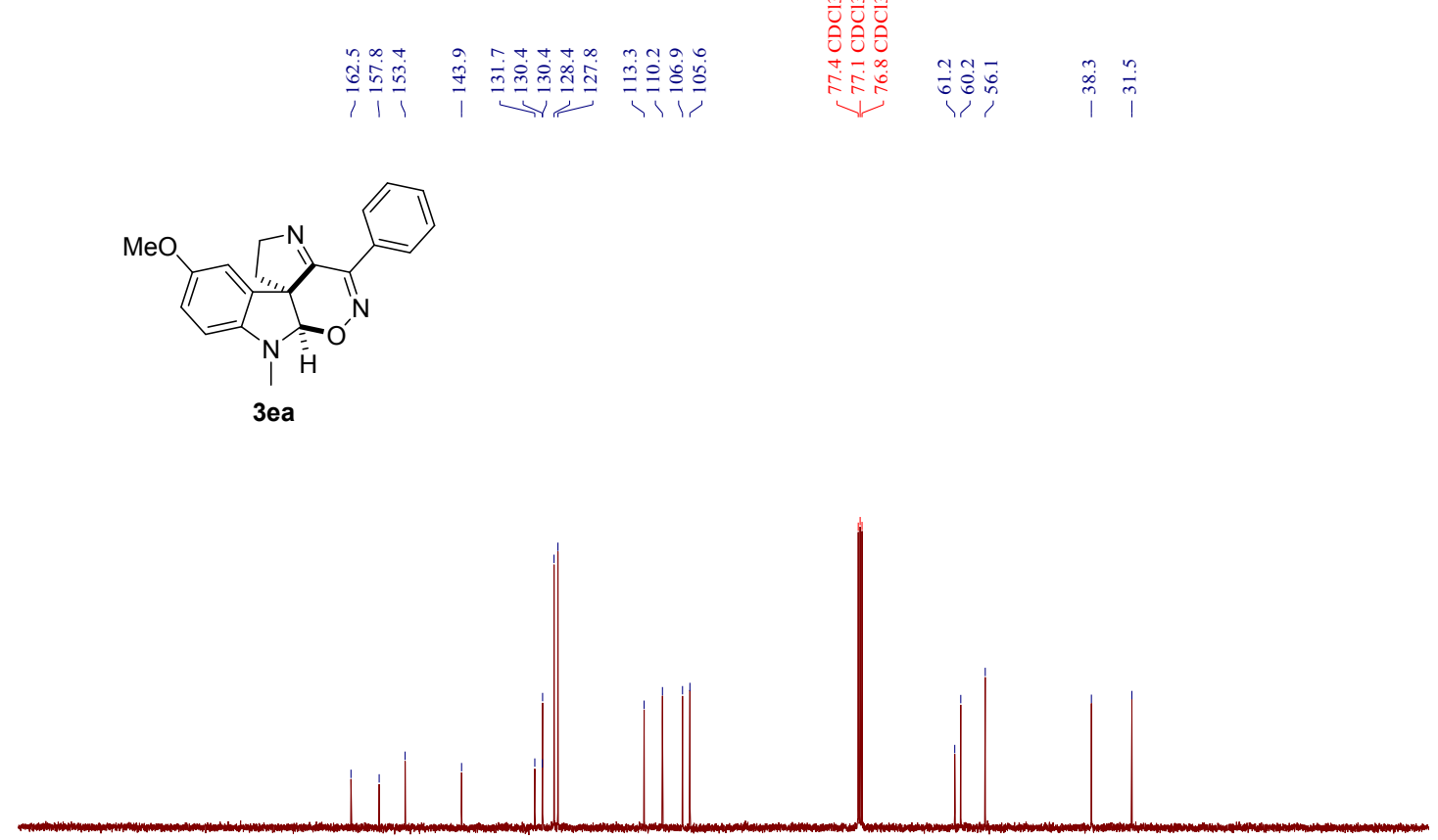
${ }^{1} \mathbf{H}$ NMR $\left(400 \mathrm{MHz}, \mathrm{CDCl}_{3}\right)$ spectrum of $\mathbf{3 f a}$
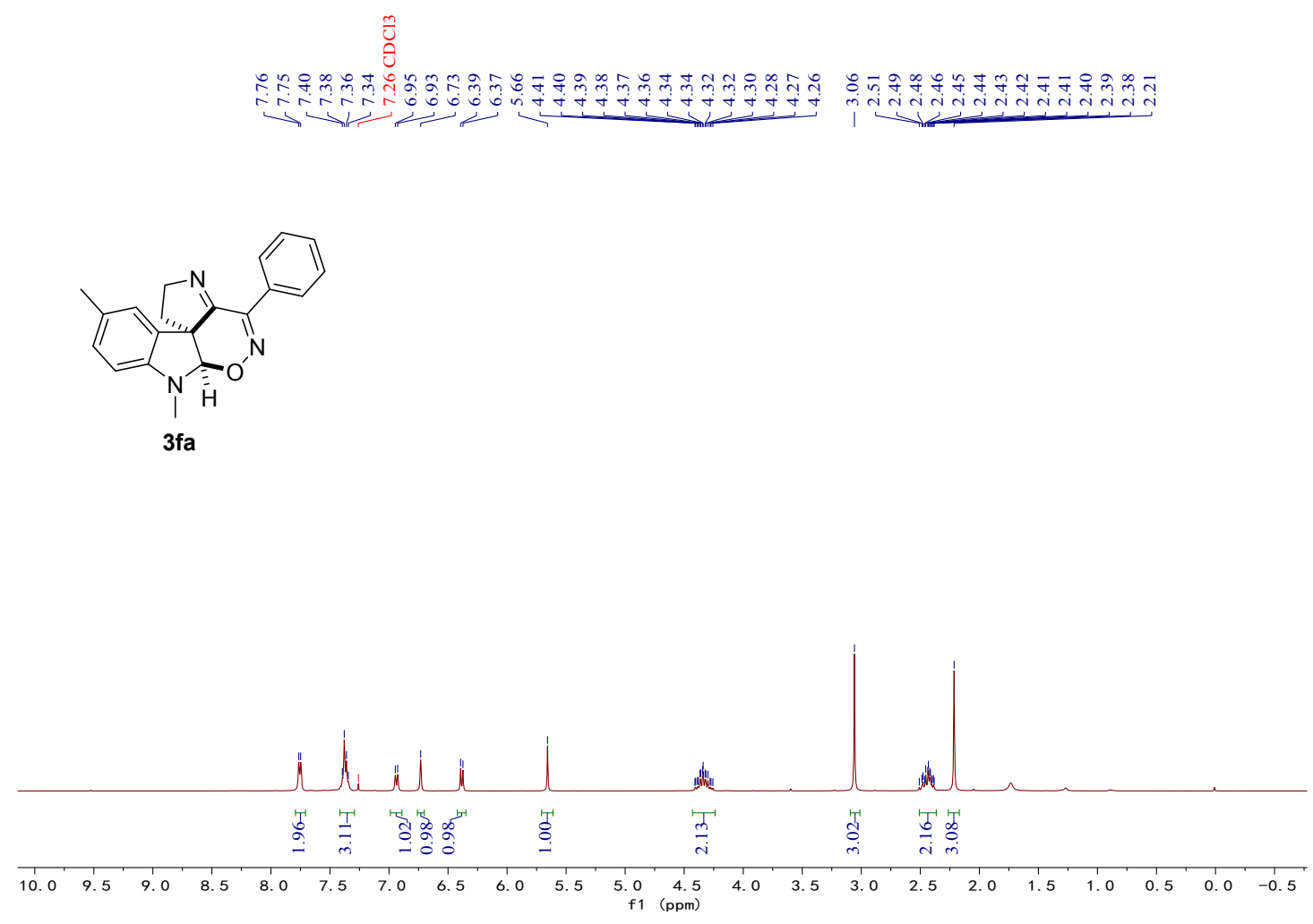

${ }^{13} \mathbf{C}\left\{{ }^{1} \mathbf{H}\right\}$ NMR $\left(100 \mathrm{MHz}, \mathrm{CDCl}_{3}\right)$ spectrum of $\mathbf{3} \mathbf{f a}$

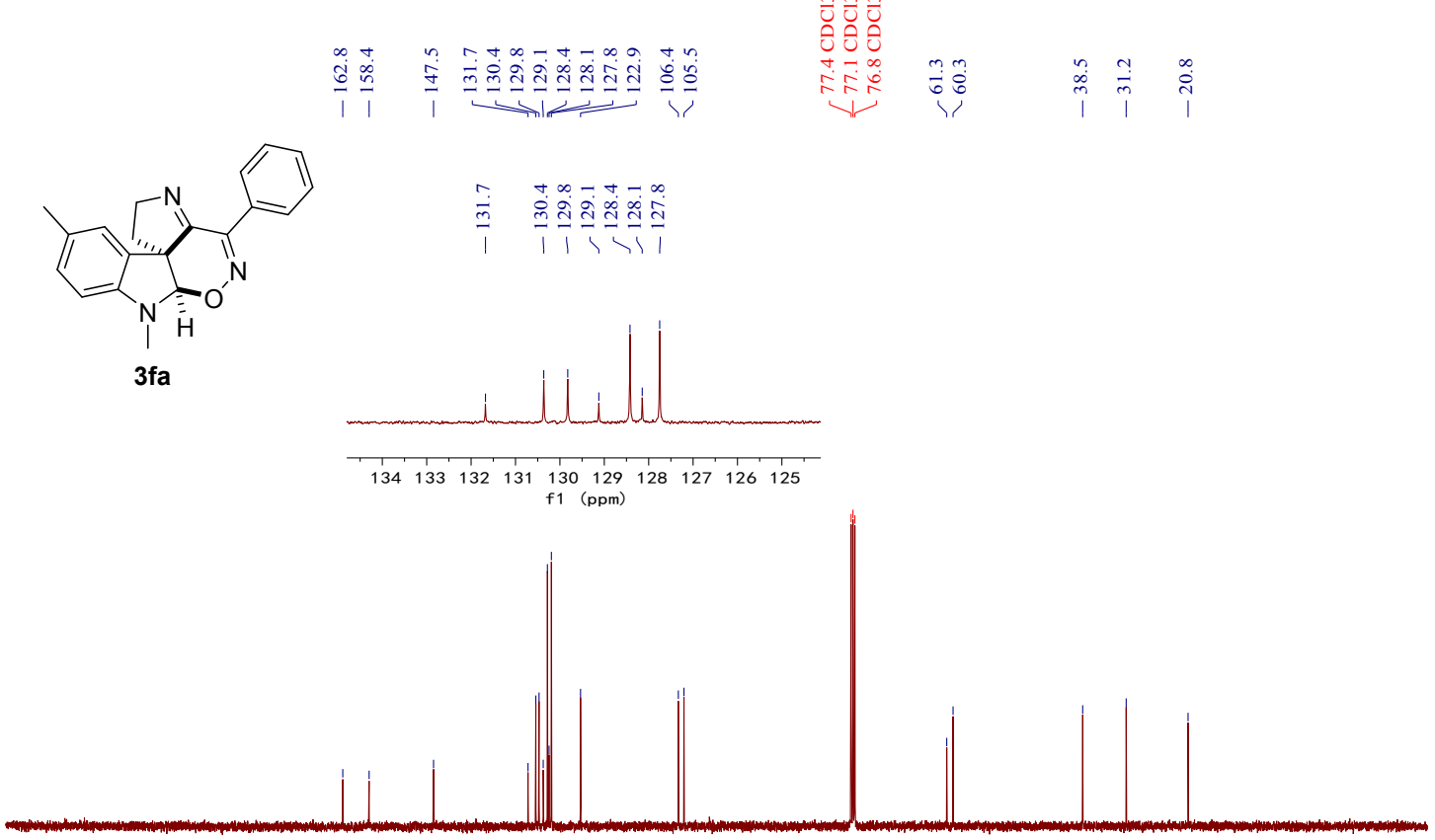

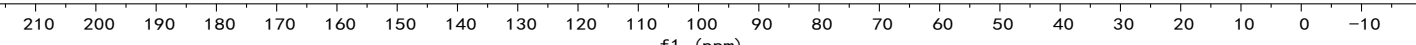


${ }^{1} \mathbf{H}$ NMR (400 MHz, $\mathrm{CDCl}_{3}$ ) spectrum of 3ga
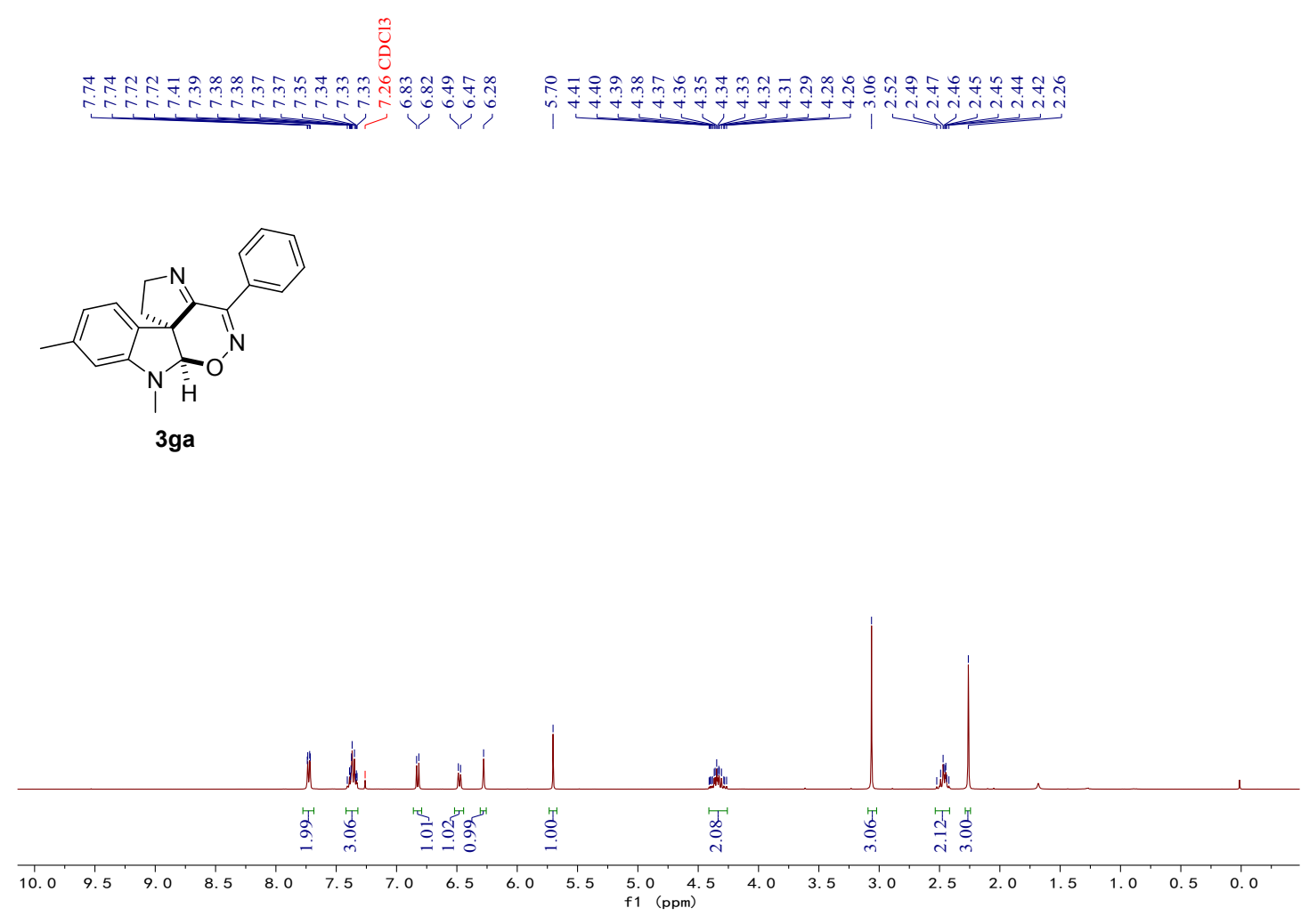

${ }^{13} \mathbf{C}\left\{{ }^{1} \mathbf{H}\right\}$ NMR $\left(100 \mathrm{MHz}, \mathrm{CDCl}_{3}\right)$ spectrum of $\mathbf{3 g a}$
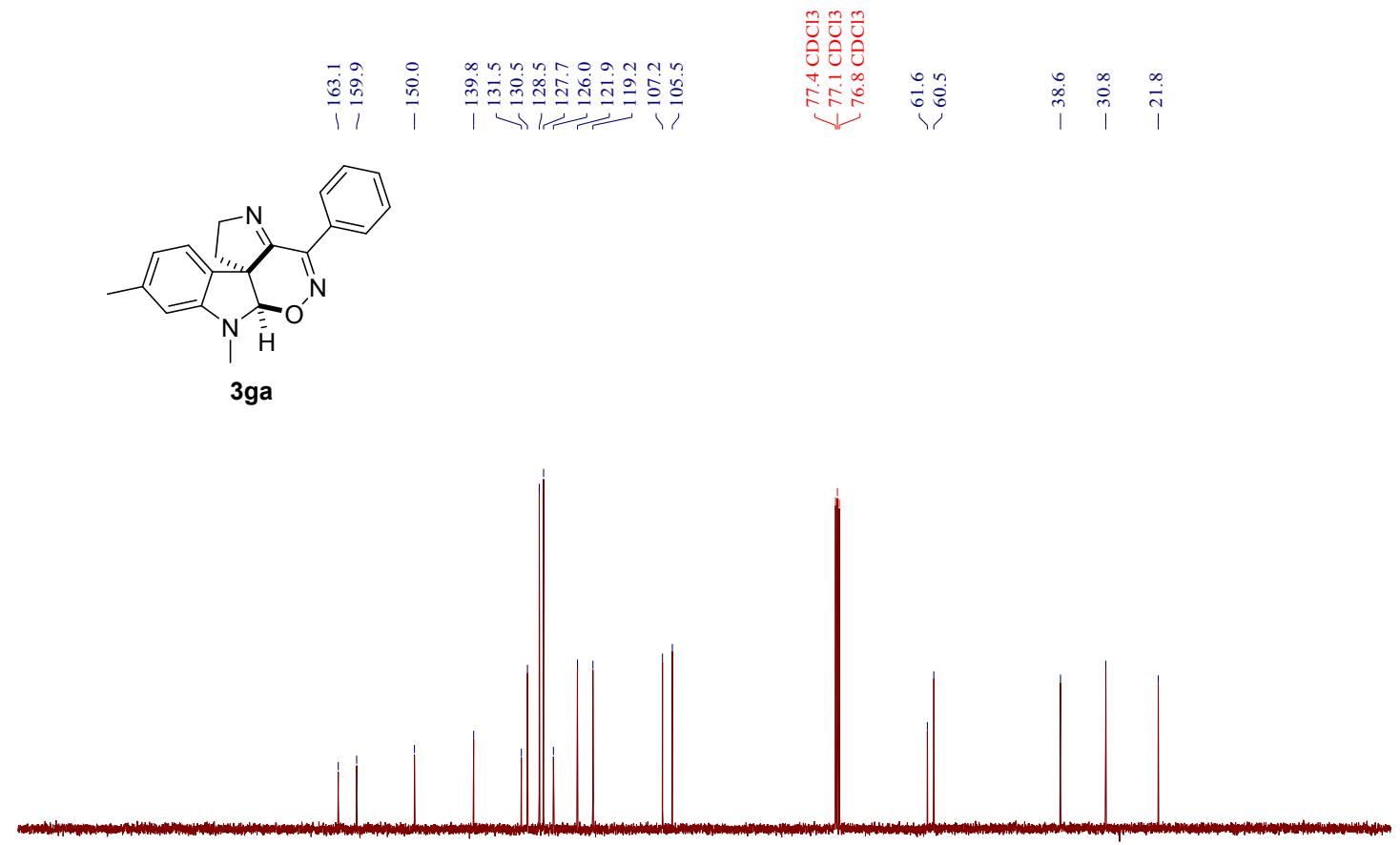

$\begin{array}{llllllllllllllllllllllllll}1 & 210 & 200 & 190 & 180 & 170 & 160 & 150 & 140 & 130 & 120 & 110 & 100 & 90 & 80 & 70 & 60 & 50 & 40 & 30 & 20 & 10 & 0 & -10\end{array}$ 
${ }^{\mathbf{1}} \mathbf{H}$ NMR (400 MHz, $\mathrm{CDCl}_{3}$ ) spectrum of $\mathbf{3 h a}$ (major)
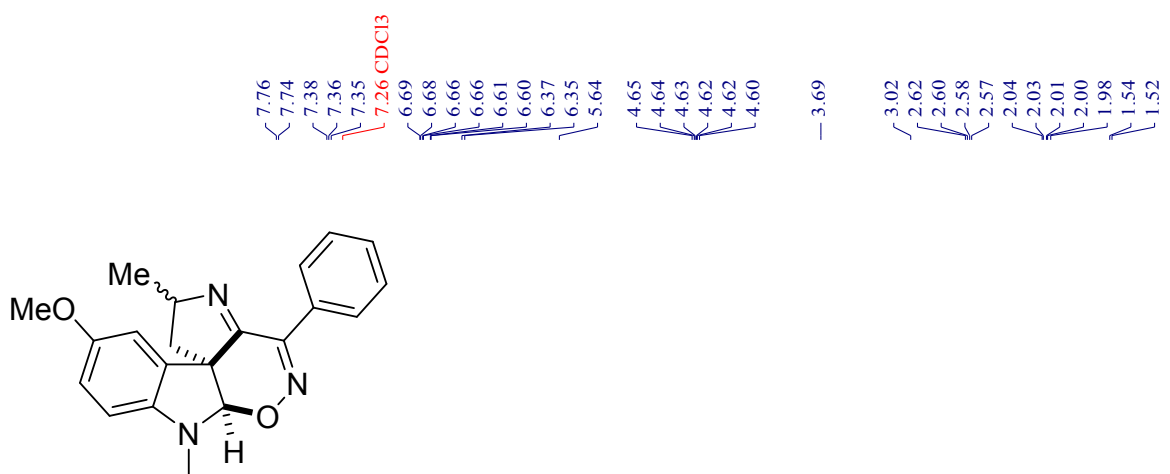

3ha

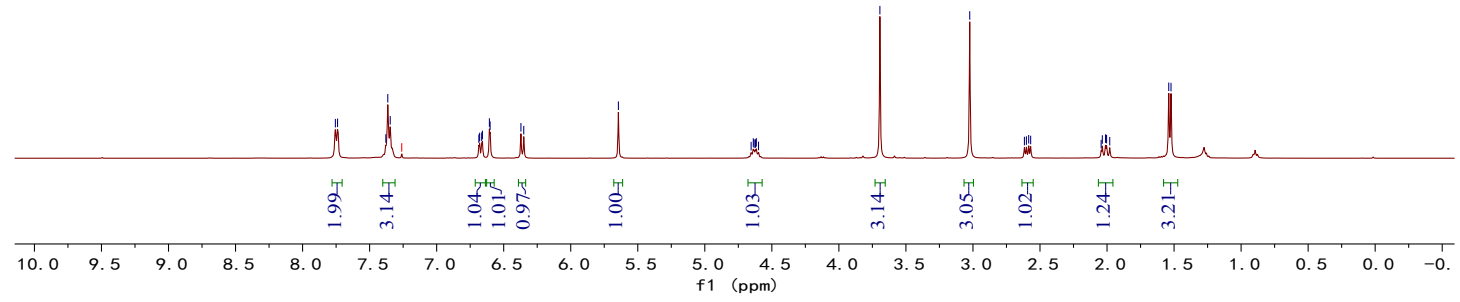

${ }^{13} \mathbf{C}\left\{{ }^{1} \mathbf{H}\right\}$ NMR (100 MHz, $\left.\mathrm{CDCl}_{3}\right)$ spectrum of $\mathbf{3 h a}$ (major)

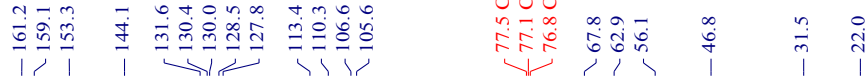<smiles>COc1ccc2c(c1)[C@@]13CCN(C)[C@@H](C1)ON=C3C(c1ccccc1)=N2</smiles>

3ha

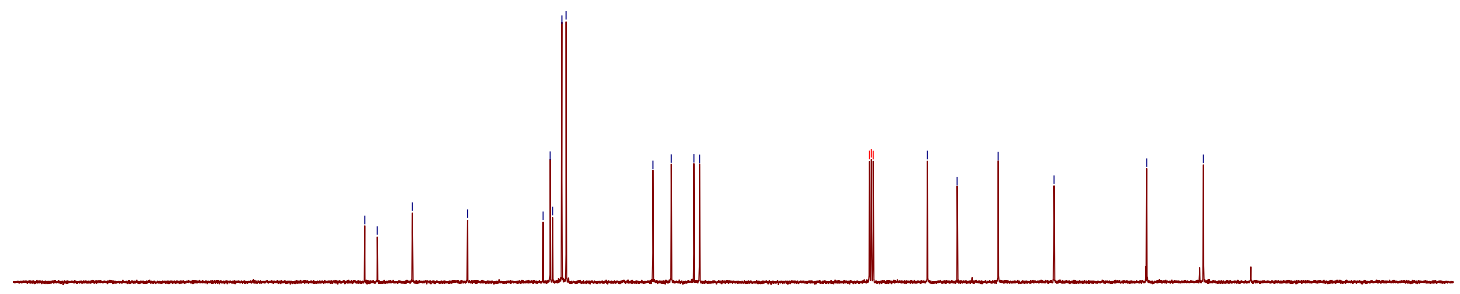

$\begin{array}{lllllllllllll}210 & 200 & 190 & 180 & 170 & 160 & 150 & 140 & 130 & 120 & 110 & 100 & 90\end{array}$ 
${ }^{1} \mathbf{H}$ NMR (400 MHz, $\mathrm{CDCl}_{3}$ ) spectrum of $\mathbf{3 h a}$ (minor)
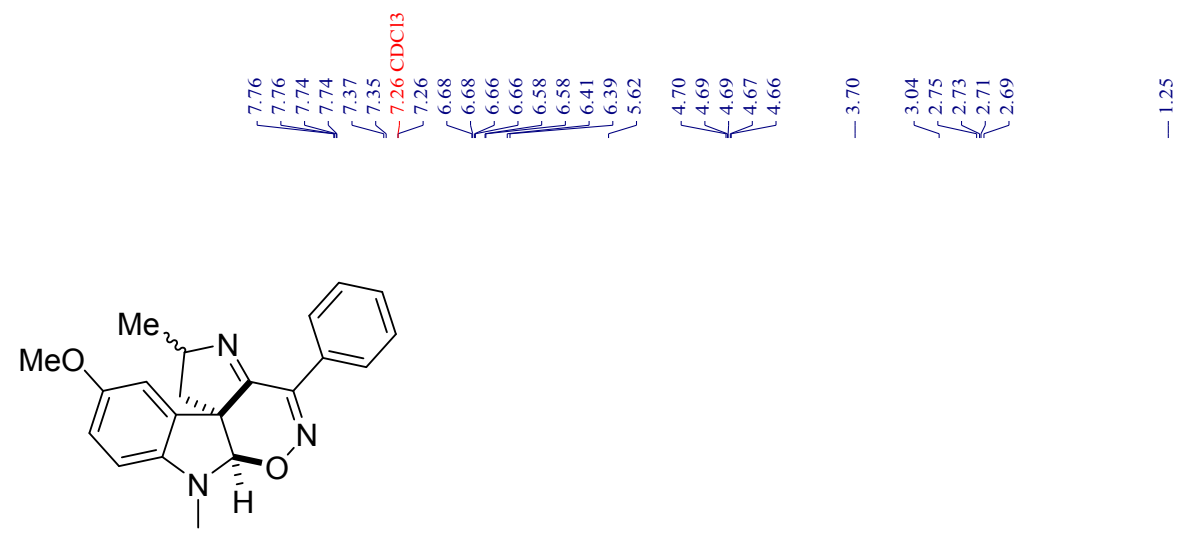

3ha

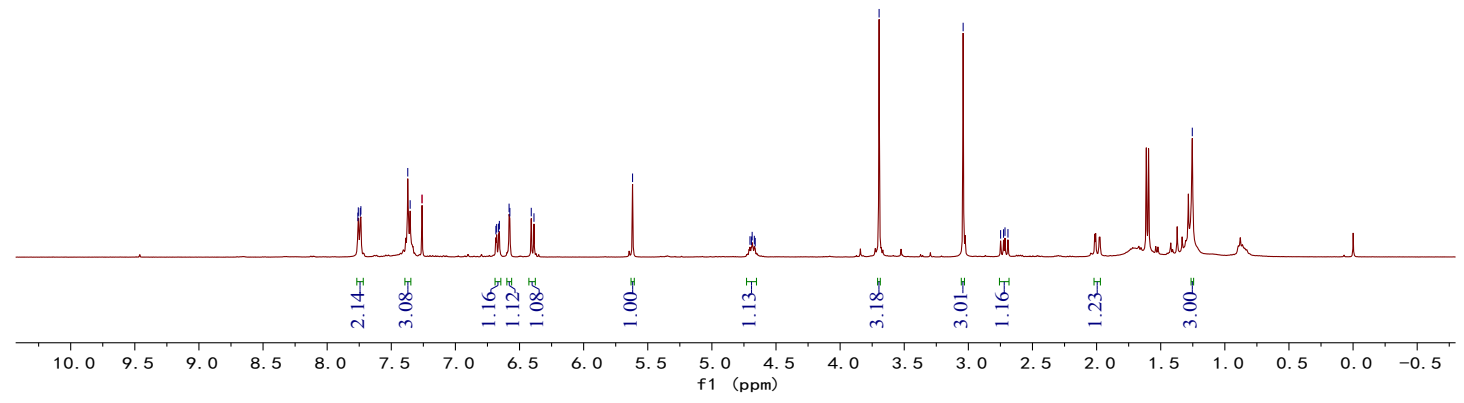

Note: Because the minor stereoisomer is ready to convert into the major one or deteriorate, the perfect NMR spectrum is hard to be obtained.

${ }^{13} \mathbf{C}\left\{{ }^{1} \mathbf{H}\right\}$ NMR (100 MHz, $\left.\mathrm{CDCl}_{3}\right)$ spectrum of $\mathbf{3 h a}$ (minor)

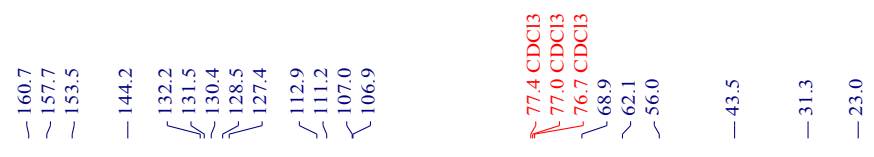<smiles>COc1ccc2c(c1)C1C(=N2)C(c2ccccc2)=NOC1N(C)C</smiles>

3ha

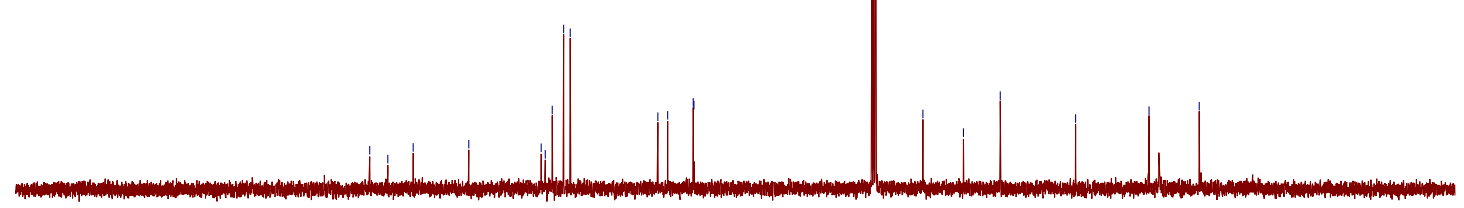

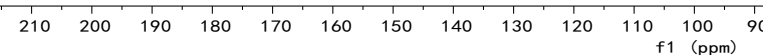


${ }^{1} \mathbf{H}$ NMR (400 MHz, $\mathrm{CDCl}_{3}$ ) spectrum of 3ia (major)
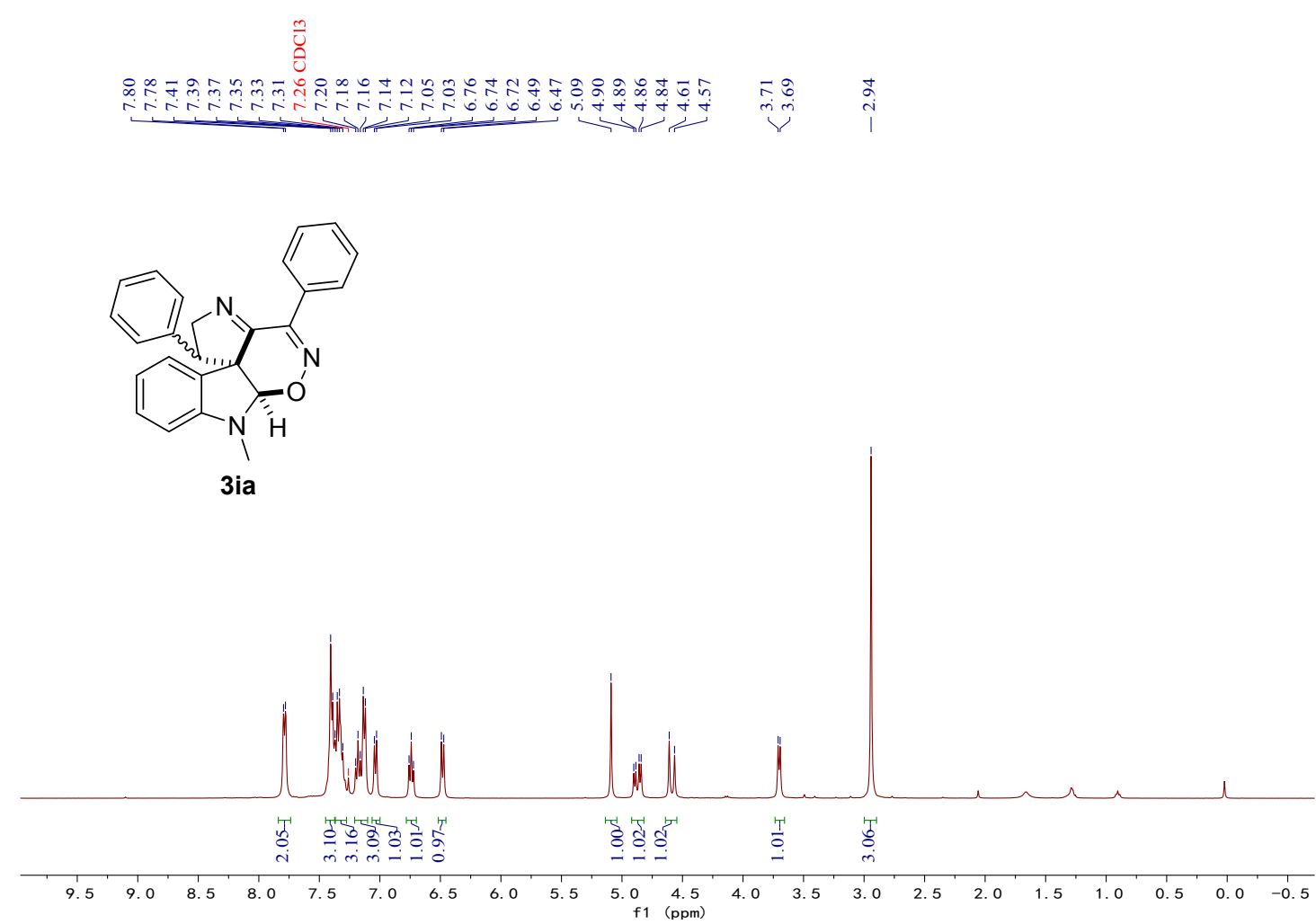

${ }^{13} \mathbf{C}\left\{{ }^{1} \mathbf{H}\right\}$ NMR (100 MHz, $\left.\mathrm{CDCl}_{3}\right)$ spectrum of 3ia (major)

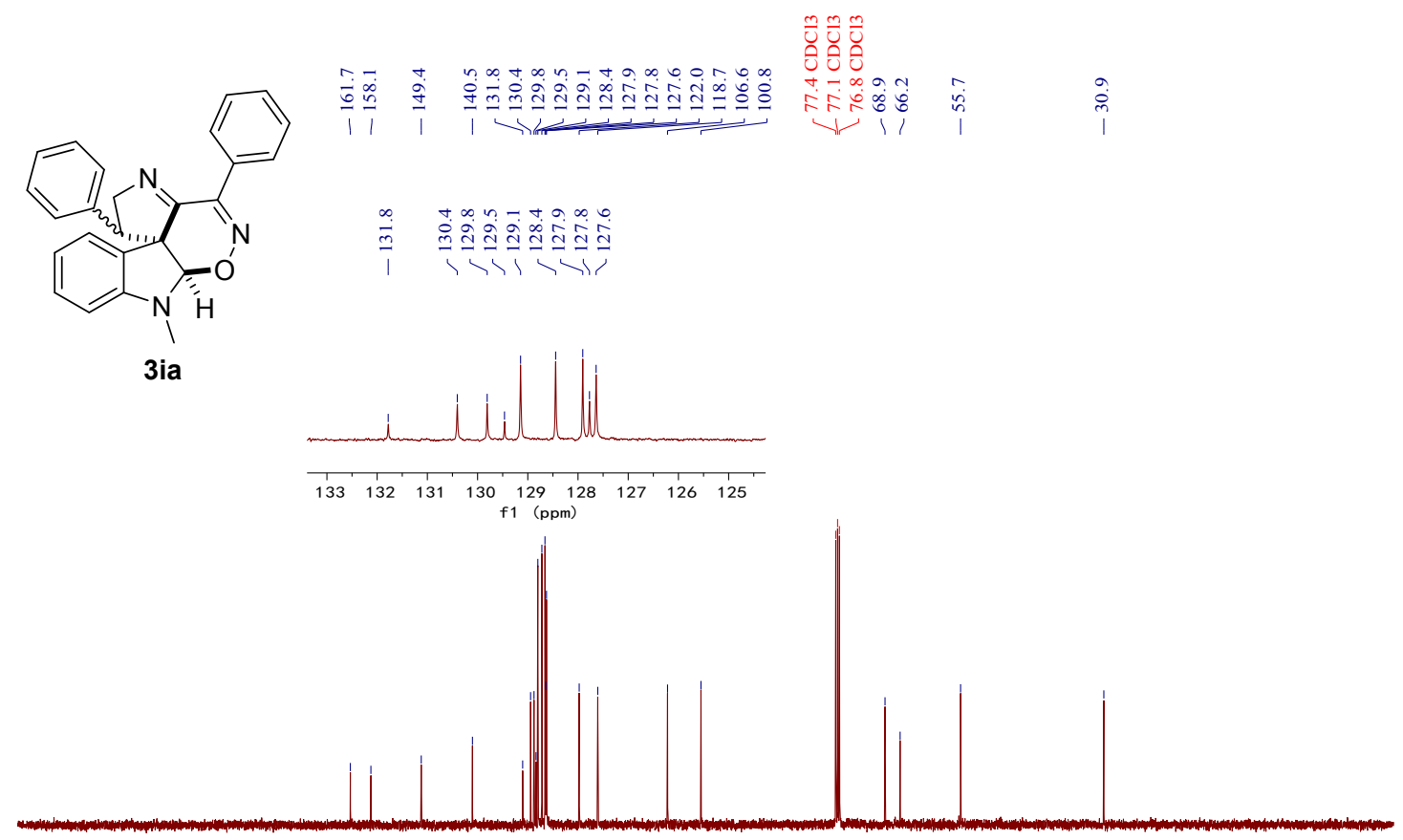

$\begin{array}{lllllllllllllllllllllllllllllllllll}210 & 200 & 190 & 180 & 170 & 160 & 150 & 140 & 130 & 120 & 110 & 100 & 90 & 80 & 70 & 60 & 50 & 40 & 30 & 20 & 10 & 0 & -10\end{array}$ 
${ }^{1} \mathbf{H}$ NMR (400 MHz, $\mathrm{CDCl}_{3}$ ) spectrum of 3ia (minor)
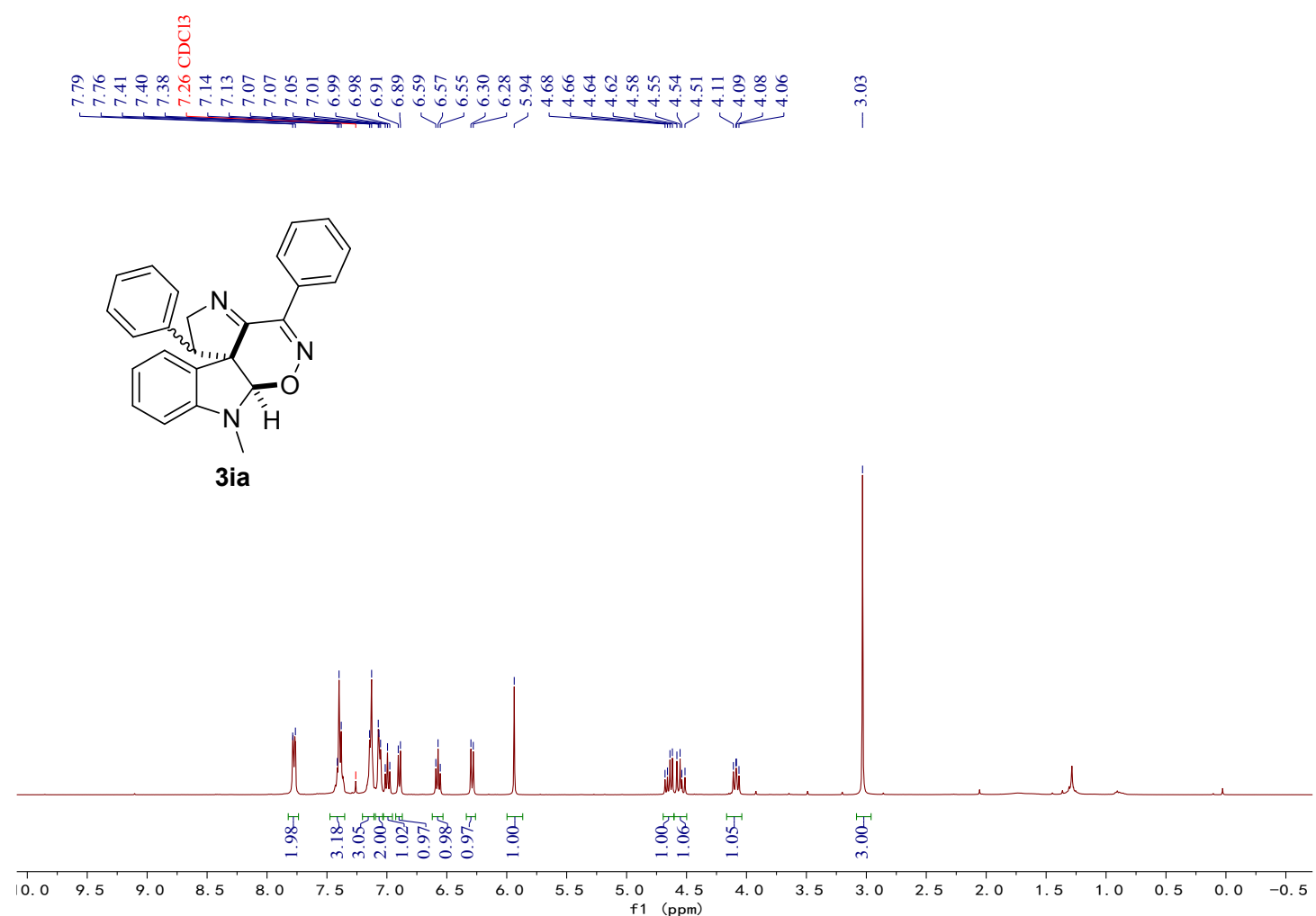

${ }^{13} \mathbf{C}\left\{{ }^{1} \mathbf{H}\right\}$ NMR (100 MHz, $\left.\mathrm{CDCl}_{3}\right)$ spectrum of $3 \mathbf{i a}$ (minor)

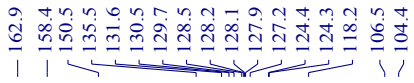
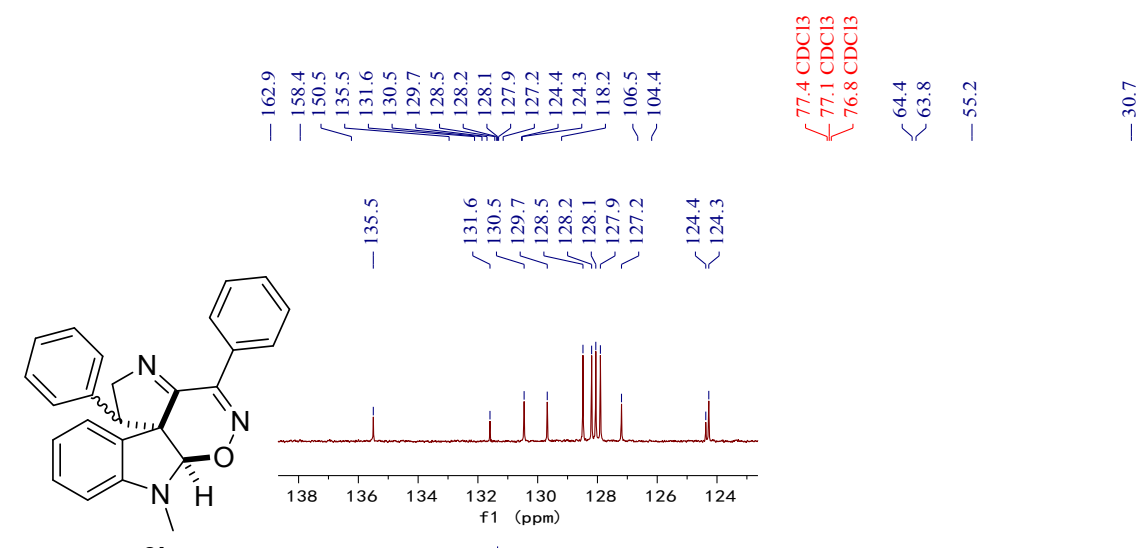

3ia

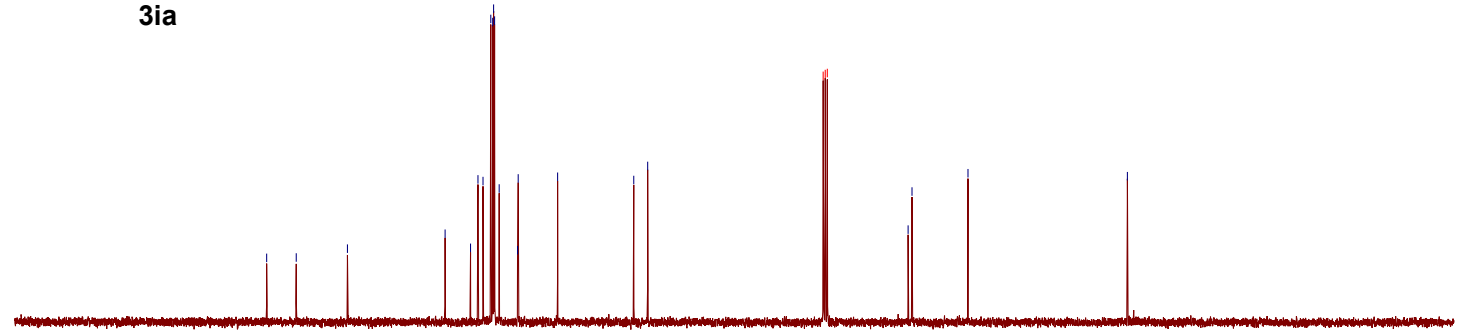

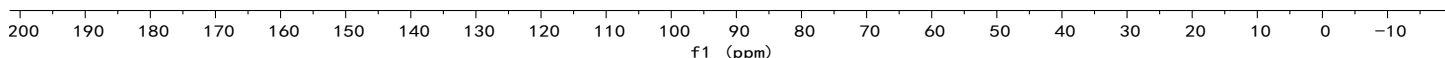


${ }^{1} \mathbf{H}$ NMR $\left(400 \mathrm{MHz}, \mathrm{CDCl}_{3}\right)$ spectrum of $\mathbf{3 j a}$

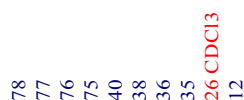

岂

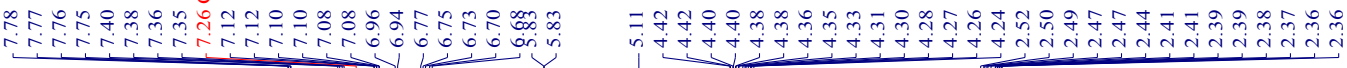
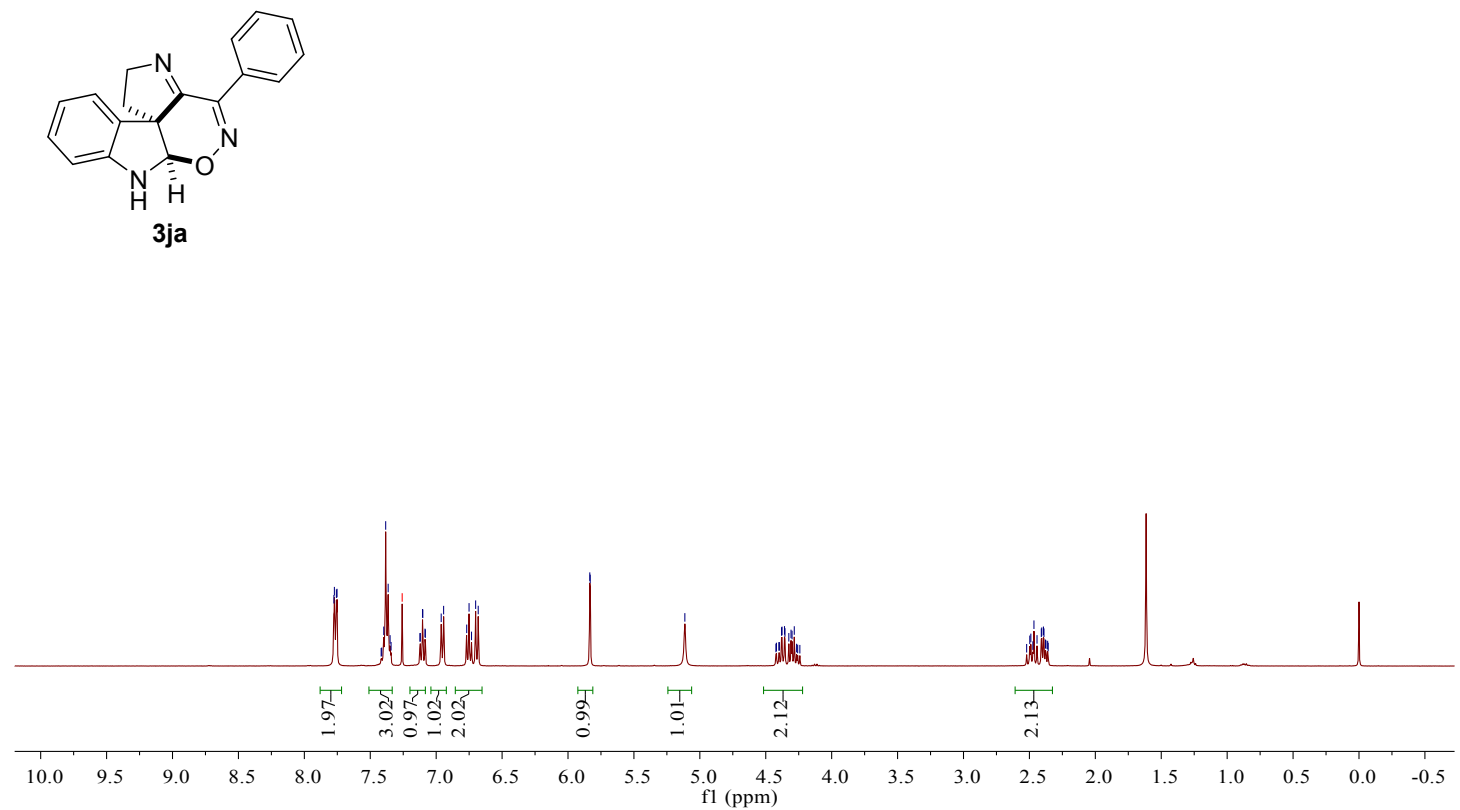

${ }^{13} \mathbf{C}\left\{{ }^{1} \mathbf{H}\right\}$ NMR $\left(100 \mathrm{MHz}, \mathrm{CDCl}_{3}\right)$ spectrum of $\mathbf{3 j a}$

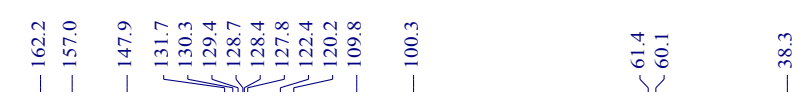<smiles>c1ccc(C2=NOC3Nc4ccccc4C23)cc1</smiles>

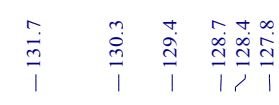

3ja
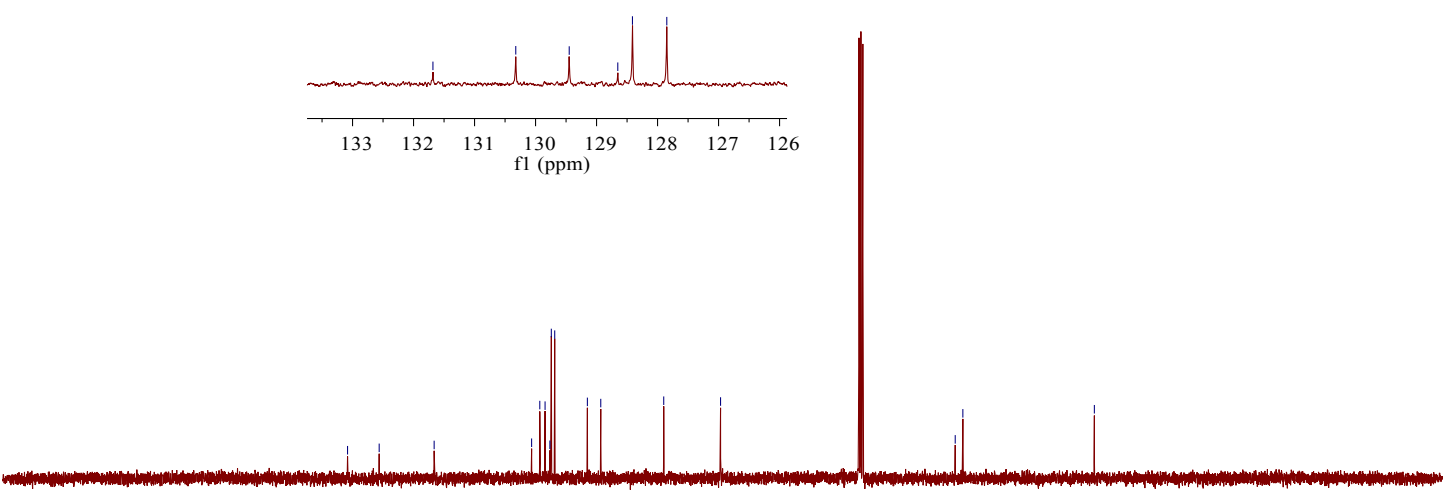

$\begin{array}{llllllllllllllllllllllll}210 & 200 & 190 & 180 & 170 & 160 & 150 & 140 & 130 & 120 & 110 & 100 & 90 & 80 & 70 & 60 & 50 & 40 & 30 & 20 & 10 & 0 & -10\end{array}$ 
${ }^{\mathbf{1}} \mathbf{H}$ NMR (400 MHz, $\mathrm{CDCl}_{3}$ ) spectrum of 3ka

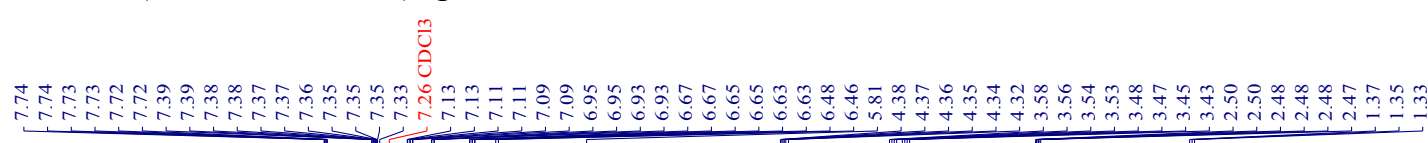

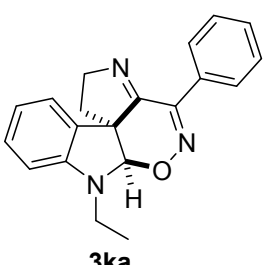

3ka

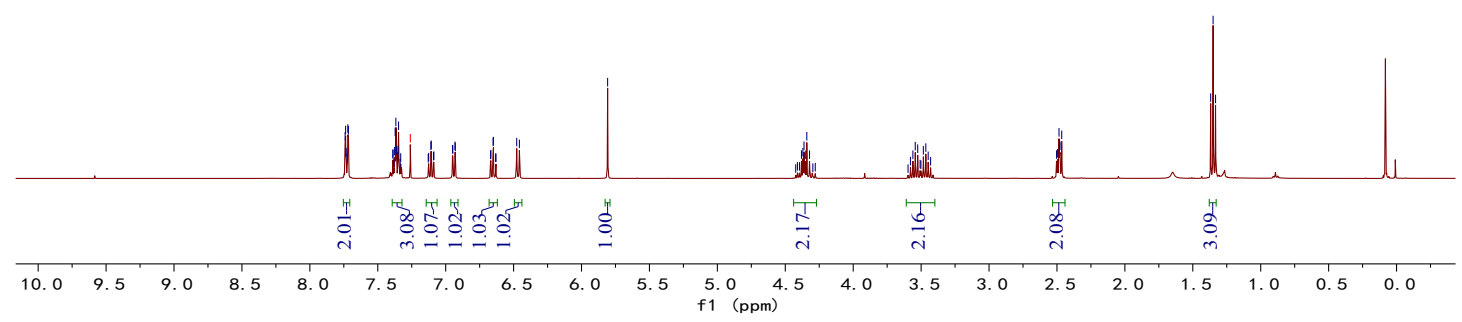

${ }^{13} \mathbf{C}\left\{{ }^{1} \mathbf{H}\right\}$ NMR $\left(100 \mathrm{MHz}, \mathrm{CDCl}_{3}\right)$ spectrum of $\mathbf{3} \mathbf{k a}$
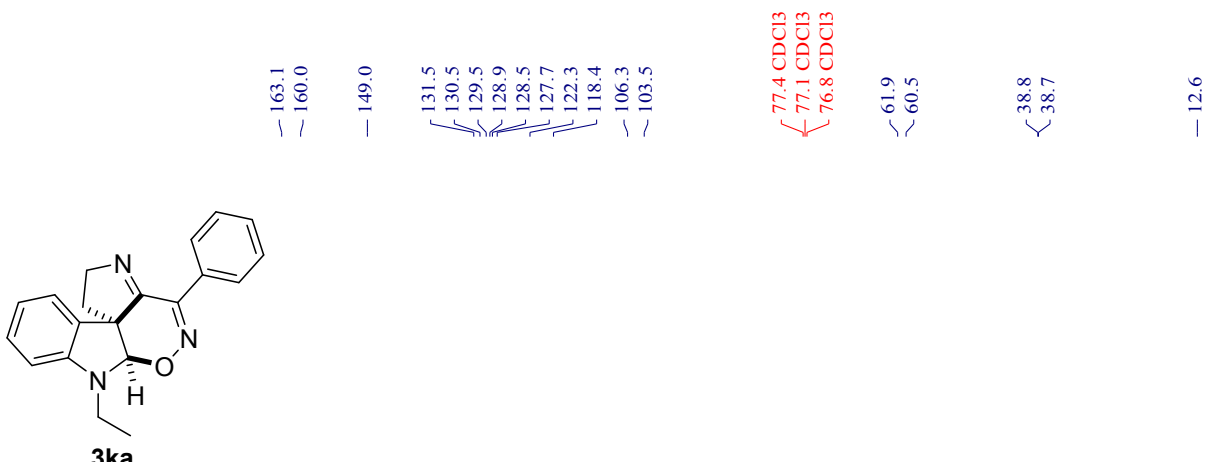

3ka

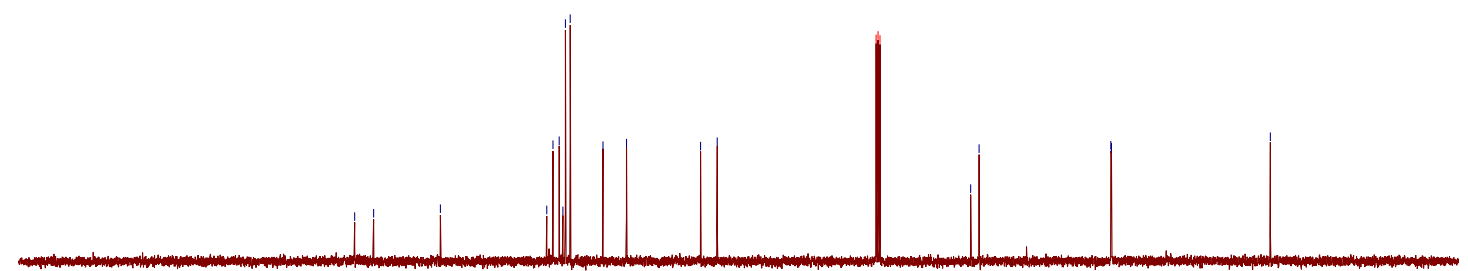

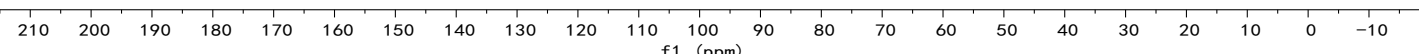


${ }^{1} \mathbf{H}$ NMR $\left(400 \mathrm{MHz}, \mathrm{CDCl}_{3}\right)$ spectrum of $\mathbf{3 l a}$

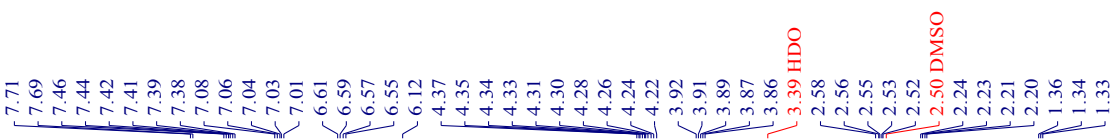

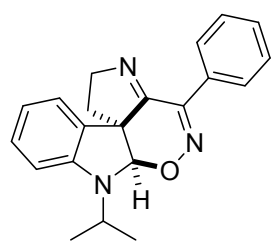

3la

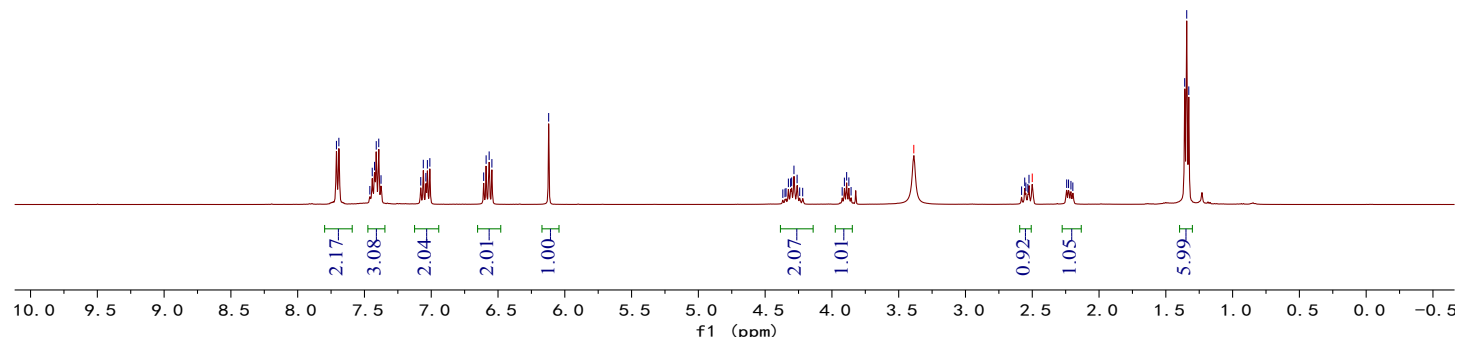

${ }^{13} \mathbf{C}\left\{{ }^{1} \mathbf{H}\right\}$ NMR $\left(100 \mathrm{MHz}, \mathrm{CDCl}_{3}\right)$ spectrum of 3la

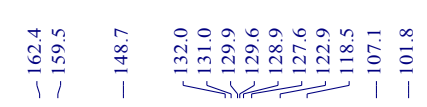
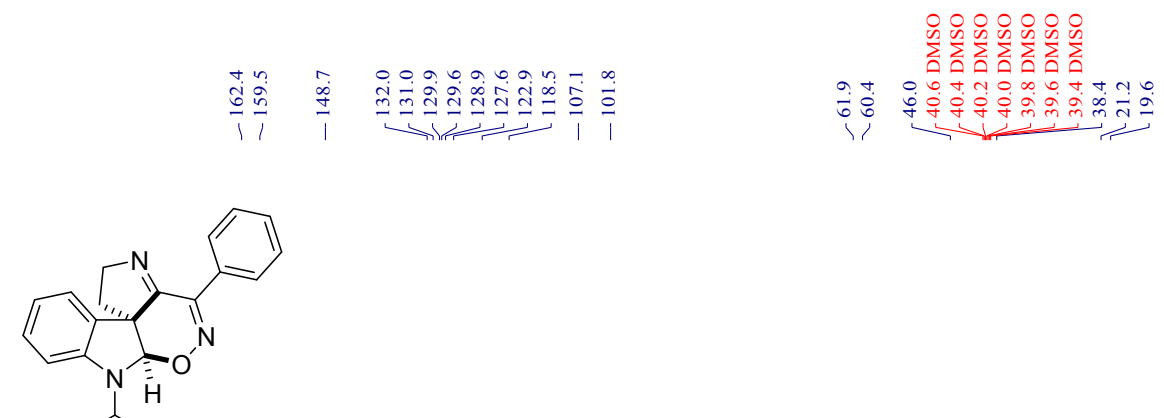

3la

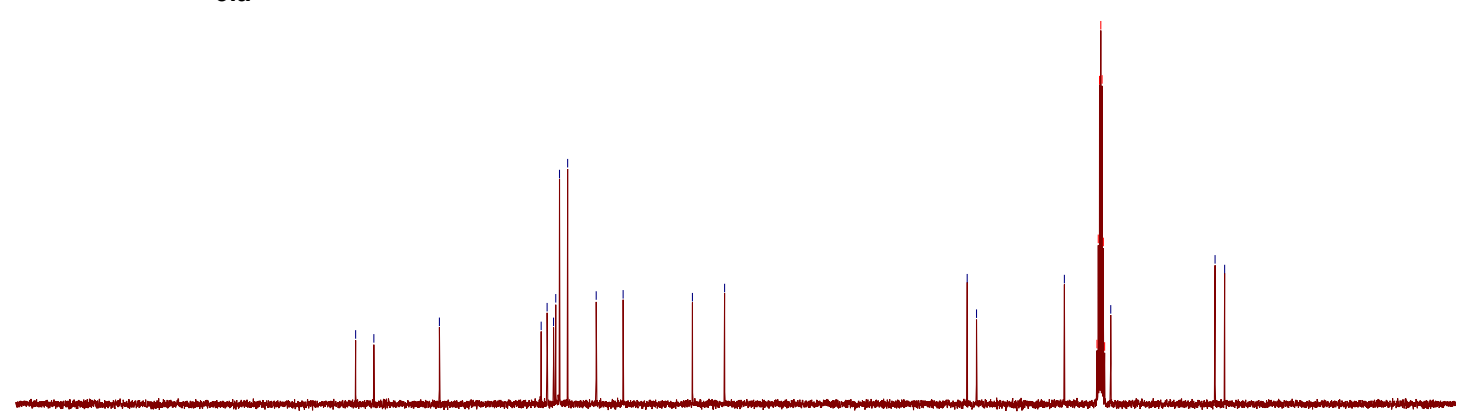

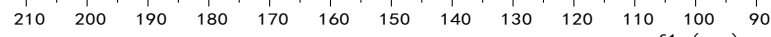


${ }^{1} \mathbf{H}$ NMR (400 MHz, $\mathrm{CDCl}_{3}$ ) spectrum of $\mathbf{3 m a}$
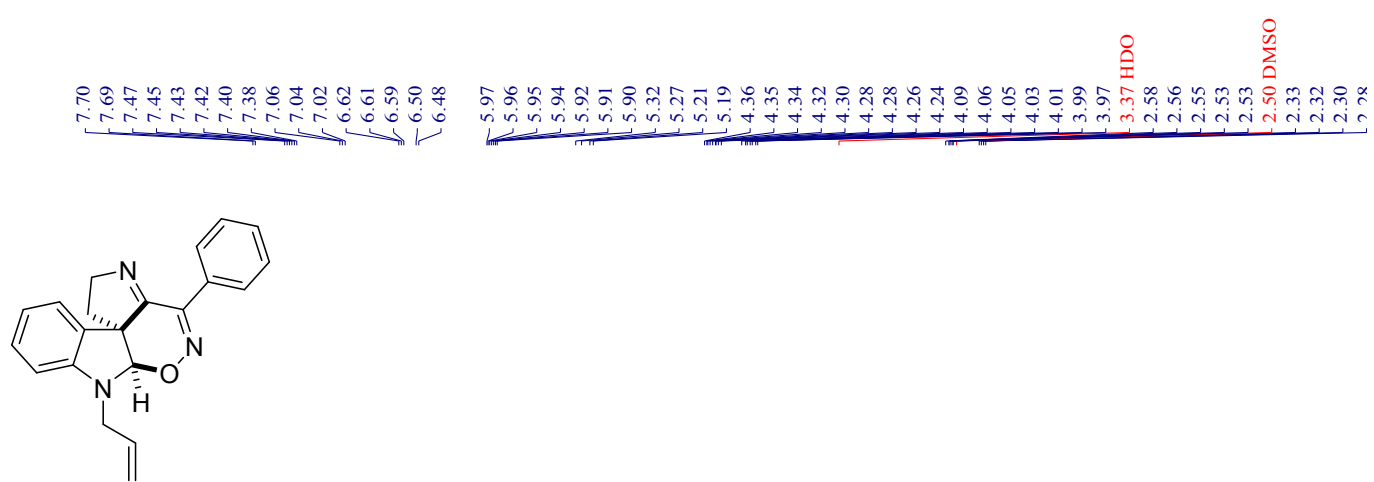

$3 \mathrm{ma}$

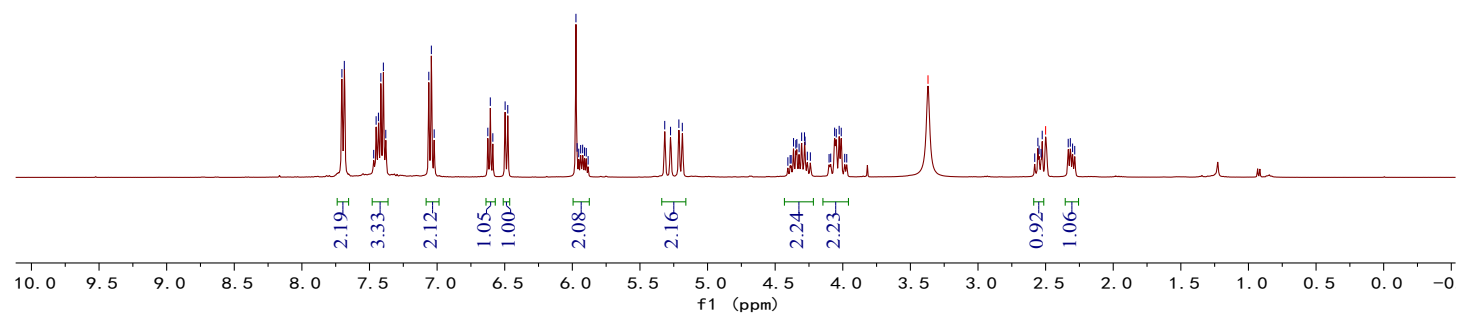

${ }^{13} \mathbf{C}\left\{{ }^{1} \mathbf{H}\right\}$ NMR (100 MHz, $\left.\mathrm{CDCl}_{3}\right)$ spectrum of $\mathbf{3} \mathbf{m a}$
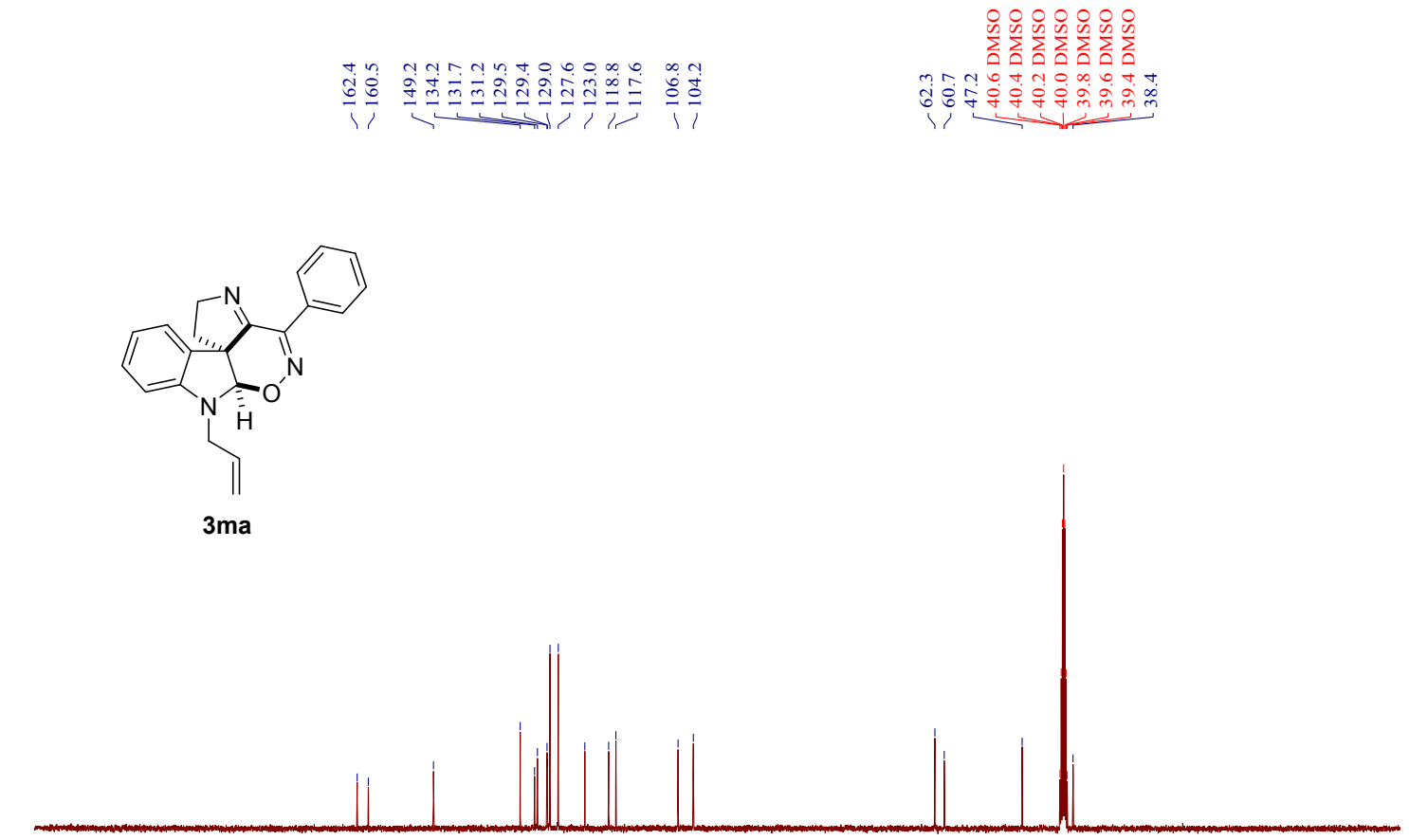

$3 \mathrm{ma}$

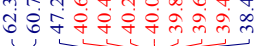

$\begin{array}{lllllllllllll}210 & 200 & 190 & 180 & 170 & 160 & 150 & 140 & 130 & 120 & 110 & 100 & 90\end{array}$ 
${ }^{\mathbf{1}} \mathbf{H}$ NMR (400 MHz, $\mathrm{CDCl}_{3}$ ) spectrum of 3na

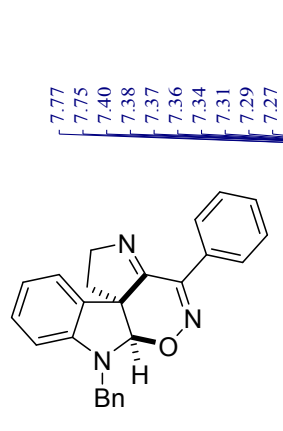

己ु

$\cos ^{2}$

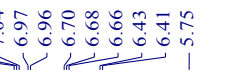

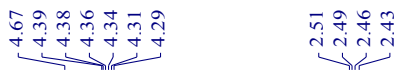

3na

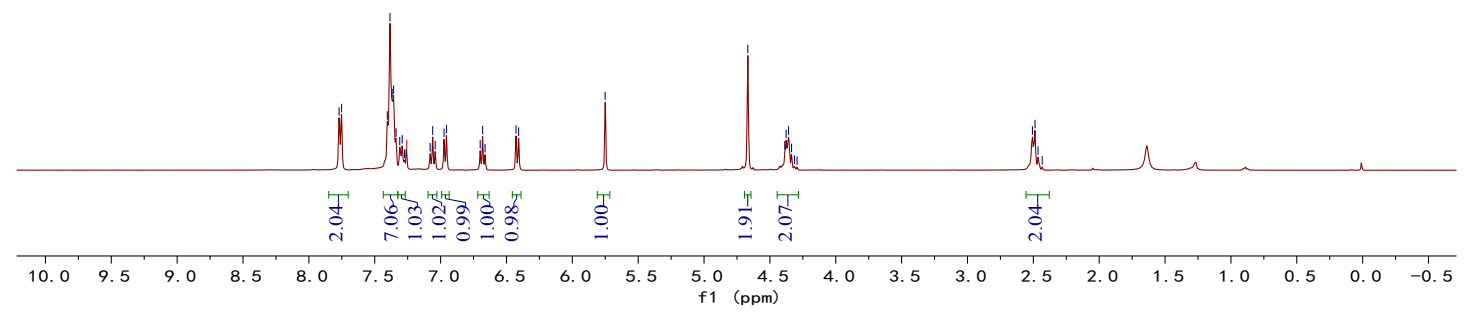

${ }^{13} \mathbf{C}\left\{{ }^{1} \mathbf{H}\right\}$ NMR $\left(100 \mathrm{MHz}, \mathrm{CDCl}_{3}\right)$ spectrum of $\mathbf{3 n a}$
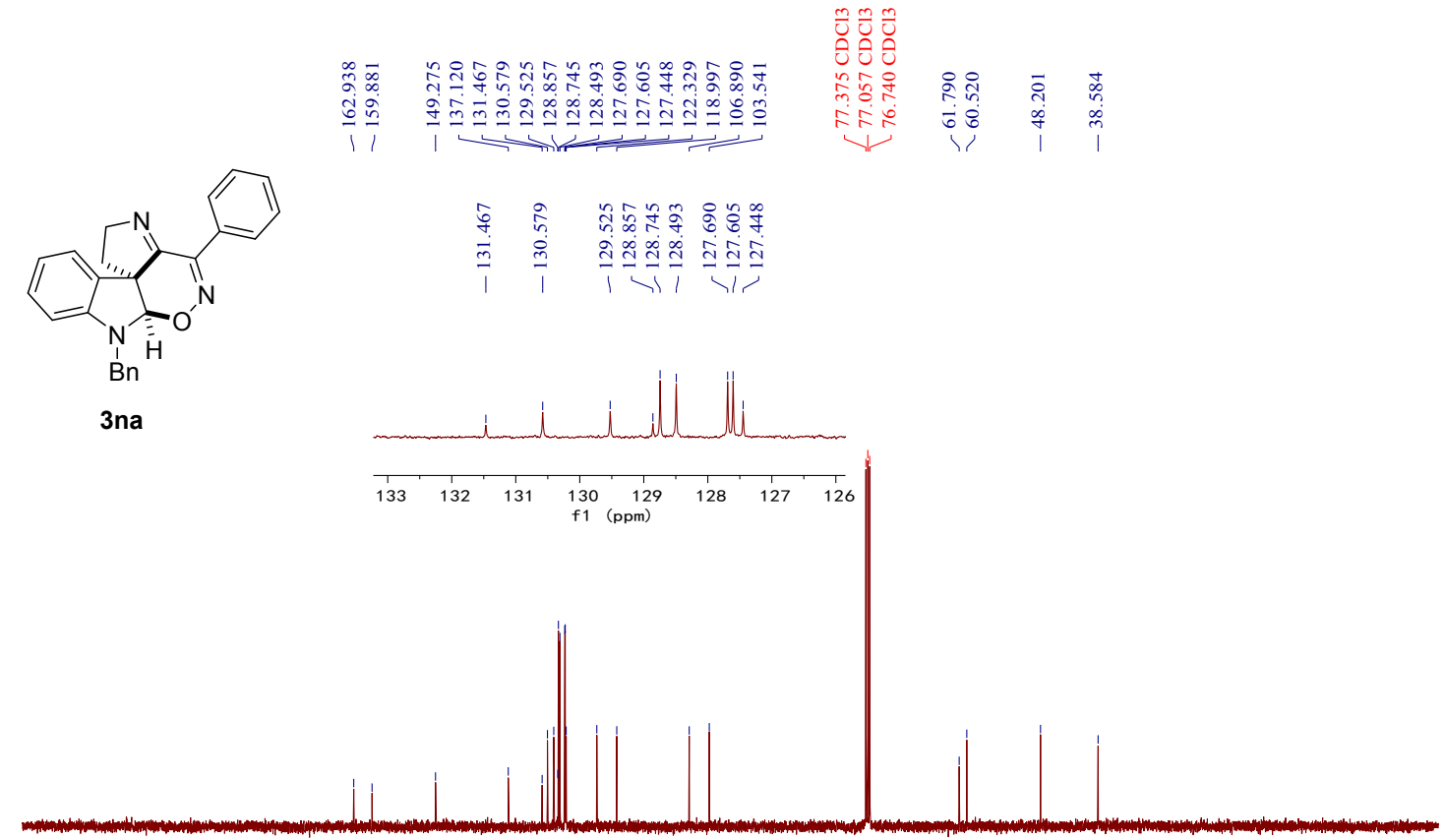

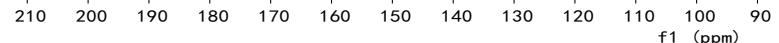


${ }^{\mathbf{1}} \mathbf{H}$ NMR (400 MHz, $\mathrm{CDCl}_{3}$ ) spectrum of $\mathbf{3 o a}$
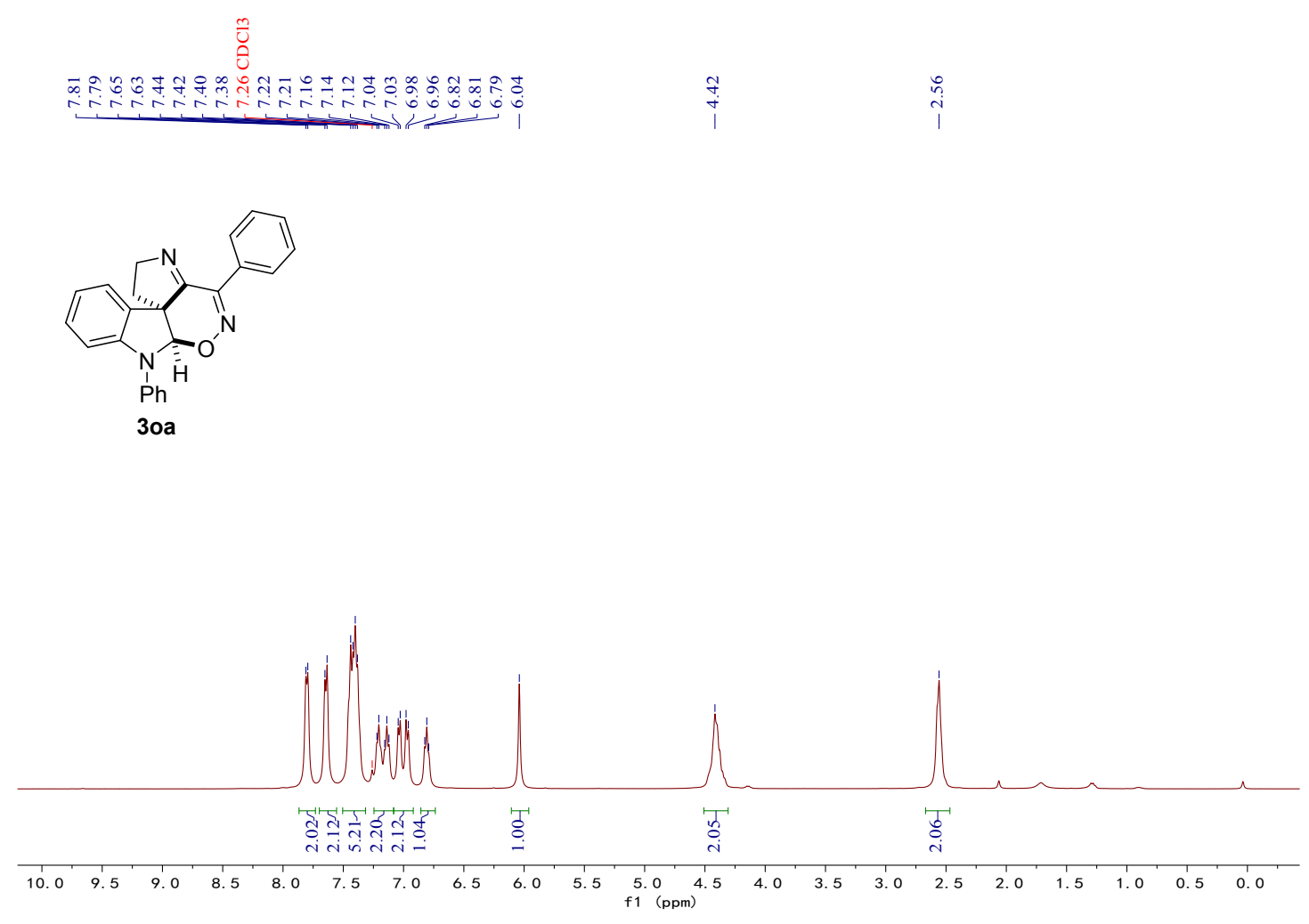

${ }^{13} \mathbf{C}\left\{{ }^{1} \mathbf{H}\right\}$ NMR $\left(100 \mathrm{MHz}, \mathrm{CDCl}_{3}\right)$ spectrum of $\mathbf{3 o a}$
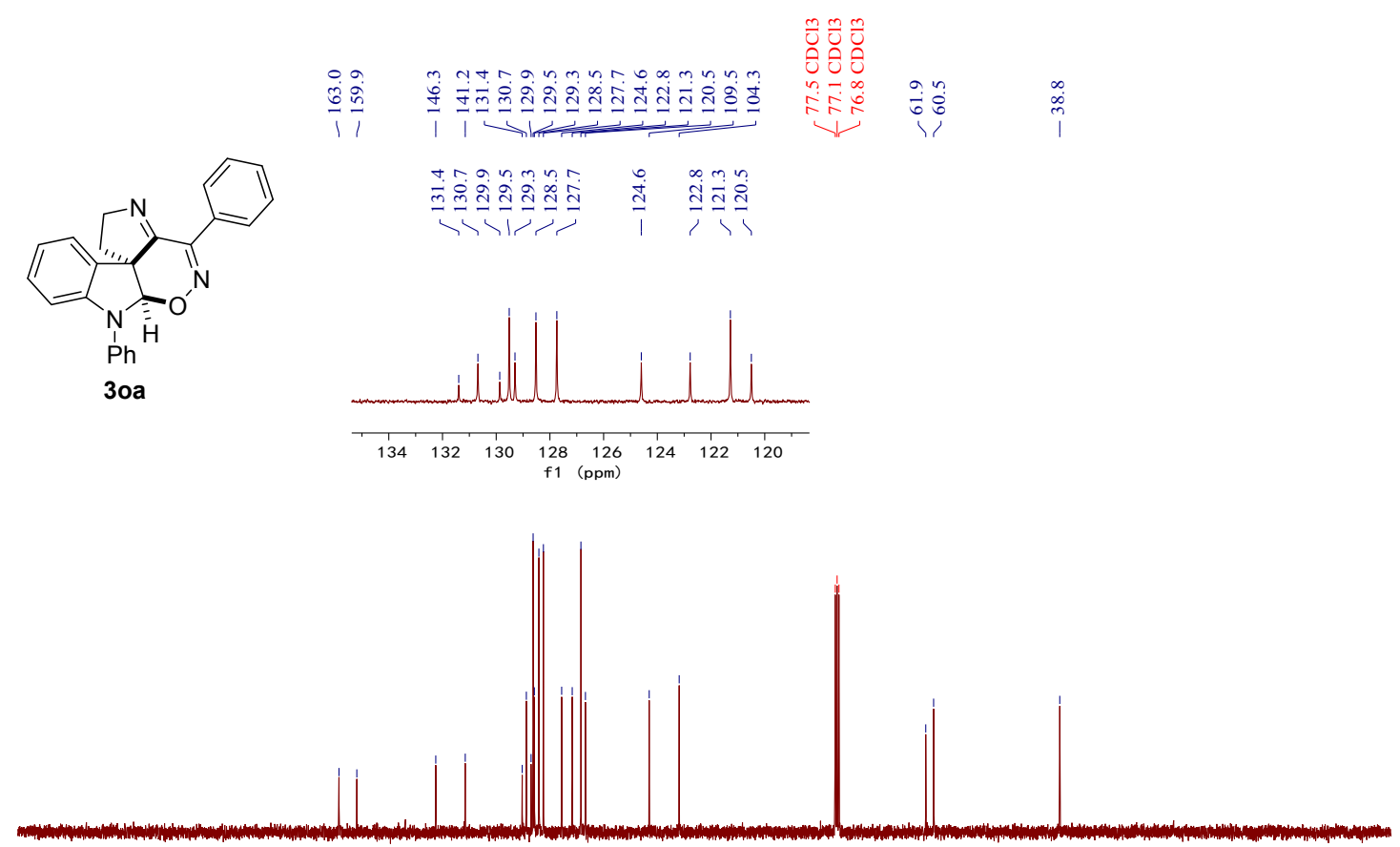

$\begin{array}{llllllllllllllllllllllllllllllll}210 & 200 & 190 & 180 & 170 & 160 & 150 & 140 & 130 & 120 & 110 & 100 & 90 & 80 & 70 & 60 & 50 & 40 & 30 & 20 & 10 & 0 & -10\end{array}$ 
${ }^{1} \mathbf{H}$ NMR (400 MHz, $\mathrm{CDCl}_{3}$ ) spectrum of 3qa
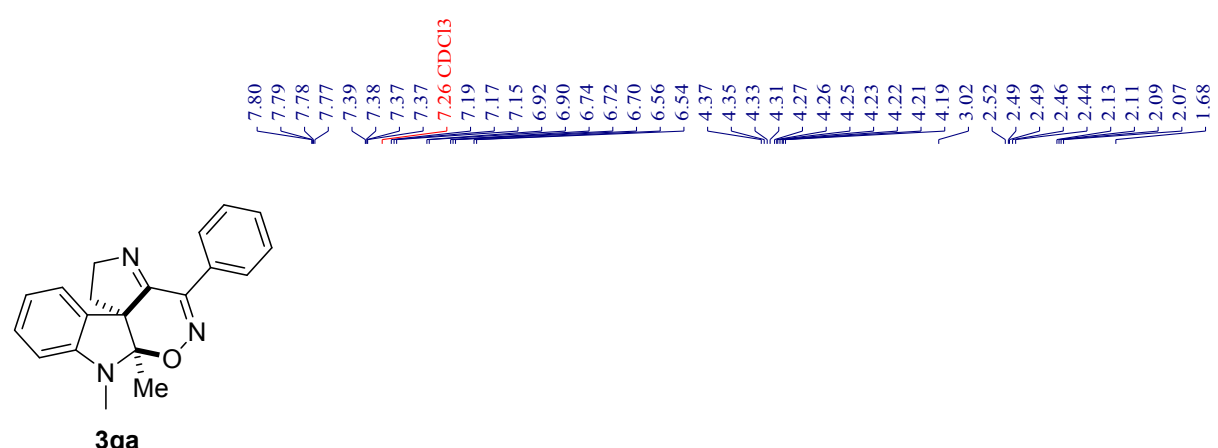

$3 q a$

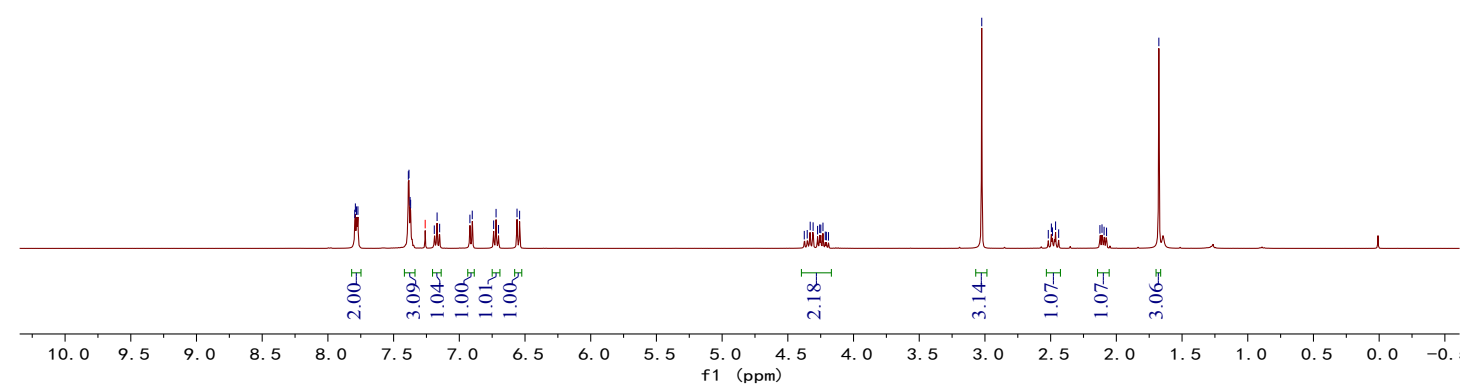

${ }^{13} \mathbf{C}\left\{{ }^{1} \mathbf{H}\right\}$ NMR $\left(100 \mathrm{MHz}, \mathrm{CDCl}_{3}\right)$ spectrum of $\mathbf{3 q a}$
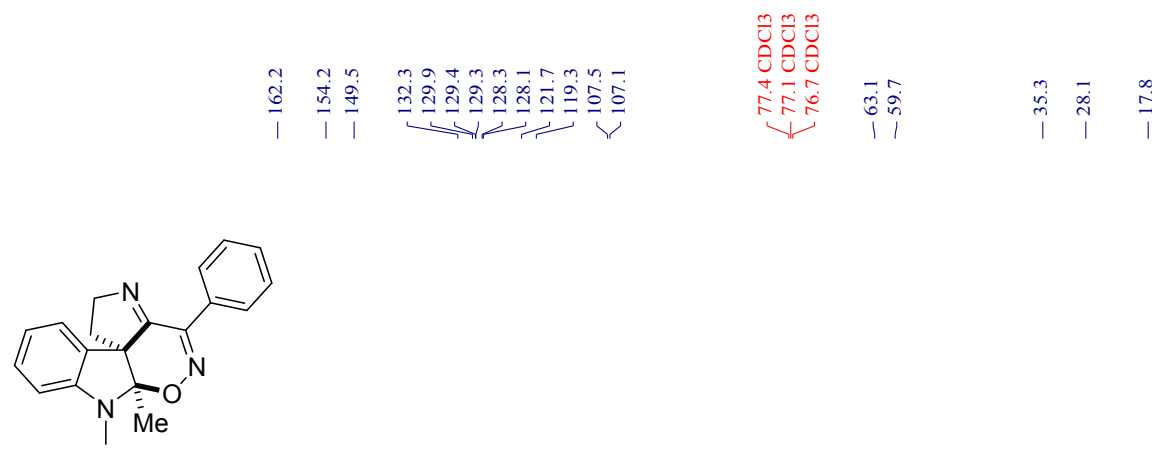

$3 q a$

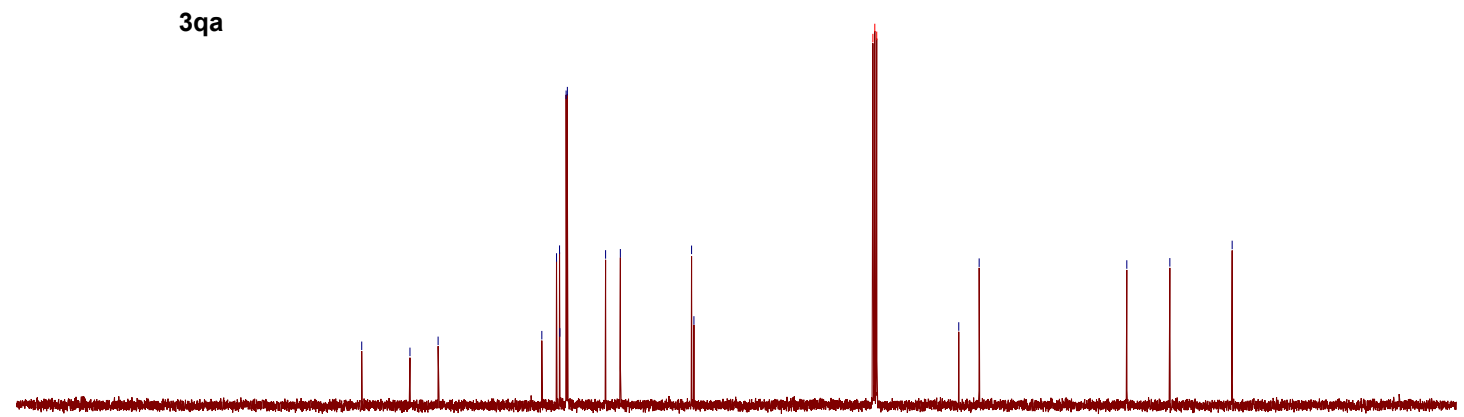

$\begin{array}{lllllllllllll}210 & 200 & 190 & 180 & 170 & 160 & 150 & 140 & 130 & 120 & 110 & 100 & 90\end{array}$

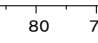

$60 \quad 50$

40 
${ }^{\mathbf{1}} \mathbf{H}$ NMR (400 MHz, $\mathrm{CDCl}_{3}$ ) spectrum of 3ra
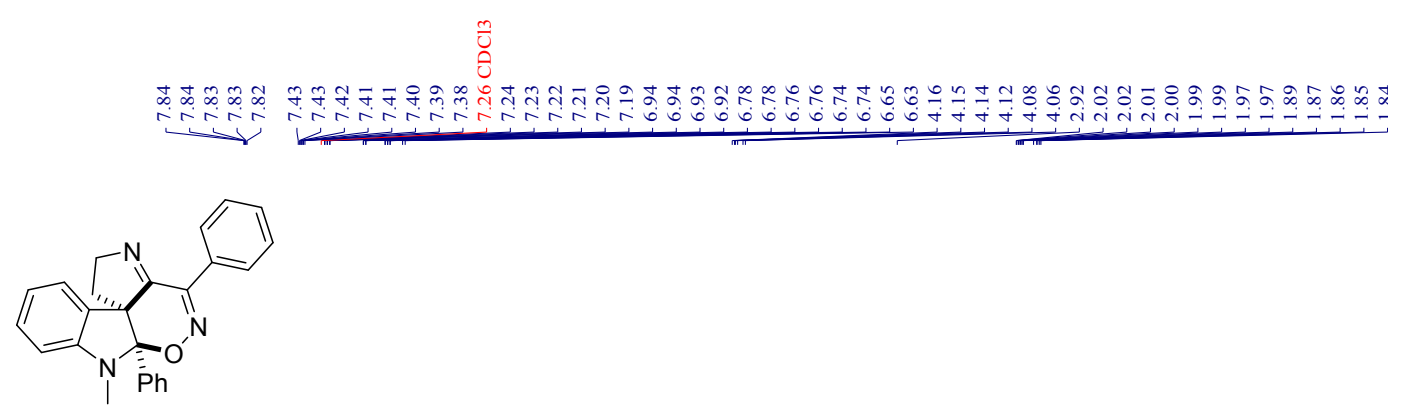

3ra

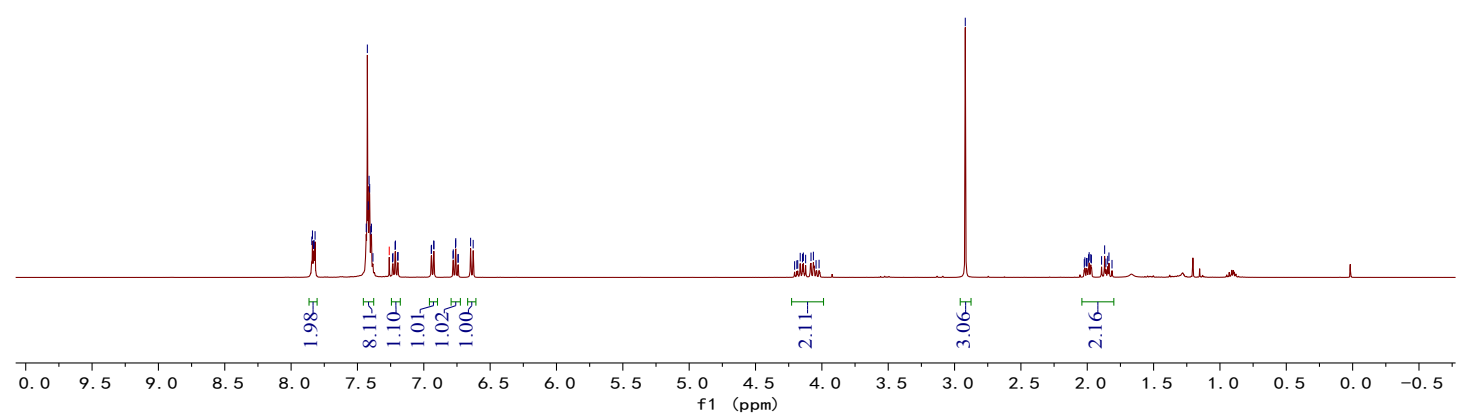

${ }^{13} \mathbf{C}\left\{{ }^{1} \mathbf{H}\right\}$ NMR $\left(100 \mathrm{MHz}, \mathrm{CDCl}_{3}\right)$ spectrum of $\mathbf{3} \mathbf{r a}$
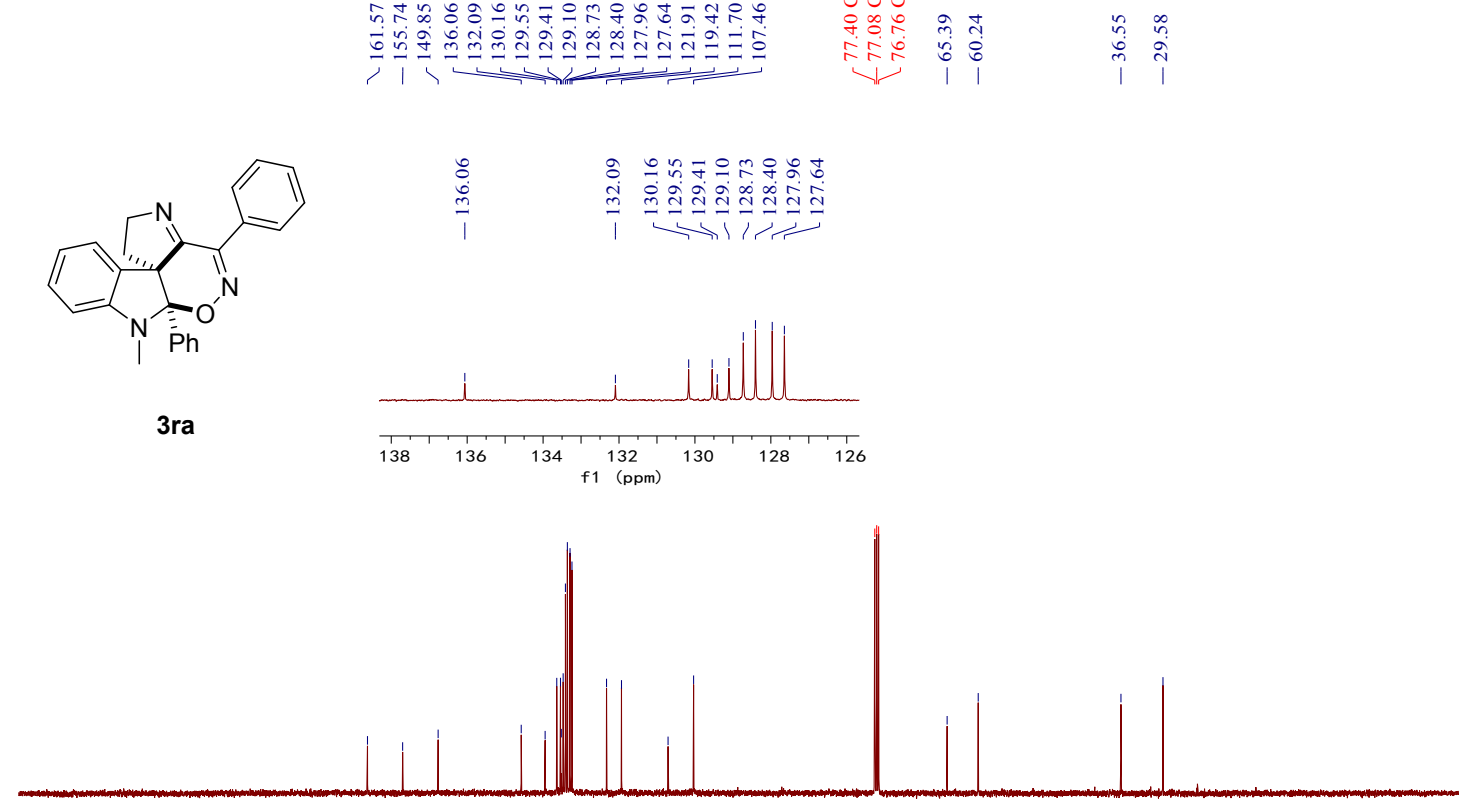

$\begin{array}{llllllllllllllllllllllllllll}210 & 200 & 190 & 180 & 170 & 160 & 150 & 140 & 130 & 120 & 110 & 100 & 90 & 80 & 70 & 60 & 50 & 40 & 30 & 20 & 10 & 0 & -10\end{array}$ 
${ }^{1} \mathbf{H}$ NMR (400 MHz, $\mathrm{CDCl}_{3}$ ) spectrum of $\mathbf{3 a b}$
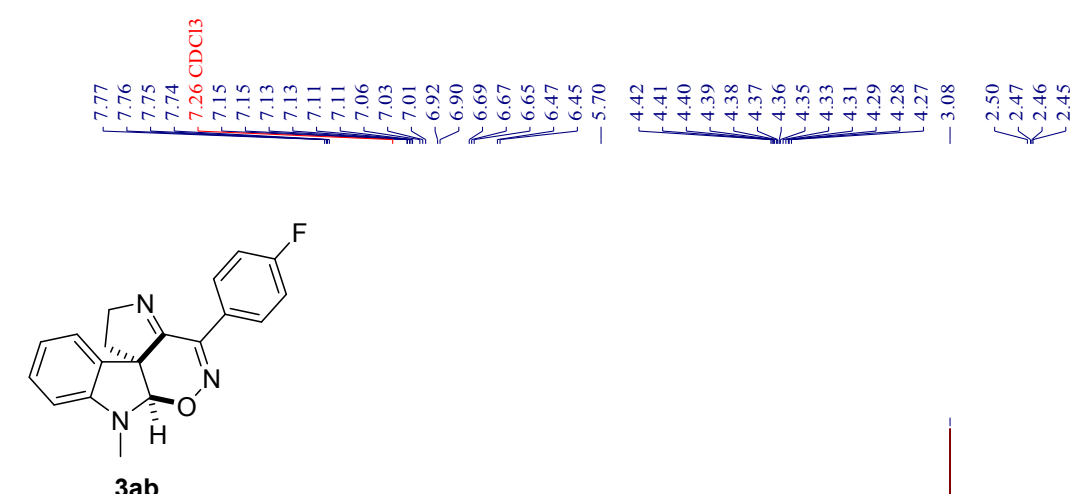

$3 a b$

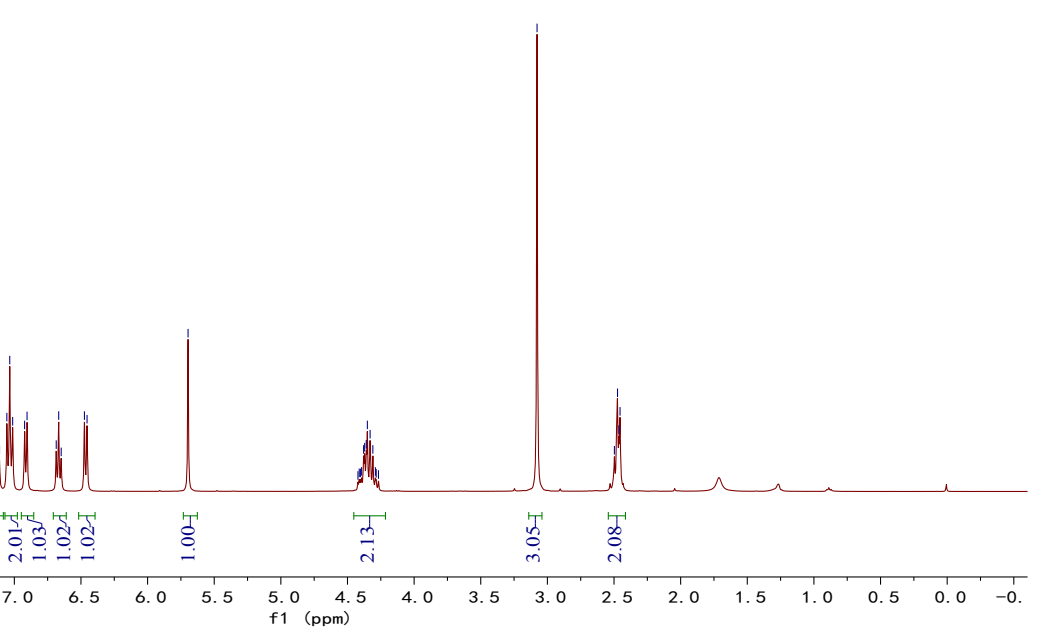

${ }^{13} \mathbf{C}\left\{{ }^{1} \mathbf{H}\right\}$ NMR $\left(100 \mathrm{MHz}, \mathrm{CDCl}_{3}\right)$ spectrum of $\mathbf{3 a b}$
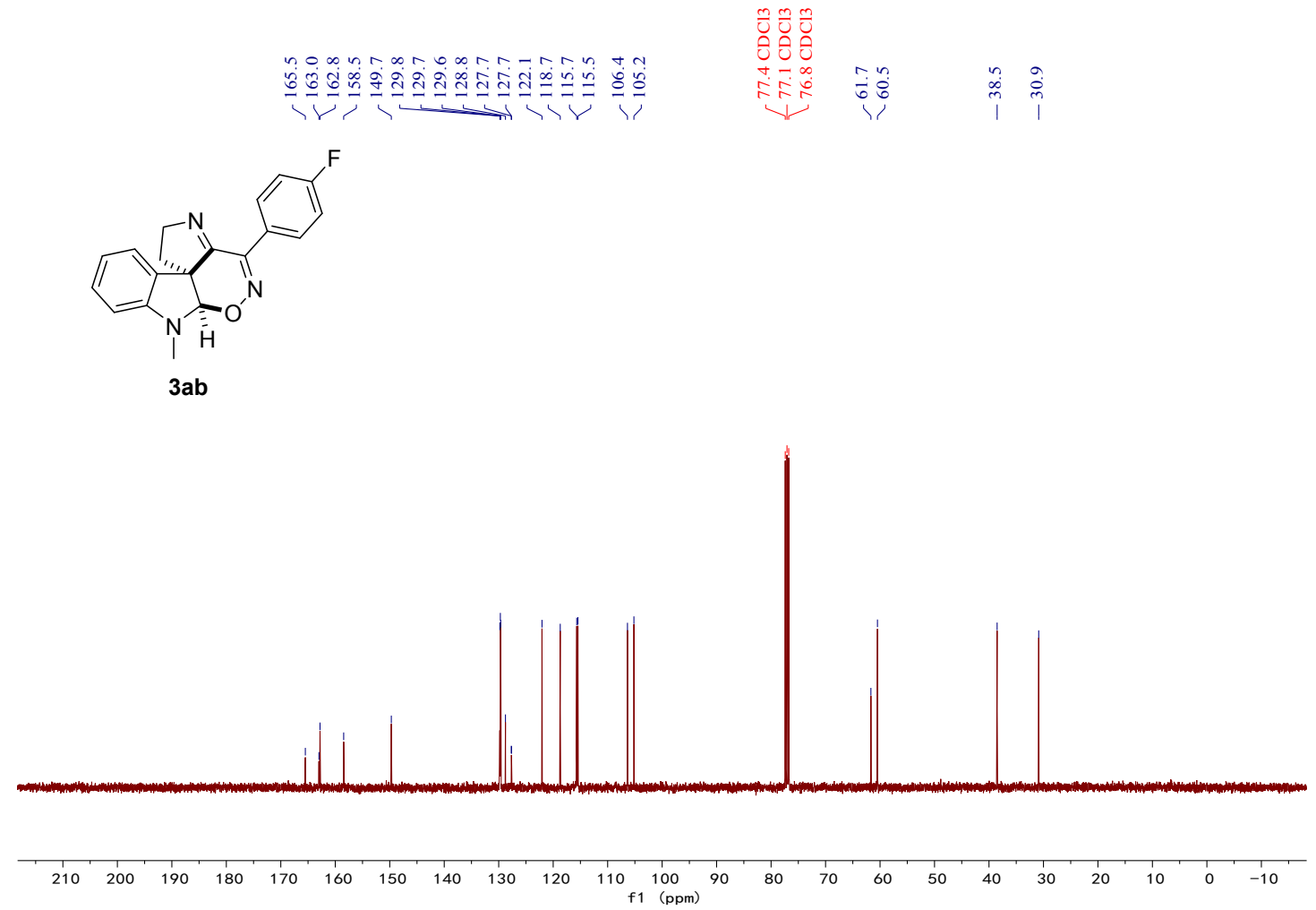
${ }^{19} \mathbf{F}$ NMR (376 MHz, $\mathrm{CDCl}_{3}$ ) spectrum of $\mathbf{3 a b}$

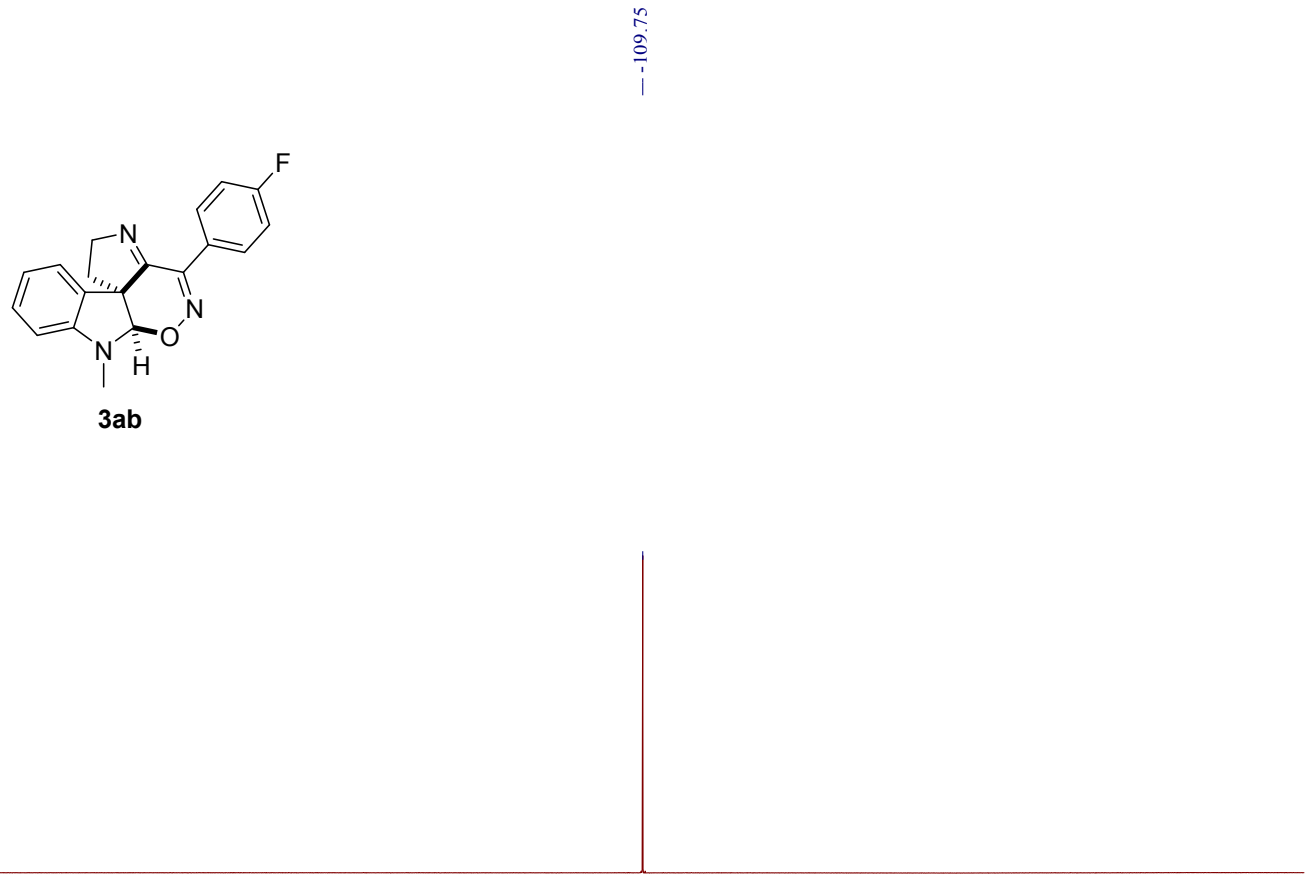

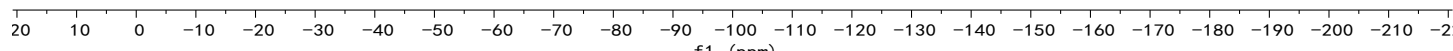


${ }^{\mathbf{1}} \mathbf{H}$ NMR (400 MHz, $\mathrm{CDCl}_{3}$ ) spectrum of $\mathbf{3 a c}$
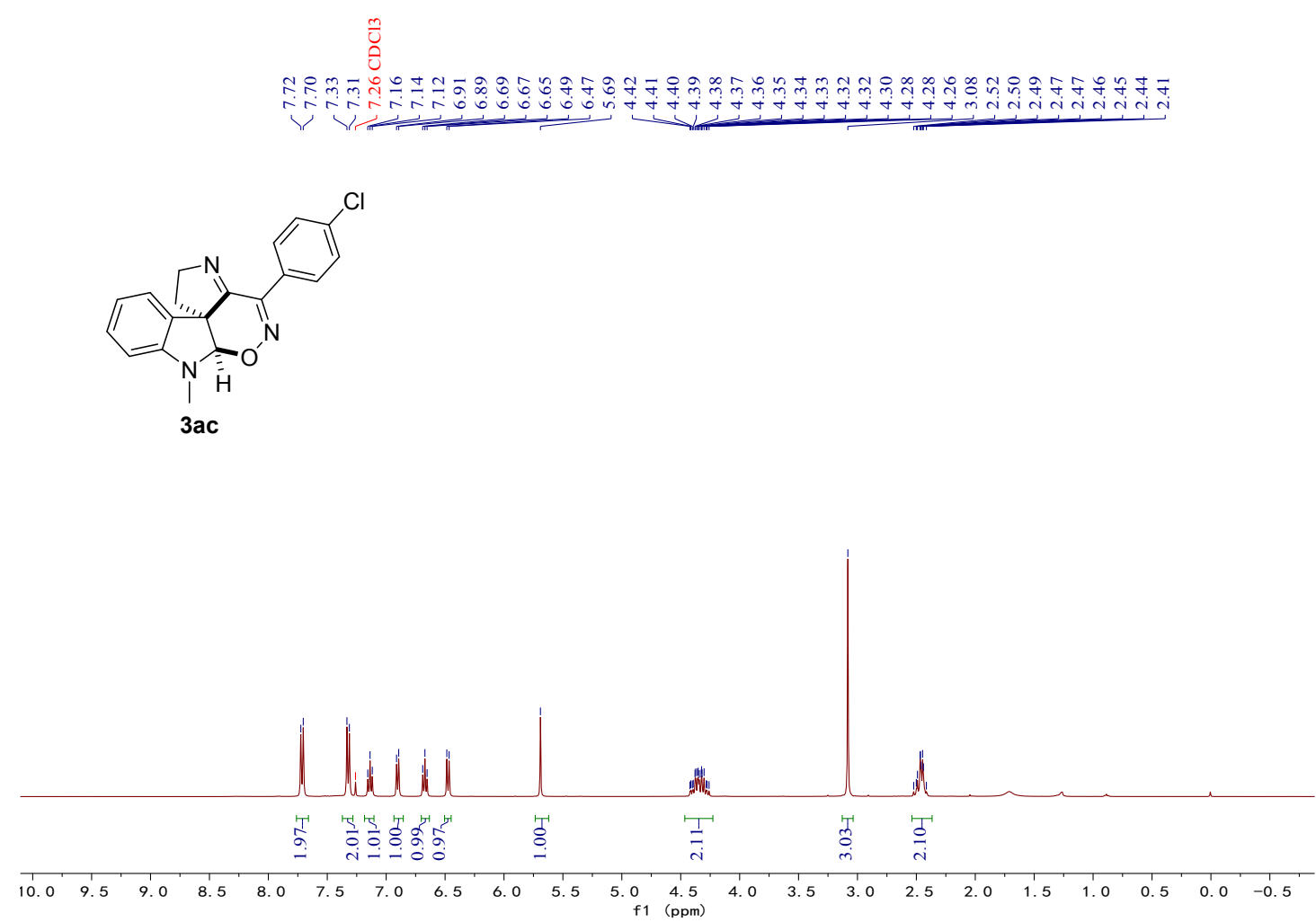

${ }^{13} \mathbf{C}\left\{{ }^{1} \mathbf{H}\right\}$ NMR $\left(100 \mathrm{MHz}, \mathrm{CDCl}_{3}\right)$ spectrum of $\mathbf{3 a c}$

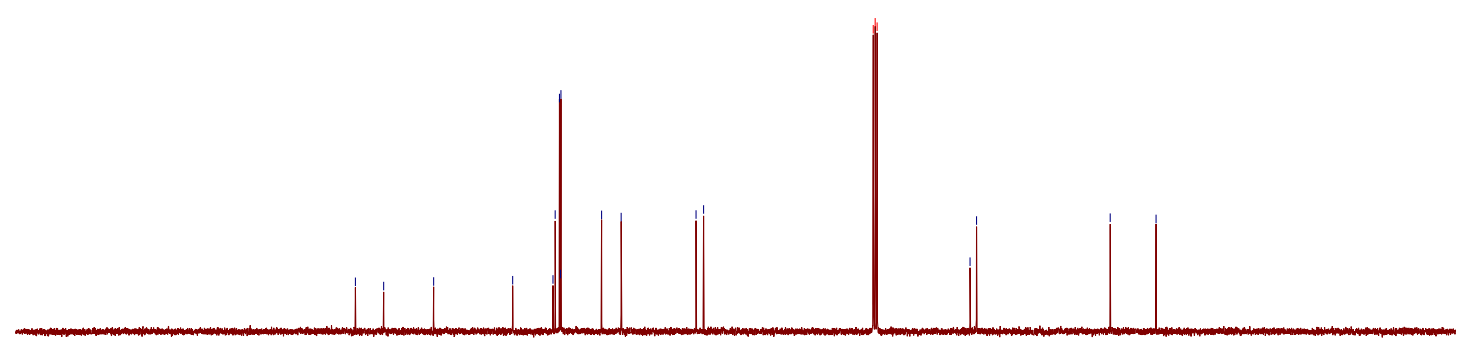

$\begin{array}{llllllllllllllllllllllll}1 & 210 & 200 & 190 & 180 & 170 & 160 & 150 & 140 & 130 & 120 & 110 & 100 & 90 & 80 & 70 & 60 & 50 & 40 & 30 & 20 & 10 & 0 & -10\end{array}$ 
${ }^{1} \mathbf{H}$ NMR (400 MHz, $\mathrm{CDCl}_{3}$ ) spectrum of 3ad
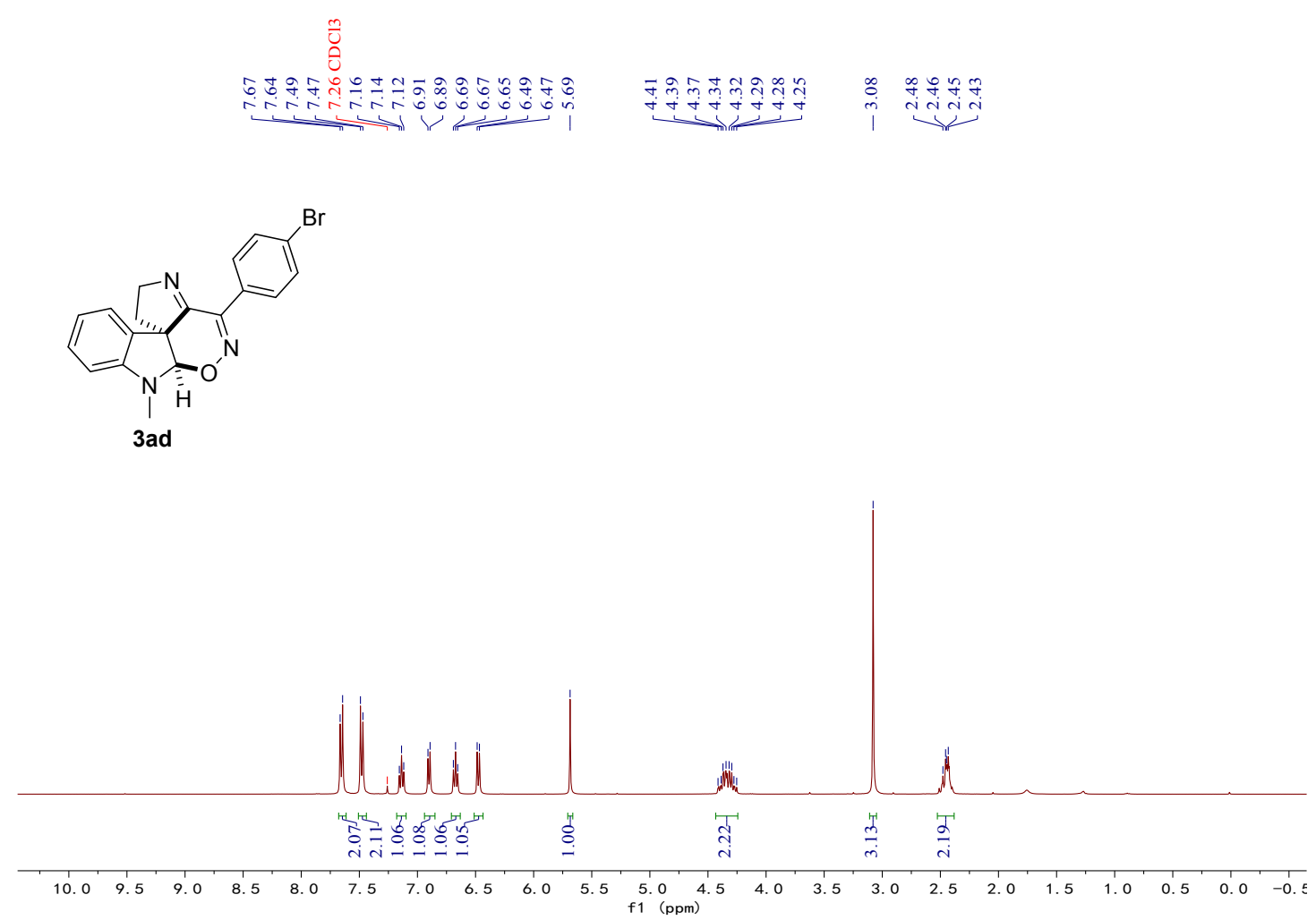

${ }^{13} \mathbf{C}\left\{{ }^{1} \mathbf{H}\right\}$ NMR $\left(100 \mathrm{MHz}, \mathrm{CDCl}_{3}\right)$ spectrum of $\mathbf{3 a d}$
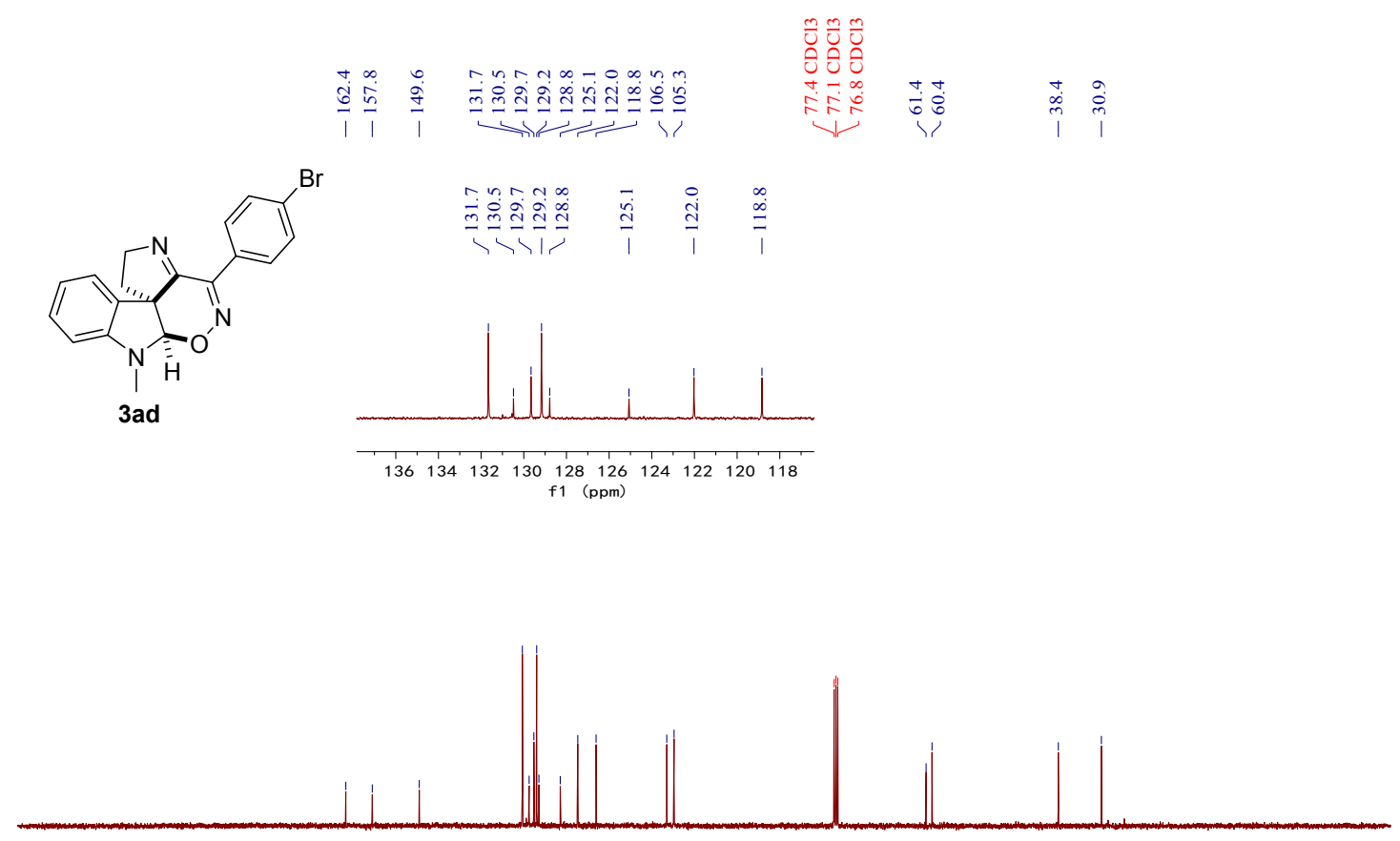
${ }^{1} \mathbf{H}$ NMR (400 MHz, $\mathrm{CDCl}_{3}$ ) spectrum of $\mathbf{3 a e}$
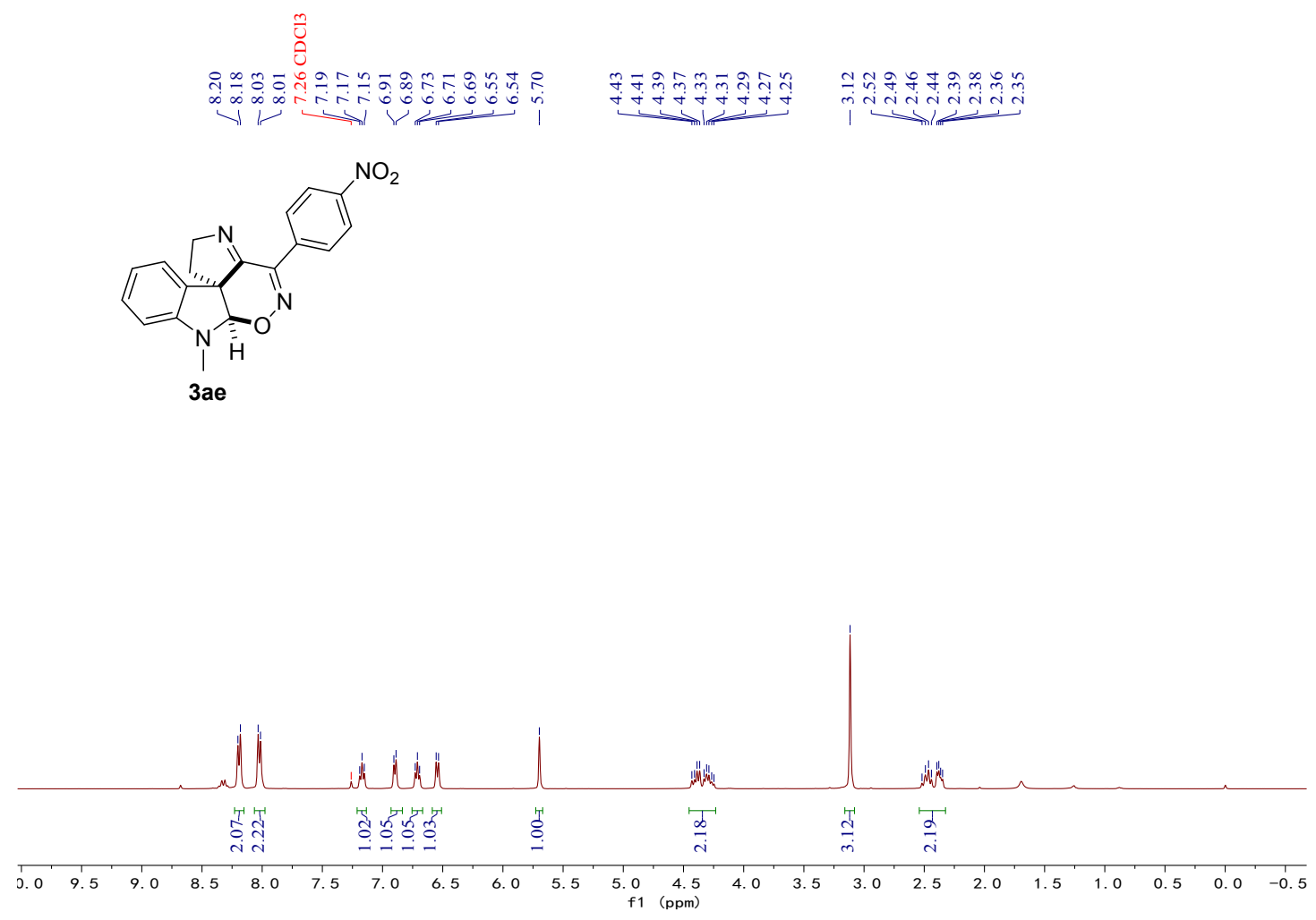

${ }^{13} \mathbf{C}\left\{{ }^{1} \mathbf{H}\right\}$ NMR $\left(100 \mathrm{MHz}, \mathrm{CDCl}_{3}\right)$ spectrum of $\mathbf{3 a e}$
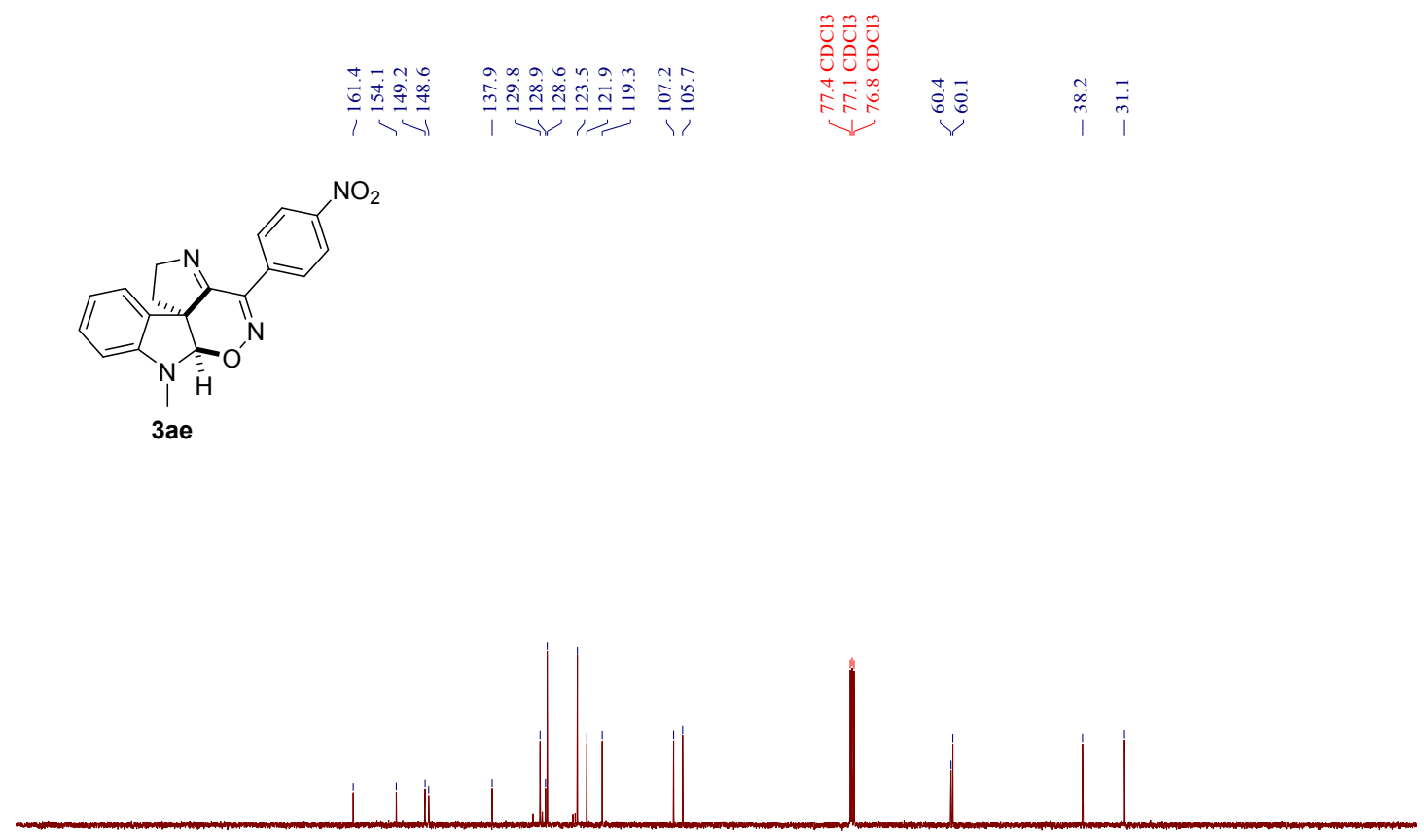

$\begin{array}{llllllllllllllllllllllllll}1 & 210 & 200 & 190 & 180 & 170 & 160 & 150 & 140 & 130 & 120 & 110 & 100 & 90 & 80 & 70 & 60 & 50 & 40 & 30 & 20 & 10 & 0 & -10\end{array}$ 
${ }^{\mathbf{1}} \mathbf{H}$ NMR (400 MHz, $\mathrm{CDCl}_{3}$ ) spectrum of 3af
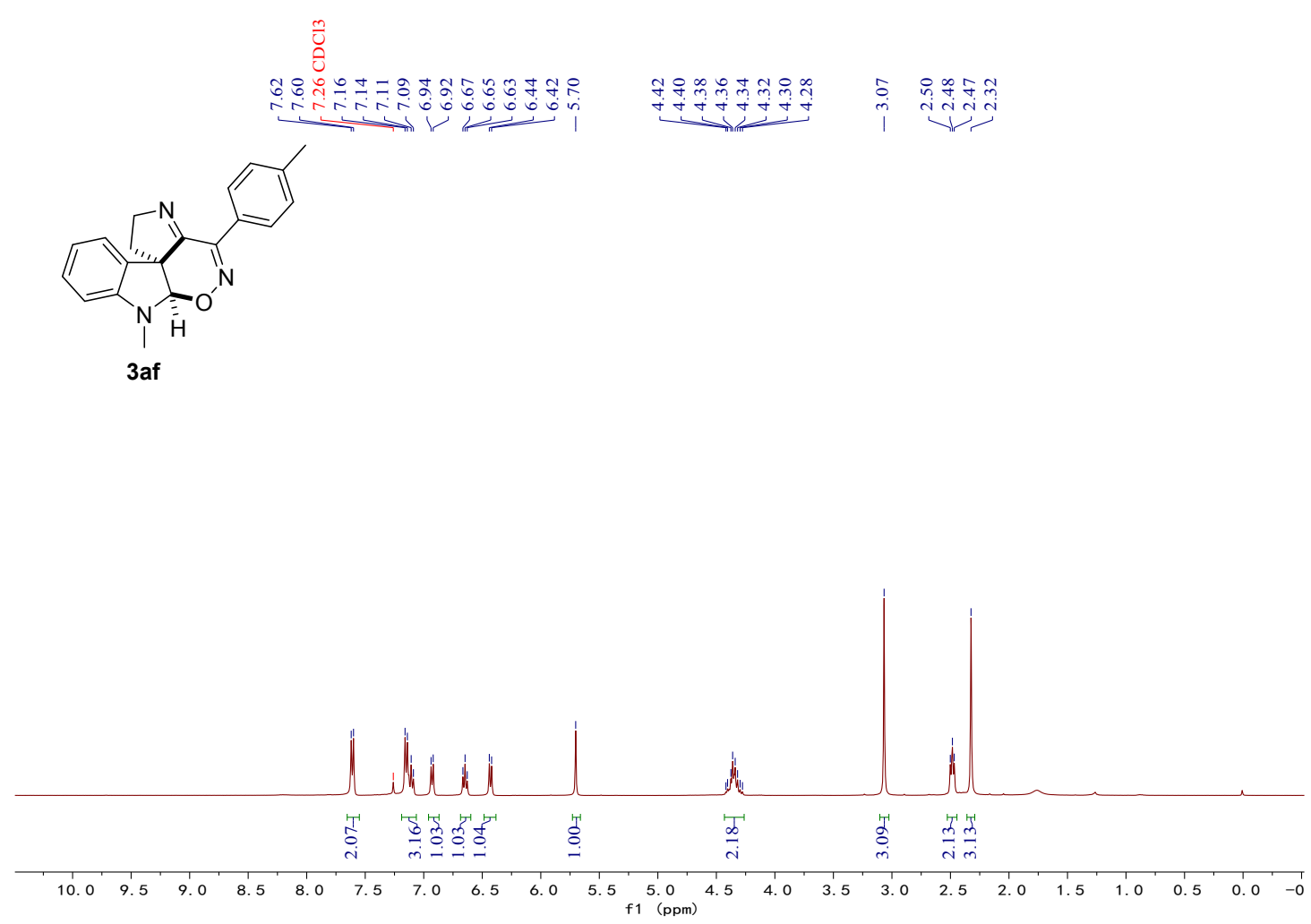

${ }^{13} \mathbf{C}\left\{{ }^{1} \mathbf{H}\right\}$ NMR $\left(100 \mathrm{MHz}, \mathrm{CDCl}_{3}\right)$ spectrum of $\mathbf{3 a f}$

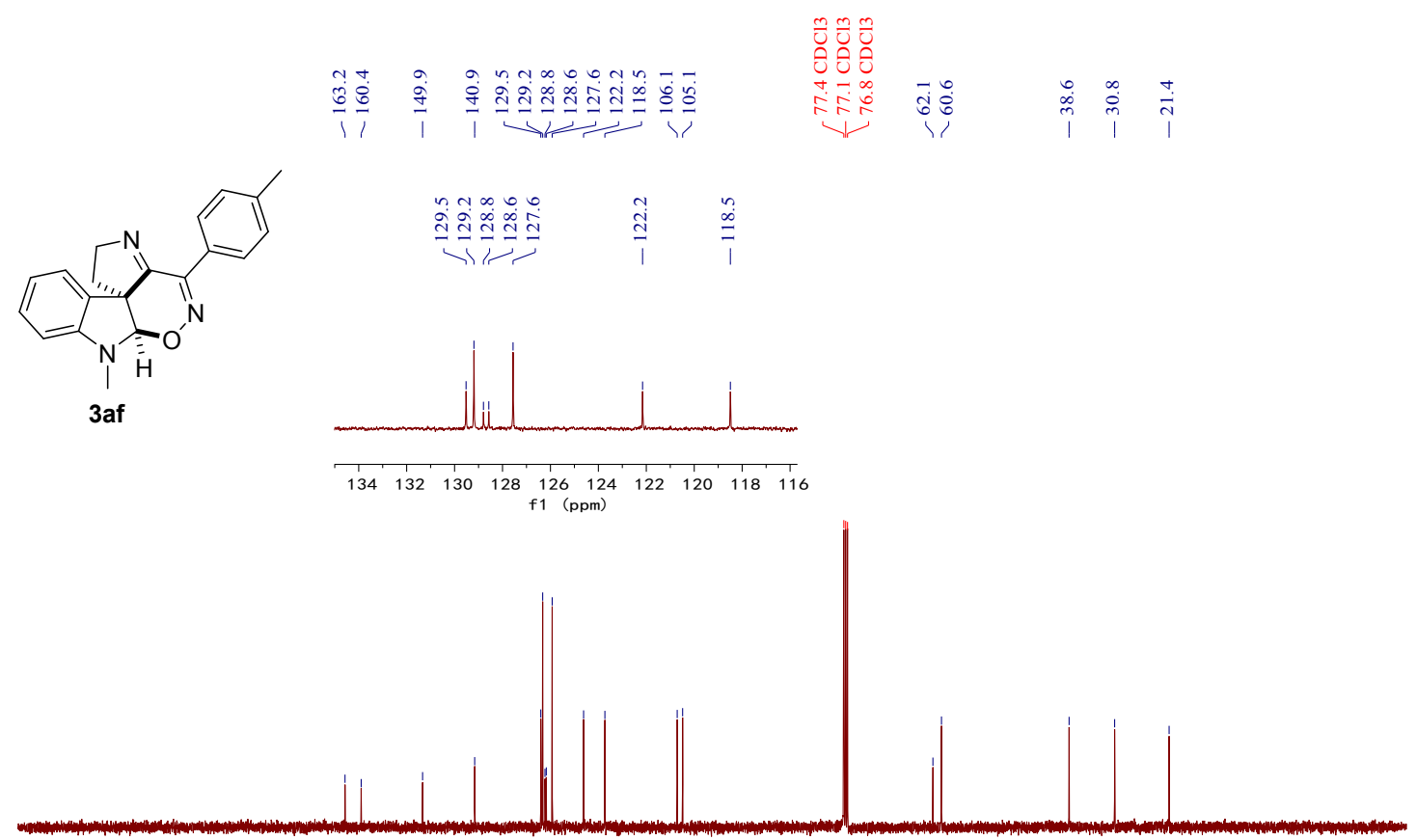

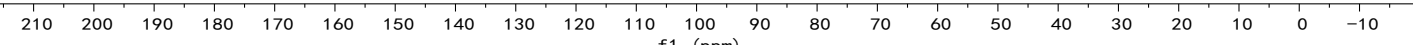


${ }^{1} \mathbf{H}$ NMR (400 MHz, $\mathrm{CDCl}_{3}$ ) spectrum of $\mathbf{3 a g}$
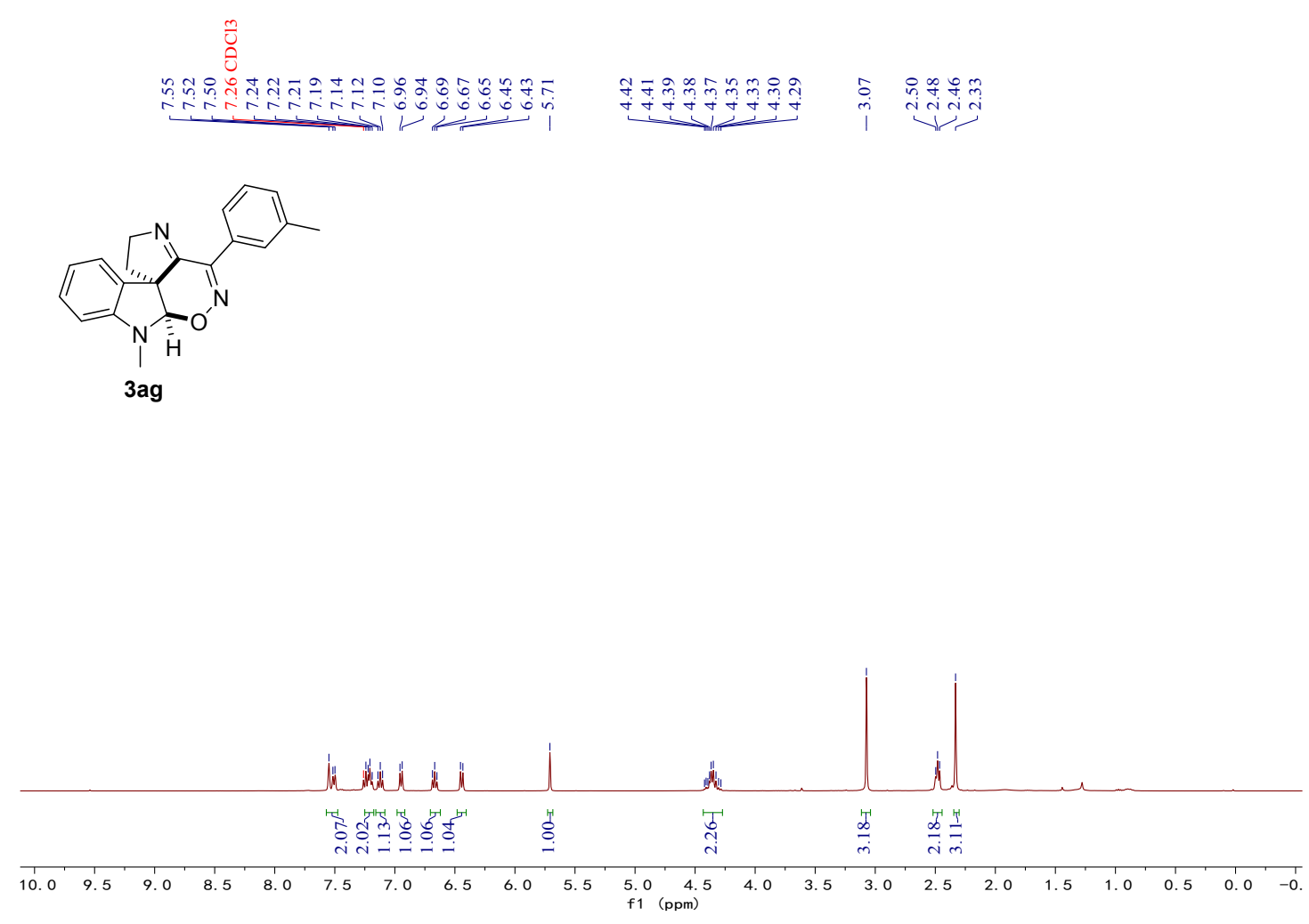

${ }^{13} \mathbf{C}\left\{{ }^{1} \mathbf{H}\right\}$ NMR $\left(100 \mathrm{MHz}, \mathrm{CDCl}_{3}\right)$ spectrum of $\mathbf{3 a g}$

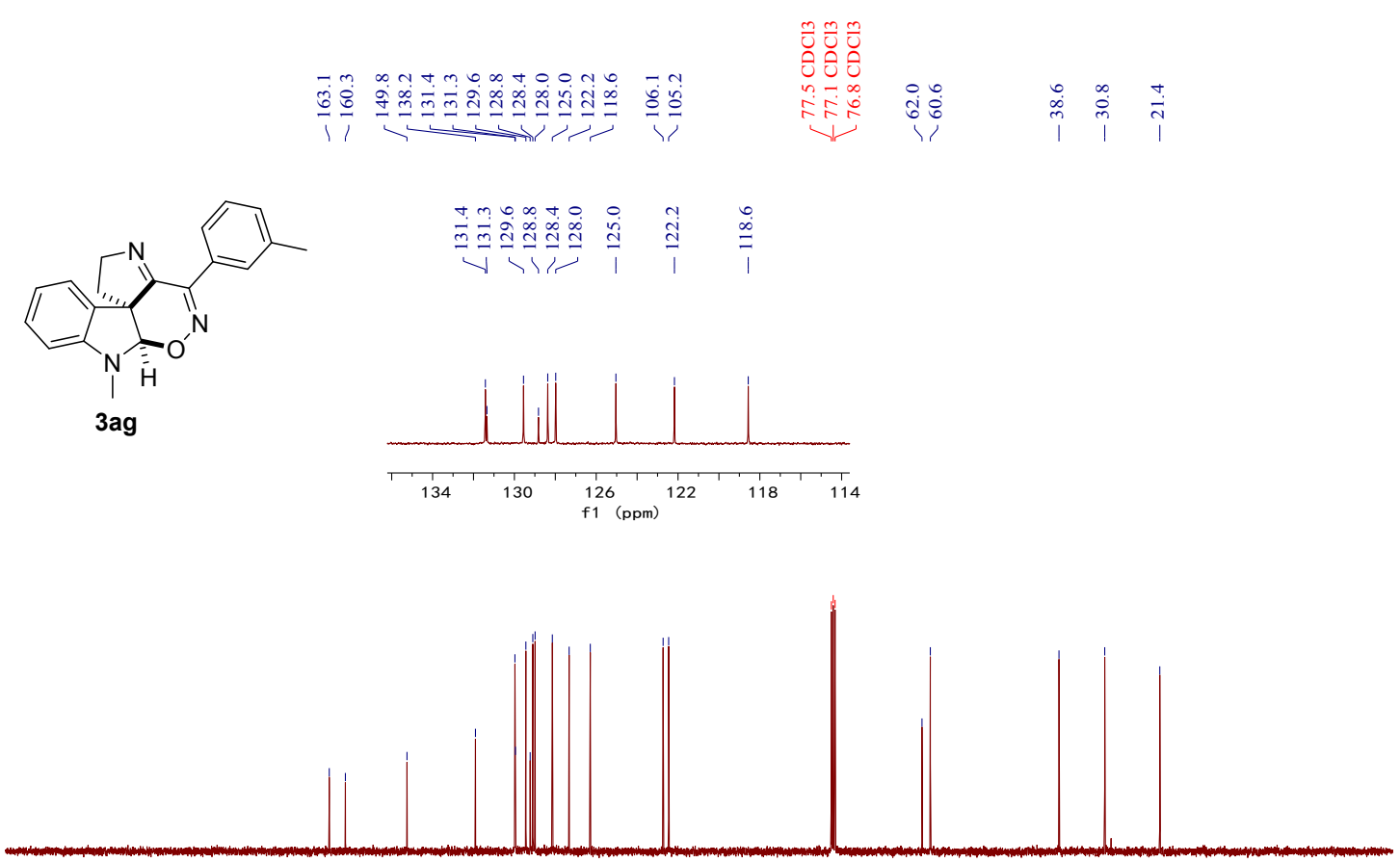

$\begin{array}{llllllllllllllllllllllllllllll}1 & 210 & 200 & 190 & 180 & 170 & 160 & 150 & 140 & 130 & 120 & 110 & 100 & 90 & 80 & 70 & 60 & 50 & 40 & 30 & 20 & 10 & 0 & -10\end{array}$ 
${ }^{1} \mathbf{H}$ NMR (400 MHz, $\mathrm{CDCl}_{3}$ ) spectrum of $\mathbf{3 a h}$
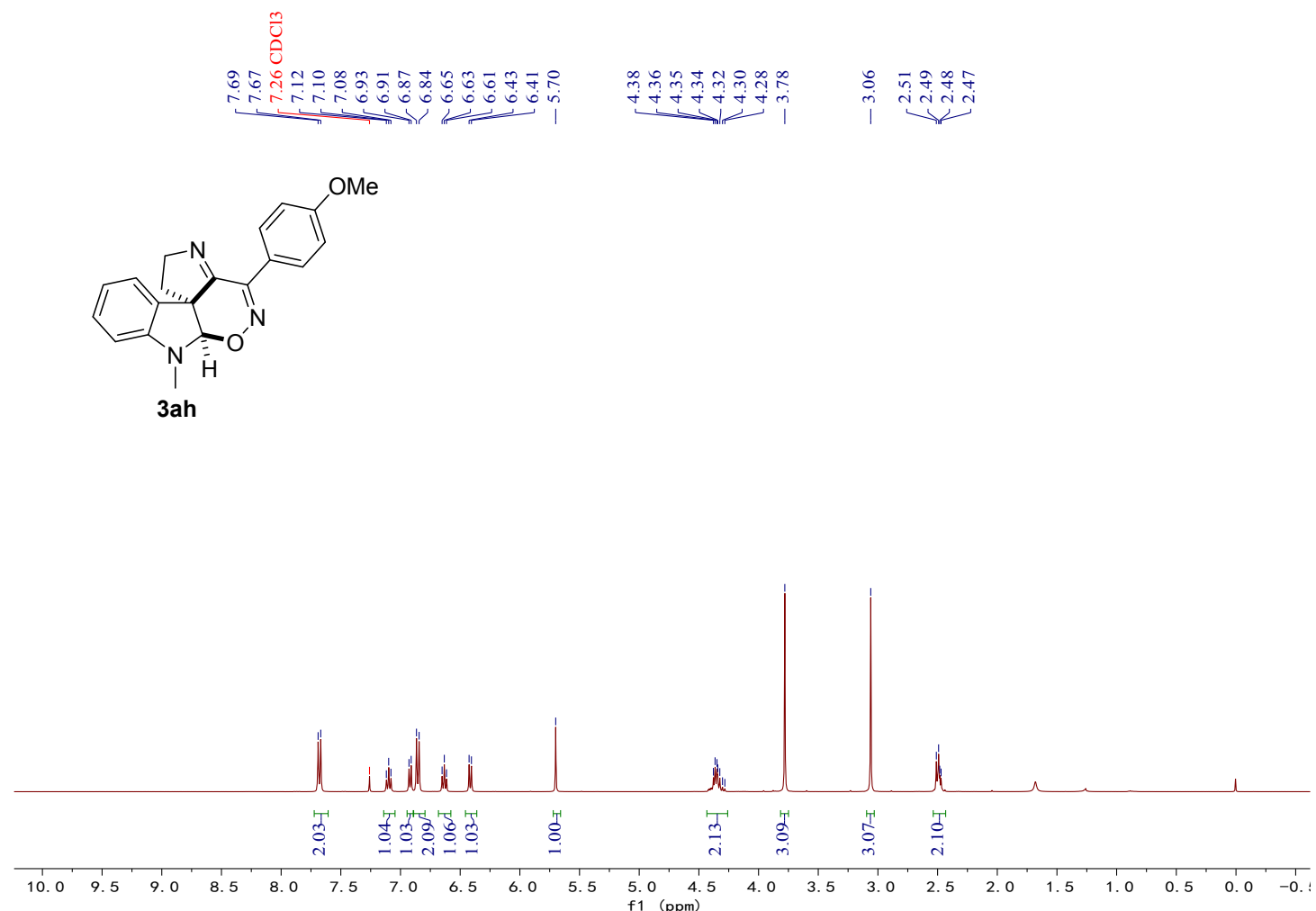

${ }^{13} \mathbf{C}\left\{{ }^{1} \mathbf{H}\right\}$ NMR $\left(100 \mathrm{MHz}, \mathrm{CDCl}_{3}\right)$ spectrum of $\mathbf{3 a h}$
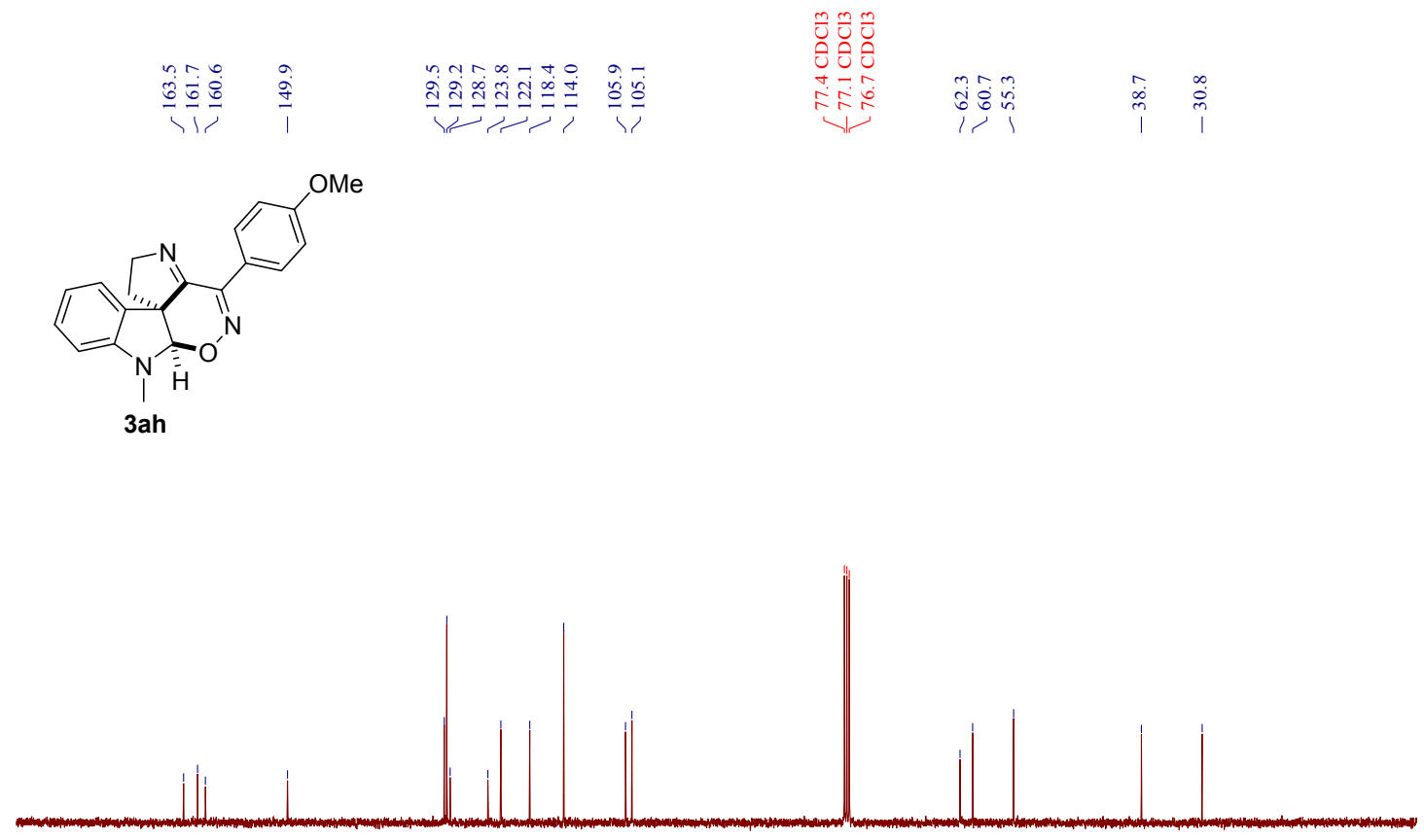
${ }^{\mathbf{1}} \mathbf{H}$ NMR (400 MHz, $\mathrm{CDCl}_{3}$ ) spectrum of 3ai
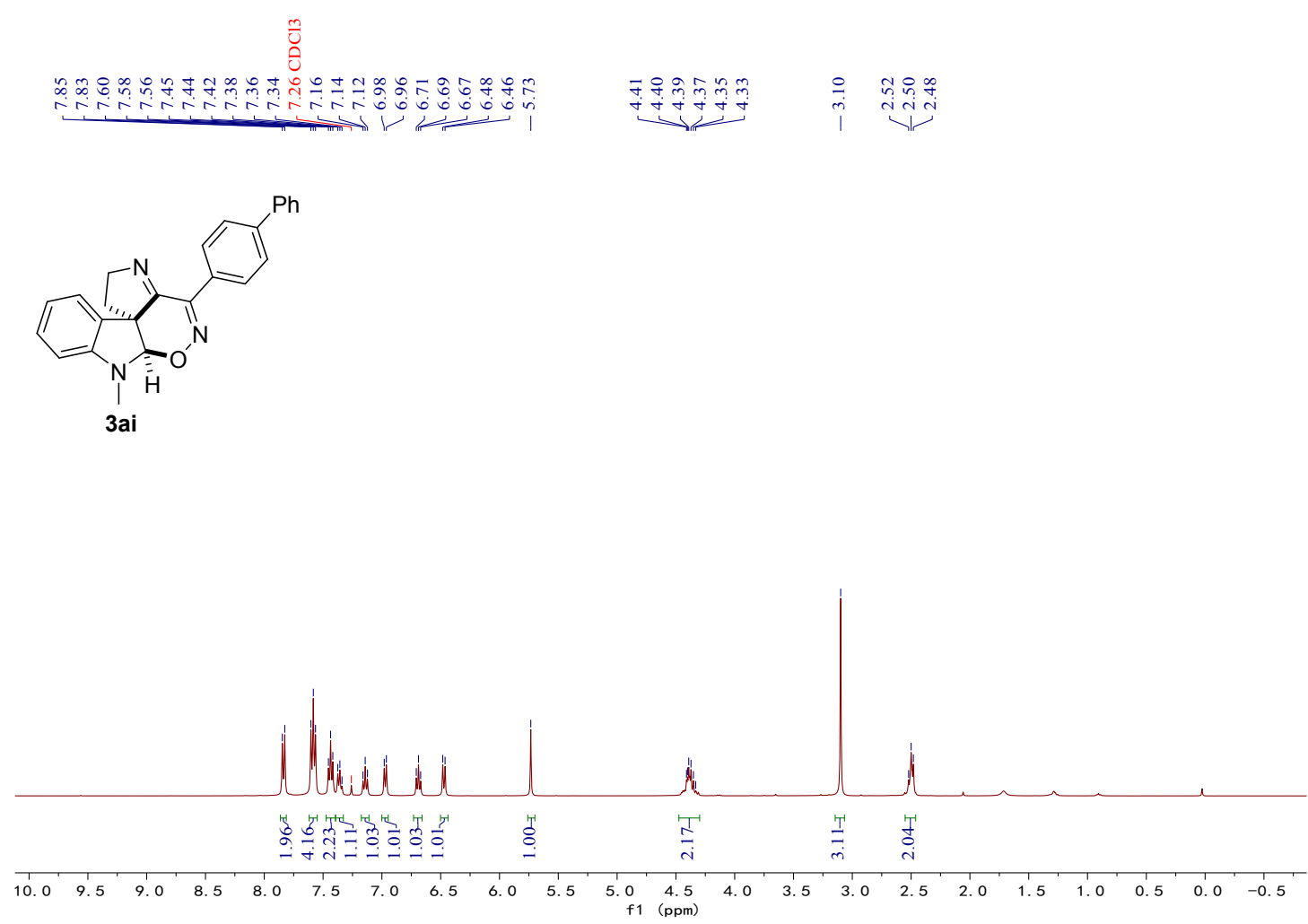

${ }^{13} \mathbf{C}\left\{{ }^{1} \mathbf{H}\right\}$ NMR $\left(100 \mathrm{MHz}, \mathrm{CDCl}_{3}\right)$ spectrum of $\mathbf{3 a i}$
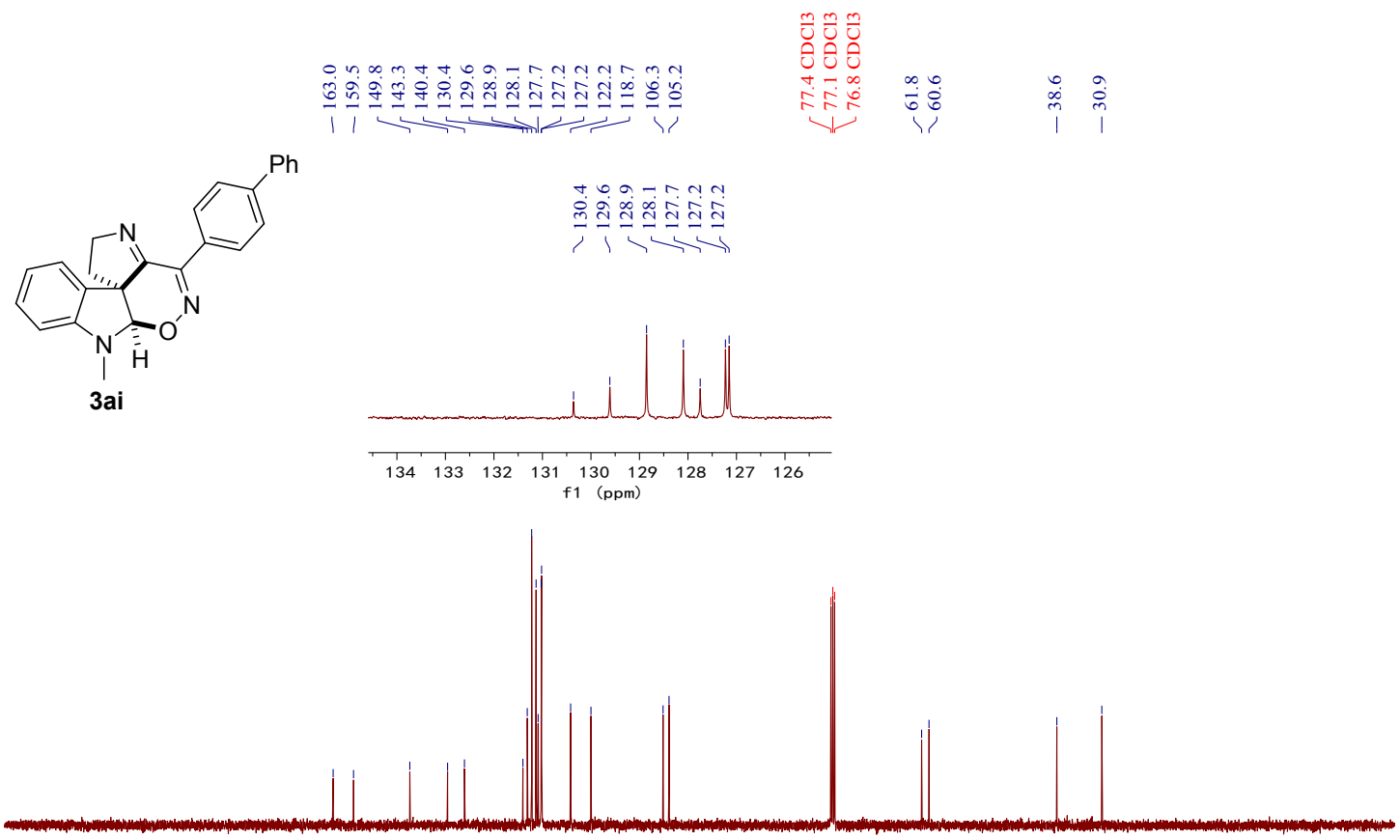

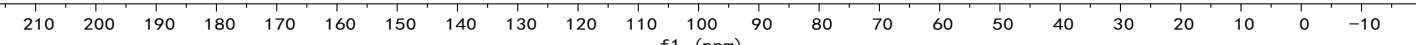


${ }^{1} \mathbf{H}$ NMR (400 MHz, $\mathrm{CDCl}_{3}$ ) spectrum of 3aj
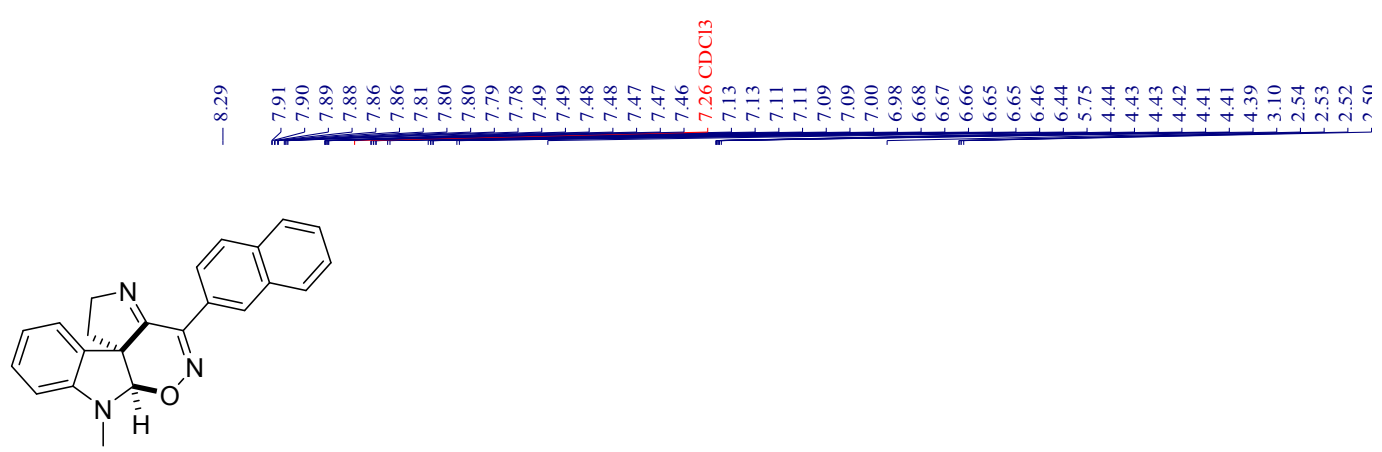

3aj

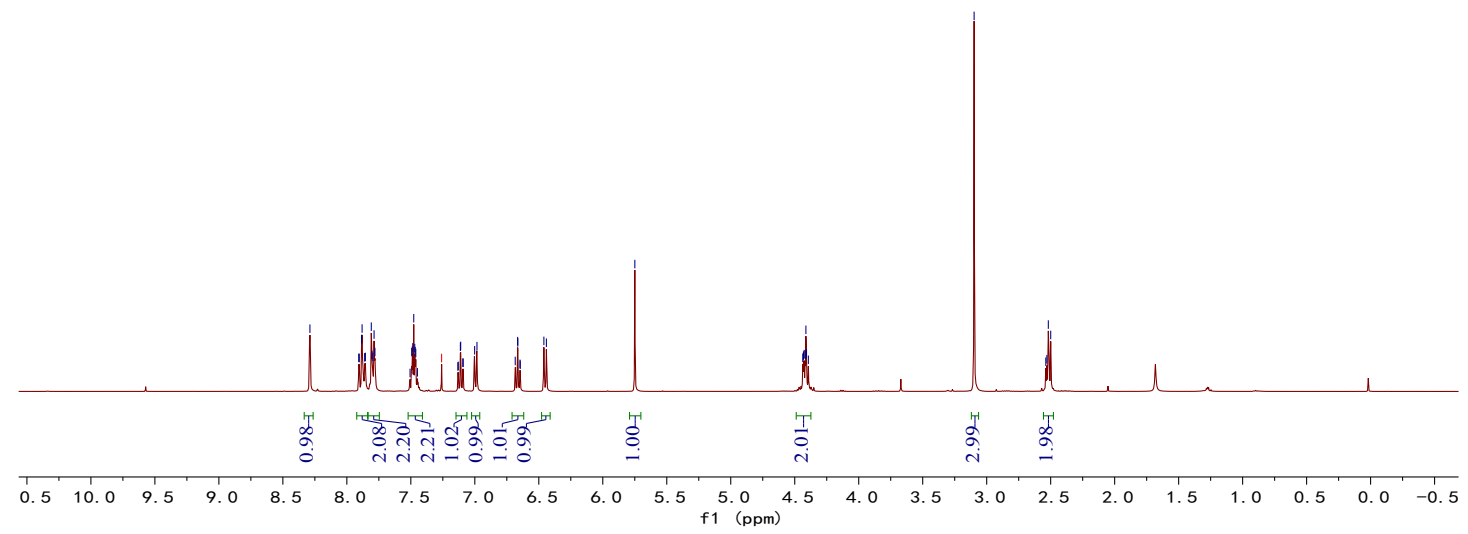

${ }^{13} \mathbf{C}\left\{{ }^{1} \mathbf{H}\right\}$ NMR $\left(100 \mathrm{MHz}, \mathrm{CDCl}_{3}\right)$ spectrum of $\mathbf{3 a j}$

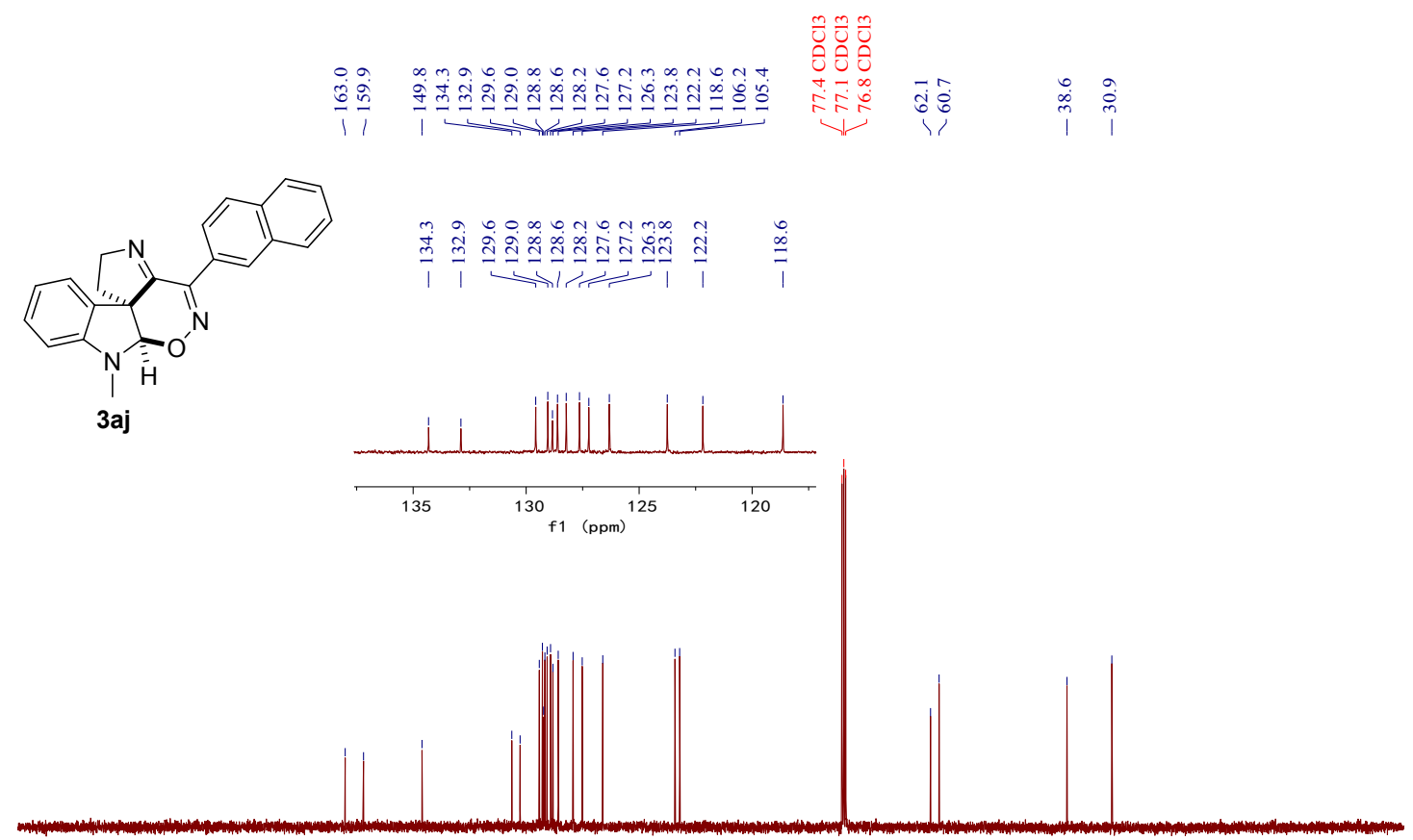

$\begin{array}{llllllllllllllllllllllll} & 1 \\ 210 & 200 & 190 & 180 & 170 & 160 & 150 & 140 & 130 & 120 & 110 & 100 & 90 & 80 & 70 & 60 & 50 & 40 & 30 & 20 & 10 & 0 & -10\end{array}$ 
${ }^{1} \mathbf{H}$ NMR (400 MHz, $\mathrm{CDCl}_{3}$ ) spectrum of $\mathbf{3 a k}$
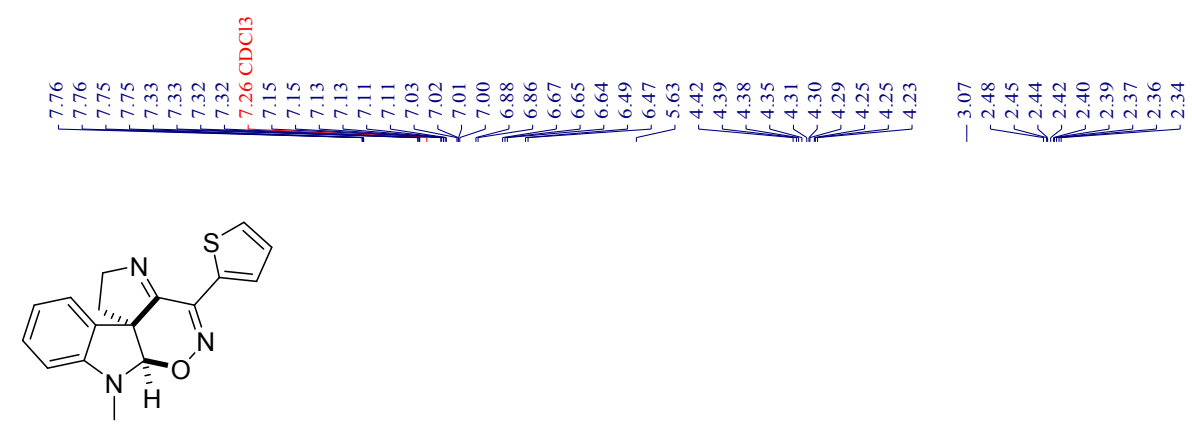

3ak

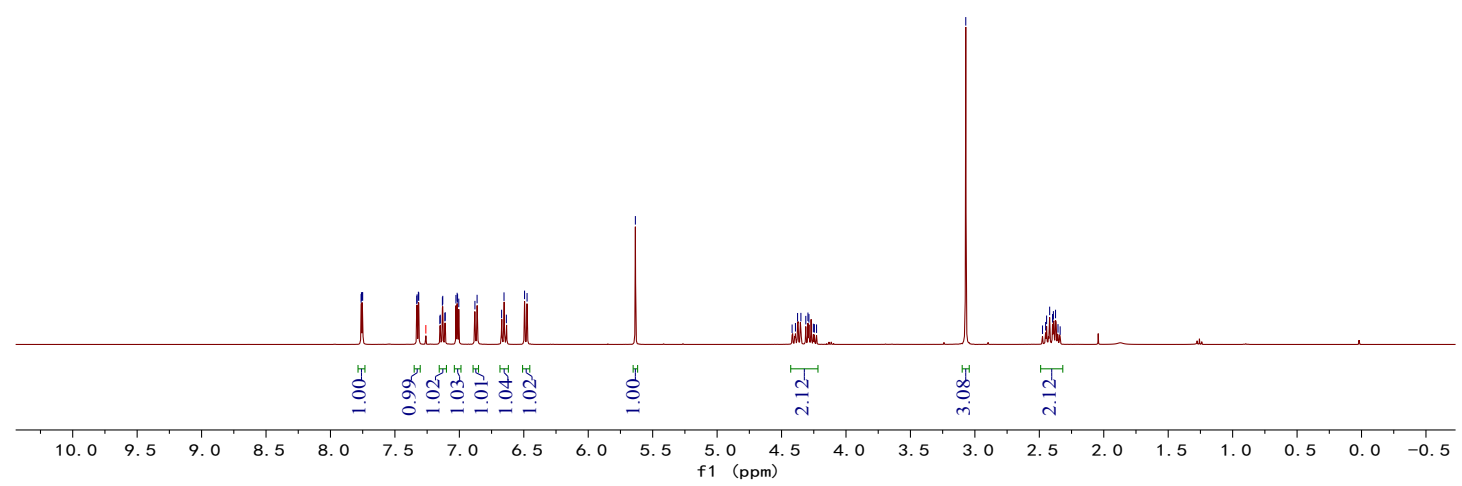

${ }^{13} \mathbf{C}\left\{{ }^{1} \mathbf{H}\right\}$ NMR $\left(100 \mathrm{MHz}, \mathrm{CDCl}_{3}\right)$ spectrum of $\mathbf{3 a k}$
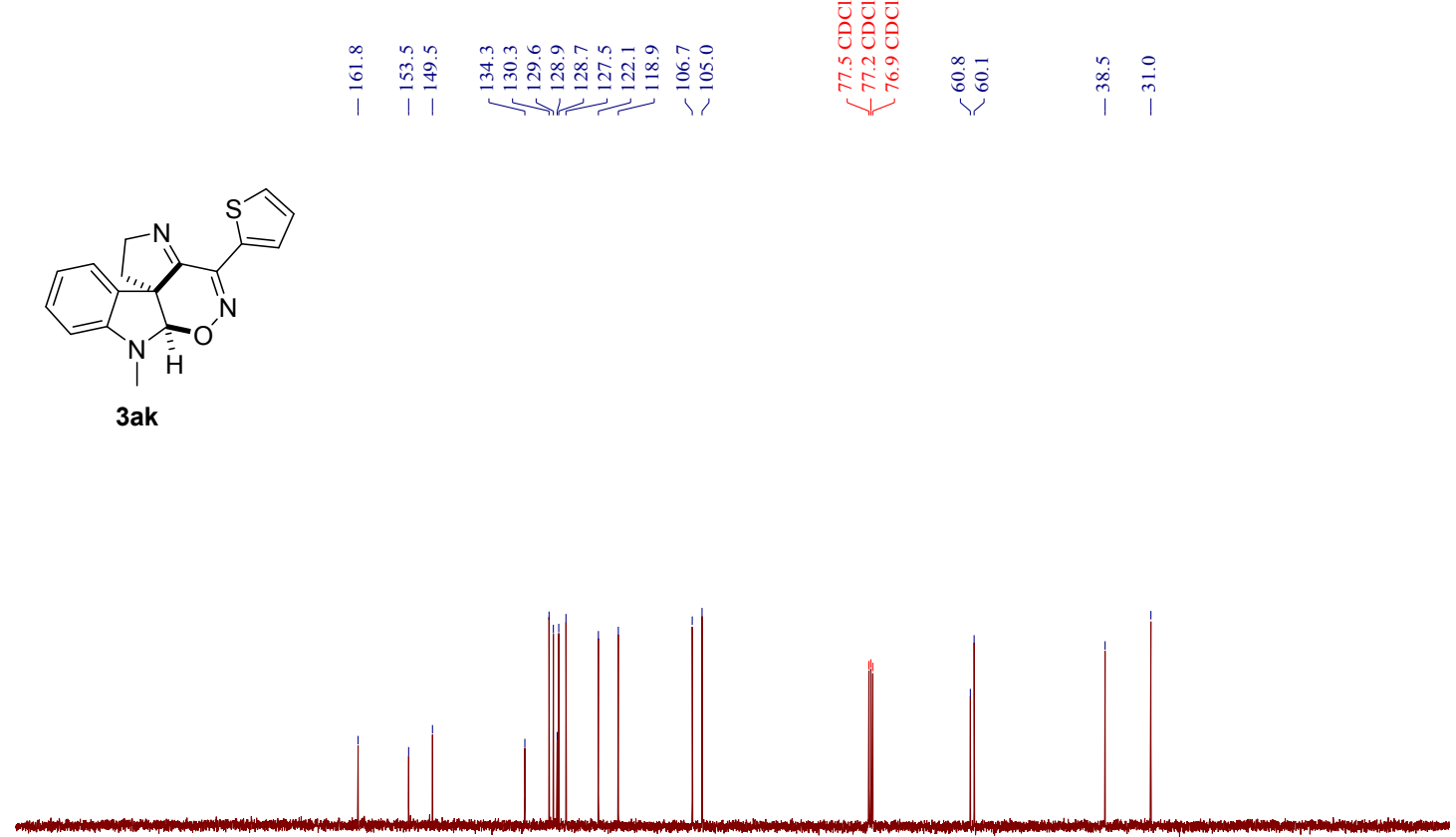

$\begin{array}{lllllllllllll}210 & 200 & 190 & 180 & 170 & 160 & 150 & 140 & 130 & 120 & 110 & 100 & 90\end{array}$ 
${ }^{1} \mathbf{H}$ NMR (400 MHz, $\mathrm{CDCl}_{3}$ ) spectrum of $\mathbf{3 a l}$
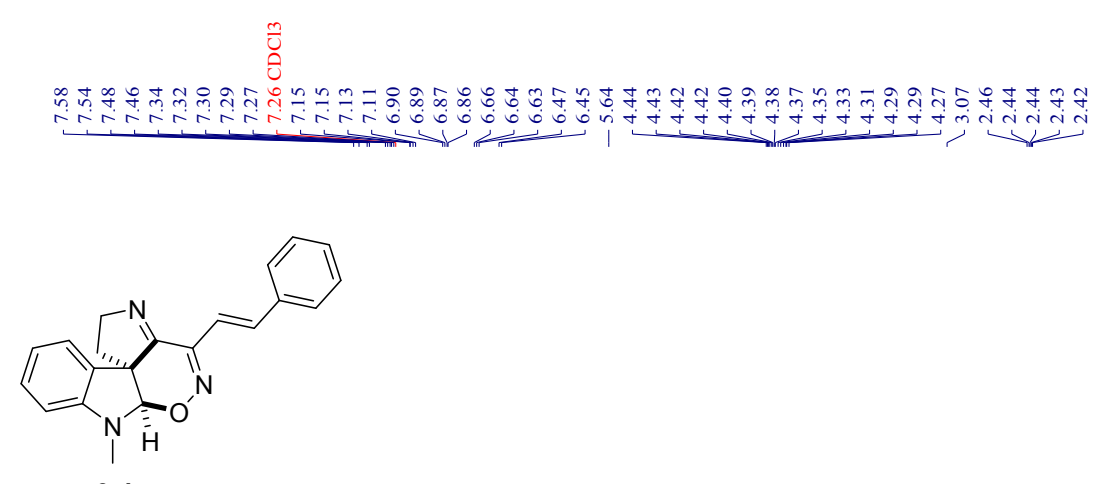

3al

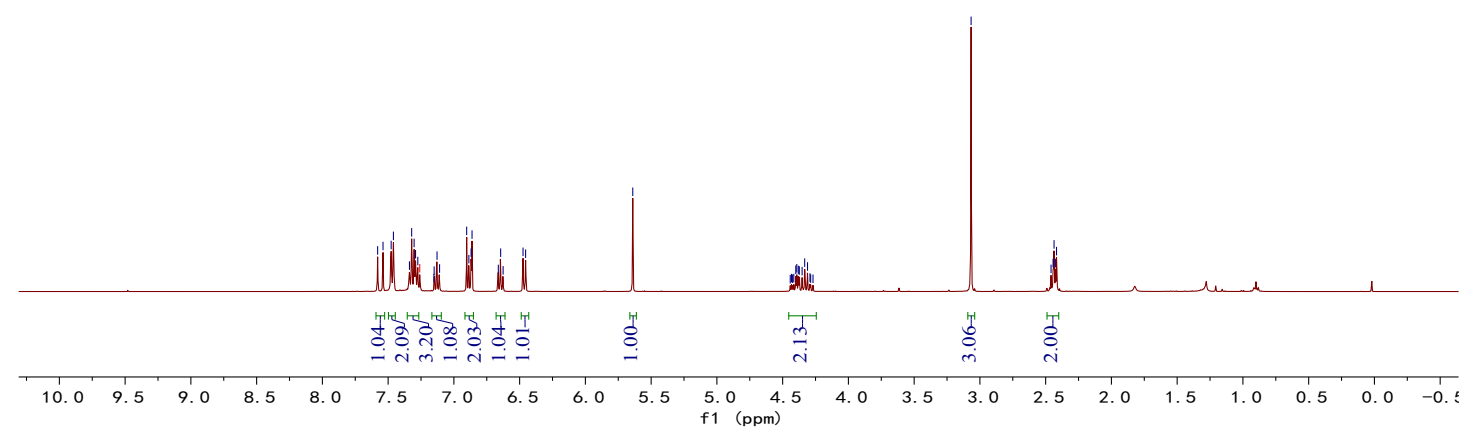

${ }^{13} \mathbf{C}\left\{{ }^{1} \mathbf{H}\right\}$ NMR $\left(100 \mathrm{MHz}, \mathrm{CDCl}_{3}\right)$ spectrum of 3al
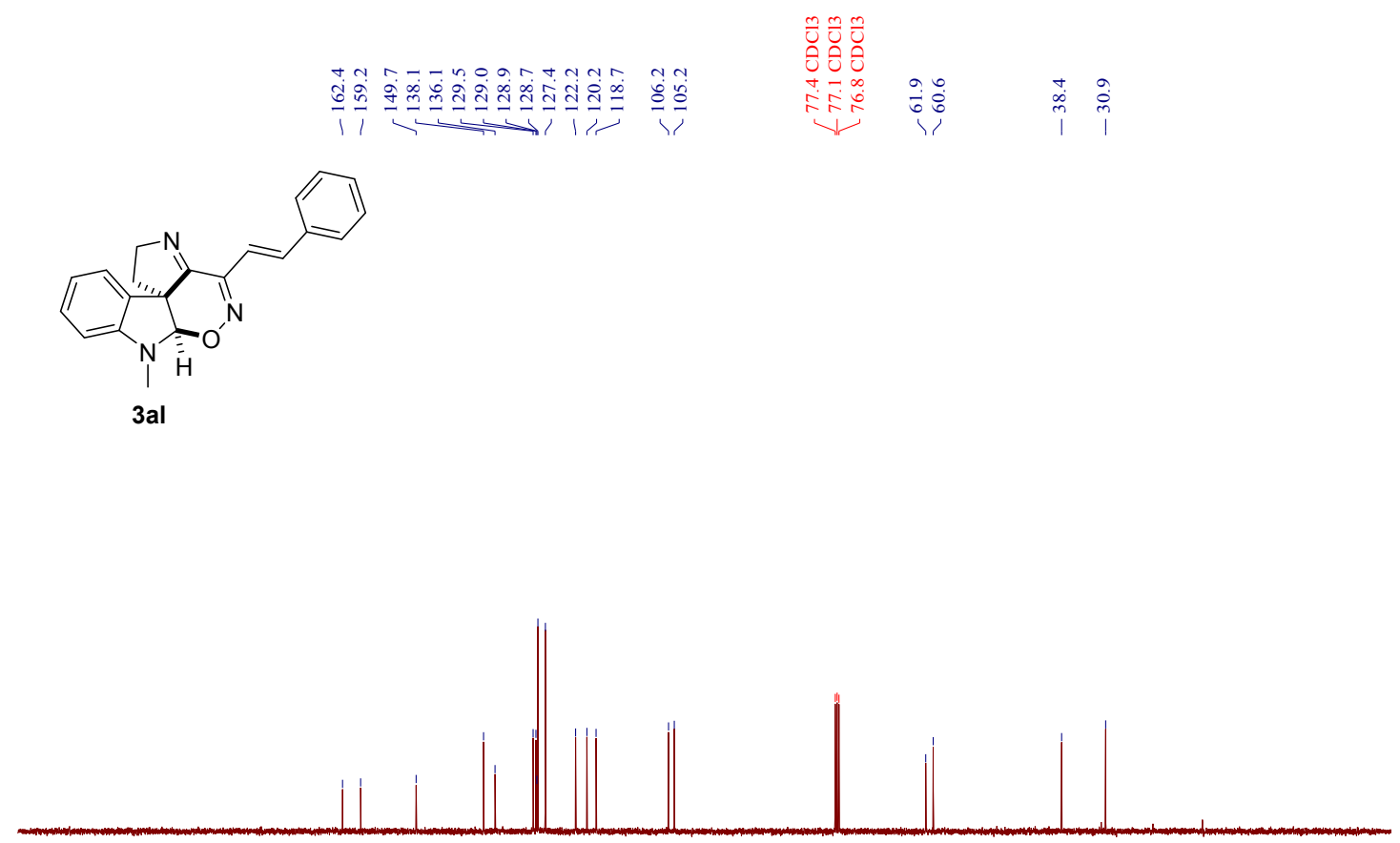

$\begin{array}{lllllllllllll}210 & 200 & 190 & 180 & 170 & 160 & 150 & 140 & 130 & 120 & 110 & 100 & 90\end{array}$ 
${ }^{1} \mathbf{H}$ NMR (400 MHz, $\mathrm{CDCl}_{3}$ ) spectrum of $\mathbf{3 a m}$
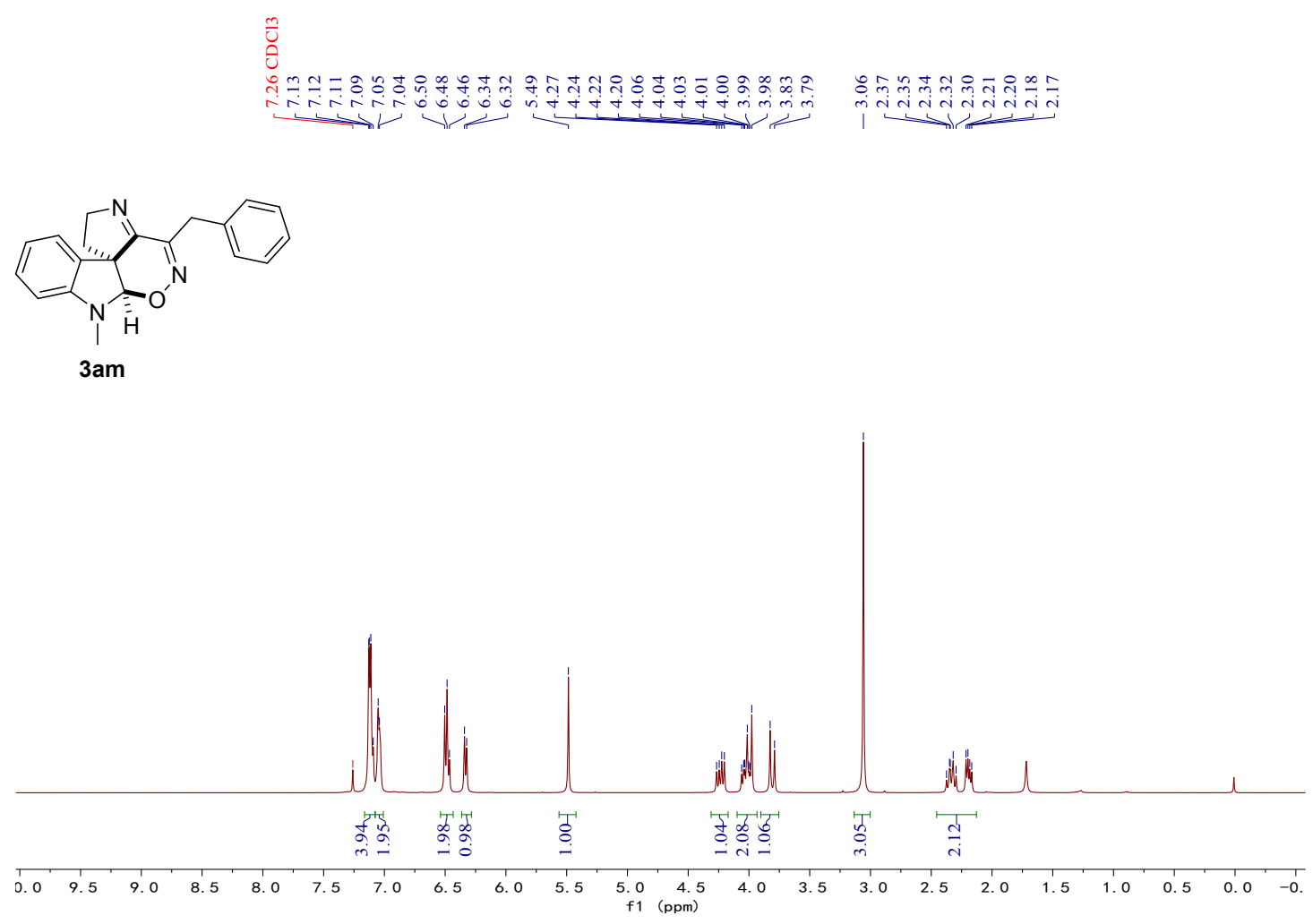

${ }^{13} \mathbf{C}\left\{{ }^{1} \mathbf{H}\right\}$ NMR (100 MHz, $\left.\mathrm{CDCl}_{3}\right)$ spectrum of $\mathbf{3} \mathbf{a m}$
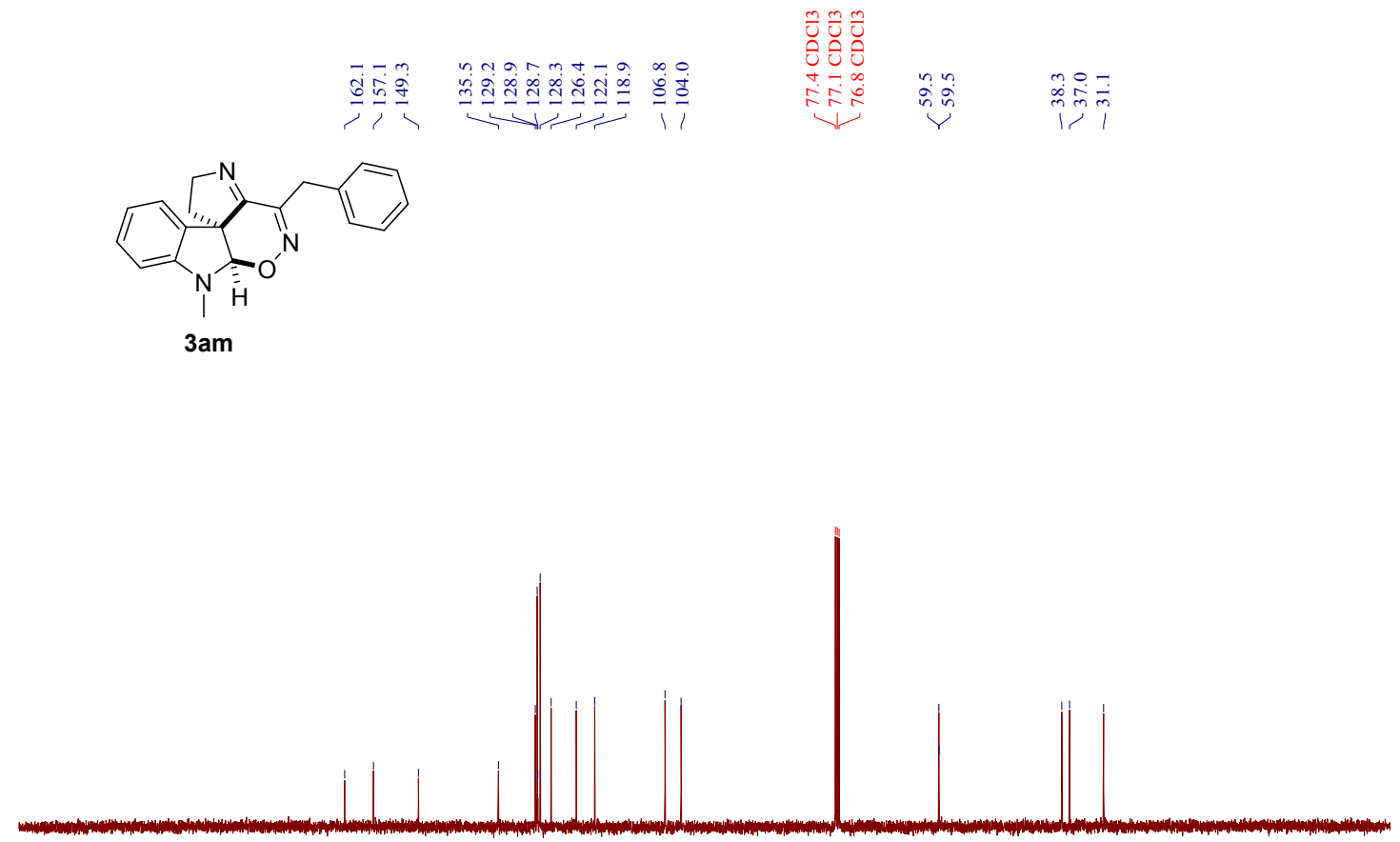

$\begin{array}{lllllllllllll}210 & 200 & 190 & 180 & 170 & 160 & 150 & 140 & 130 & 120 & 110 & 100 & 90\end{array}$ 
2. Crystal data and structure refinement for 3aa
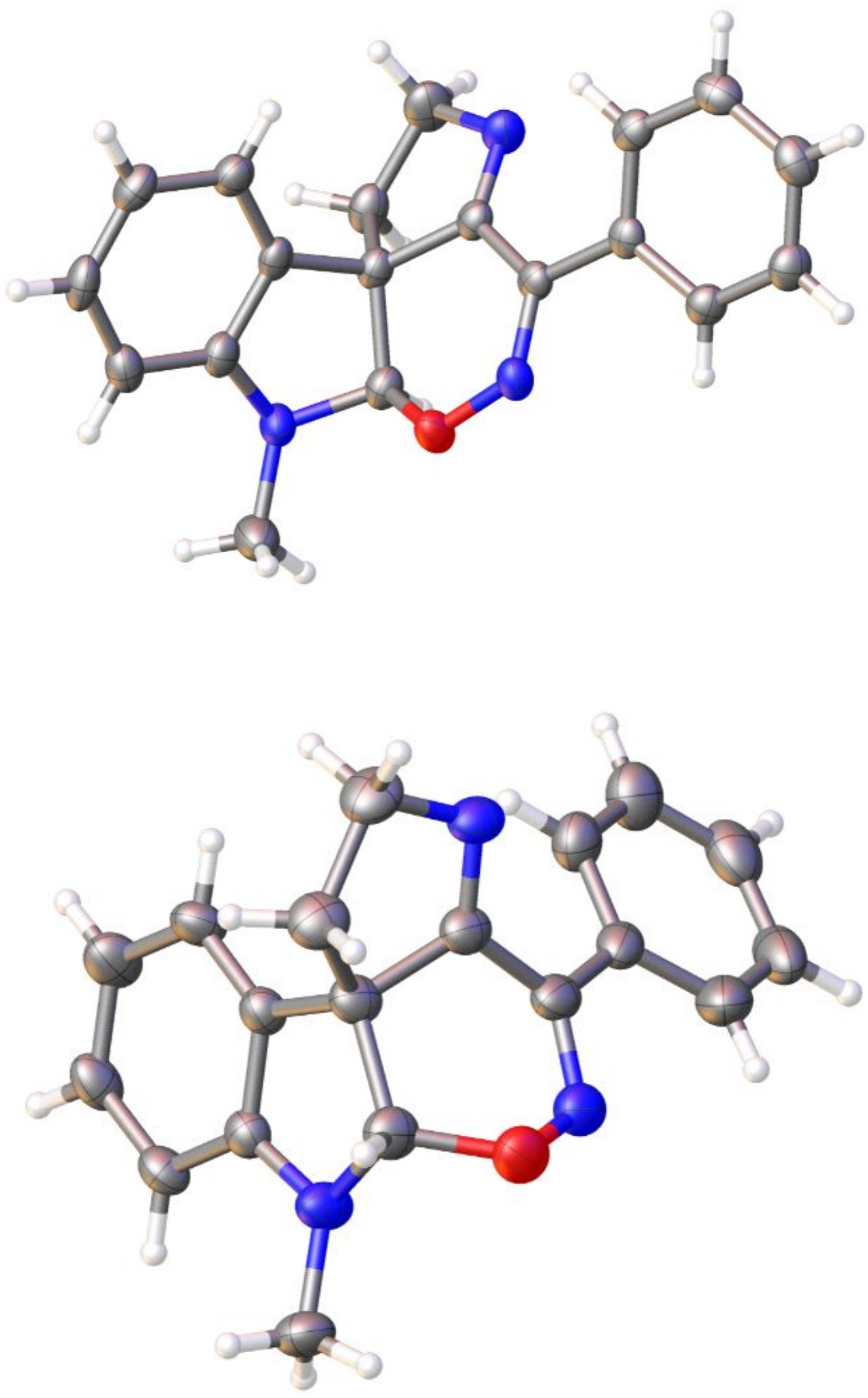
Single crystals suitable for X-ray diffraction experiment were obtained by slow evaporation of a mixed solution of ethyl acetate and petroleum ether containing the corresponding compound 3aa.

The thermal ellipsoid was drawn at the $50 \%$ probability level.

Crystal number: CCDC 2034484

Empirical formula: $\mathrm{C}_{19} \mathrm{H}_{17} \mathrm{~N}_{3} \mathrm{O}_{2}$

Formula weight: 303.36

Unit cell parameters: $a=14.4641(7) \AA, b=11.2378$ (6) $\AA, c=37.4343$ (19) $\AA$,

$$
\alpha=90, \beta=90, \gamma=90
$$

Temperature: $296 \mathrm{~K}$

Wavelength: $0.71073 \AA$

Crystal system: orthorhombic

Space group: $\mathrm{P} \mathrm{b} \mathrm{c}$ a

Volume: $6104.2(5) \AA^{3}$

Z: 8

Calculated density: $1.320 \mathrm{~g} / \mathrm{cm}^{3}$

Absorption coefficient: $0.084 \mathrm{~mm}^{-1}$

F (000): 2560.0

Crystal size: $0.10 \times 0.20 \times 0.60 \mathrm{~mm}^{3}$

Correction-type: multi-scan

h, k, I max: $18,14,48$

Tmin, Tmax: 0.980/0.992

Data completeness: 0.995

Final $\mathbf{R}$ indices [I>2sigma(I)]: 0.0603

Final R indices [all data]: 0.1131 